\title{
Consumer-Citizens of China
}

The role of foreign brands in the imagined future China

Kelly Tian and Lily Dong

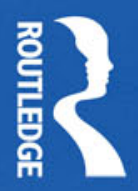

Routledge Contemporary China Series 


\section{Consumer-Citizens of China}

This book presents a comprehensive examination of Chinese consumer behaviour and challenges the previously dichotomous interpretation of the consumption of Western and non-Western brands in China. The dominant position is that Chinese consumers are driven by a desire to imitate the lifestyles of Westerners and thereby advance their social standing locally. The alternative is that consumers reject Western brands as a symbolic gesture of loyalty to their nation-state.

Drawing from survey responses and in-depth interviews with Chinese consumers in both rural and urban areas, Kelly Tian and Lily Dong find that consumers situate Western brands within select historical moments. This embellishment attaches historical meanings to Western brands in ways that render them useful in asserting preferred visions of the future China. By highlighting how Western brands are used in contests for national identity, Consumer-Citizens of China challenges the notion of the "patriot's paradox" and answers scholars' questions as to whether Chinese nationalists today allow for a Sino-Western space where the Chinese can love China without hating the West.

Consumer-Citizens of China will be of interest to students and scholars of Business Studies, Chinese and Asian Studies, and Political Science.

Kelly Tian is Professor of Marketing and holds the Anderson Chair of Business at New Mexico State University.

Lily Dong is Associate Professor of Marketing at the University of Alaska Fairbanks. 


\section{Routledge Contemporary China Series}

1 Nationalism, Democracy and National Integration in China Leong Liew and Wang Shaoguang

2 Hong Kong's Tortuous Democratization

A comparative analysis Ming Sing

3 China's Business Reforms

Institutional challenges in a globalised economy

Edited by Russell Smyth and Cherrie Zhu

\section{Challenges for China's Development}

An enterprise perspective

Edited by David H. Brown and Alasdair MacBean

5 New Crime in China

Public order and human rights

Ron Keith and Zhiqiu Lin

6 Non-Governmental Organizations in Contemporary China

Paving the way to civil society?

Qiusha Ma

7 Globalization and the Chinese City

Fulong $W u$

8 The Politics of China's Accession to the World Trade Organization

The dragon goes global

Hui Feng

9 Narrating China

Jia Pingwa and his fictional world

Yiyan Wang 
10 Sex, Science and Morality in China

Joanne McMillan

11 Politics in China Since 1949

Legitimizing authoritarian rule

Robert Weatherley

12 International Human Resource Management in Chinese Multinationals

Jie Shen and Vincent Edwards

13 Unemployment in China

Economy, human resources and labour markets

Edited by Grace Lee and Malcolm Warner

14 China and Africa

Engagement and compromise

Ian Taylor

15 Gender and Education in China

Gender discourses and women's schooling in the early twentieth century

Paul J. Bailey

16 SARS

Reception and interpretation in three Chinese cities

Edited by Deborah Davis and Helen Siu

17 Human Security and the Chinese State

Historical transformations and the modern quest for sovereignty

Robert E. Bedeski

18 Gender and Work in Urban China

Women workers of the unlucky generation

Liи Jieyu

19 China's State Enterprise Reform

From Marx to the market

John Hassard, Jackie Sheehan, Meixiang Zhou, Jane

Terpstra-Tong and Jonathan Morris

20 Cultural Heritage Management in China

Preserving the cities of the Pearl River Delta

Edited by Hilary du Cros and Yok-shiu F. Lee 
21 Paying for Progress

Public finance, human welfare and inequality in China

Edited by Vivienne Shue and Christine Wong

22 China's Foreign Trade Policy

The new constituencies

Edited by Ka Zeng

23 Hong Kong, China

Learning to belong to a nation

Gordon Mathews, Tai-lok Lui, and Eric Kit-wai Ma

24 China Turns to Multilateralism

Foreign policy and regional security

Edited by Guoguang Wu and Helen Lansdowne

25 Tourism and Tibetan Culture in Transition

A place called Shangrila

Ashild Kolås

26 China's Emerging Cities

The making of new urbanism

Edited by Fulong $\mathrm{Wu}$

27 China-US Relations Transformed

Perceptions and strategic interactions

Edited by Suisheng Zhao

28 The Chinese Party-State in the $21^{\text {st }}$ Century

Adaptation and the reinvention of legitimacy

Edited by André Laliberté and Marc Lanteigne

29 Political Change in Macao

Sonny Shiu-Hing Lo

30 China's Energy Geopolitics

The Shanghai Cooperation Organization and Central Asia

Thrassy N. Marketos

31 Regime Legitimacy in Contemporary China

Institutional change and stability

Edited by Thomas Heberer and Gunter Schubert

32 U.S.-China Relations

China Policy on Capitol Hill

Tao Xie 
33 Chinese Kinship

Contemporary anthropological perspectives

Edited by Susanne Brandtstädter and Gonçalo D. Santos

34 Politics and Government in Hong Kong

Crisis under Chinese sovereignty

Edited by Ming Sing

35 Rethinking Chinese Popular Culture

Cannibalizations of the Canon

Edited by Carlos Rojas and Eileen Cheng-yin Chow

36 Institutional Balancing in the Asia Pacific

Economic interdependence and China's rise

$\mathrm{Kai} \mathrm{He}$

37 Rent Seeking in China

Edited by Tak-Wing Ngo and Yongping Wu

38 China, Xinjiang and Central Asia

History, transition and crossborder interaction into the $21^{\text {st }}$ century

Edited by Colin Mackerras and Michael Clarke

39 Intellectual Property Rights in China

Politics of piracy, trade and protection

Gordon Cheung

40 Developing China

Land, politics and social conditions

George C.S. Lin

41 State and Society Responses to Social Welfare Needs in China Serving the people

Edited by Jonathan Schwartz and Shawn Shieh

42 Gay and Lesbian Subculture in Urban China Loretta Wing Wah Ho

43 The Politics of Heritage Tourism in China

A view from Lijiang

Xiaobo Su and Peggy Teo

44 Suicide and Justice

A Chinese perspective

$\mathrm{Wu} \mathrm{Fe} i$ 
45 Management Training and Development in China

Educating managers in a globalized economy

Edited by Malcolm Warner and Keith Goodall

46 Patron-Client Politics and Elections in Hong Kong Bruce Kam-kwan Kwong

47 Chinese Family Business and the Equal Inheritance System Unravelling the myth

Victor Zheng

48 Reconciling State, Market and Civil Society in China The long march towards prosperity

Paolo Urio

49 Innovation in China

The Chinese software industry

Shang-Ling Jui

50 Mobility, Migration and the Chinese Scientific Research System Koen Jonkers

51 Chinese Film Stars

Edited by Mary Farquhar and Yingjin Zhang

52 Chinese Male Homosexualities

Memba, tongzhi and golden boy

Travis S.K. Kong

53 Industrialisation and Rural Livelihoods in China Agricultural processing in Sichuan Susanne Lingohr-Wolf

54 Law, Policy and Practice on China's Periphery

Selective adaptation and institutional capacity

Pitman B. Potter

55 China-Africa Development Relations

Edited by Christopher M. Dent

56 Neoliberalism and Culture in China and Hong Kong

The countdown of time

Hai Ren 
57 China's Higher Education Reform and Internationalisation Edited by Janette Ryan

58 Law, Wealth and Power in China

Commercial law reforms in context

Edited by John Garrick

59 Religion in Contemporary China

Revitalization and innovation

Edited by Adam Yuet Chau

60 Consumer-Citizens of China

The role of foreign brands in the imagined future China

Kelly Tian and Lily Dong 



\section{Consumer-Citizens of China}

The role of foreign brands in the imagined future China

\section{Kelly Tian and Lily Dong}

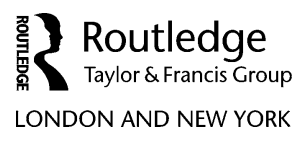


First published 2011 by Routledge

2 Park Square, Milton Park, Abingdon, Oxon OX14 5RN

Simultaneously published in the USA and Canada

by Routledge

29 West 35th Street, New York, NY 10001

Routledge is an imprint of the Taylor \& Francis Group, an informa business

This edition published in the Taylor \& Francis e-Library, 2011.

To purchase your own copy of this or any of Taylor \& Francis or Routledge's collection of thousands of eBooks please go to www.eBookstore.tandf.co.uk.

C 2011 Kelly Tian and Lily Dong

The right of Kelly Tian and Lily Dong to be identified as authors of this work has been asserted by them in accordance with the Copyright, Designs and Patent Act 1988.

All rights reserved. No part of this book may be reprinted or reproduced or utilised in any form or by any electronic, mechanical, or other means, now known or hereafter invented, including photocopying and recording, or in any information storage or retrieval system, without permission in writing from the publishers.

British Library Cataloguing in Publication Data

A catalogue record for this book is available from the British Library

Library of Congress Cataloging in Publication Data

Consumer-citizens of China : the role of foreign brands in the imagined future China/Kelly Tian and Lily Dong.

p. cm. (Routledge contemporary China series ; 60)

ISBN 978-0-415-55349-0-ISBN 978-0-203-84011-5

1. Consumers - China - Psychology. 2. Brand choice-China-Psychological aspects.

3. Nationalism-China. 4. China-Civilization-Foreign influences.

I. Dong, Lily. II. Title.

HC430.C6T53 2010

$306.30951-\mathrm{dc} 22$

2010018265

ISBN 0-203-84011-9 Master e-book ISBN

ISBN 978-0-415-55349-0 (hbk)

ISBN 978-0-203-84011-5 (ebk) 
To Mireille, Happy, and Hongkai 



\section{Contents}

Foreword $\quad$ xv

Acknowledgements xviii

1 Imagining China, imagining brands 1

Foreign brands as global brands from the imagined West 6

Western and domestic brands as materials for realizing

an imagined future China 9

Obscured state influence and consumer autonomy 15

Organization of the book 18

2 Rethinking popular notions of Chinese consumers' motives for responding to Western brands

The emulative motive for Western brand consumption 22

The patriotic motive for rejecting Western brands 24

Rethinking the primacy of the emulative motive for consuming

Western brands 26

Rethinking "consumer nationalism” as synonymous with

Western brand boycotting 32

Chinese consumers as active meaning makers 35

3 Highlighted moments in the history of branded goods in China

The emergence of branded goods in late imperial China 37 Branded goods in semi-colonial China of the early 20th century 39 Branded goods since gaige kaifang - China's economic reform 42 Relevance of these past moments to present-day brand meanings 49

4 Foreign brands in China as global brands from the imagined West

Overview of research method 52

Data collection sites 53 
xiv Contents

Our data collection methods 53

Foreign brands as Western brands with distinguishing characteristics 55

5 Chinese national narratives and the meanings of Western brands

The West as experiential venue, Western brands as instruments offreedom 70

The West as imperialist oppressor, Western brands as instruments of domination 77

The West as subjugated, conquered Western brands as redemption 88

The West as economic partner, Western brands as instruments of economic progress 93

6 National narratives in imaginative processing of Western brand promotions

Imagined consumption 97

Individual psychological processes of enlivening consumption fantasies 102

Narratives and imagined identity transformations from

Western brand consumption 105

The influence of national narratives of East-West relations on the processing of Western brand promotions 108

Discussion 117

7 Citizen-consumers in an age of globalization

Appendix

References

Index 


\section{Foreword}

\section{Kevin Lane Keller \\ E.B. Osborn Professor of Marketing Tuck School of Business at Dartmouth}

Perhaps no other topic is more at the intersection of important marketing trends and developments than globalization. Globalization is driven by a wide range of technological, cultural, economic, and environmental forces. The reality is that marketers all over the world are increasingly crossing international borders with their marketing, and the ability of a consumer in virtually any country to purchase branded products and services from companies in virtually any other country has never been greater.

Globalization offers huge opportunities for marketers, but at the same time creates enormous challenges. All these different forces have to be understood and properly accounted for. For example, technology shrinks the world, but creates much complexity at the same time because of the different standards and levels of adoption found in different countries. Cultural differences in particular are profoundly important and can often be the most difficult for marketers to grasp.

Marketing managers and consumer researchers are keenly interested in how brands will develop in this new global landscape. As brands cross more and more international boundaries, they often encounter new consumers with dramatically different needs and wants, as well as competition from brands that may very well have been a part of a country's history and heritage literally for decades. Managers and researchers have to know how brands are built in this kind of environment and how global forces will affect that.

Understanding how any brand develops in any market is challenging enough. Consumers form their impressions of brands based on potentially thousands of touch points. The image of a brand is made up of anything that becomes linked to it in the minds of consumers - all the thoughts, feelings, images, experiences, perceptions, beliefs, attitudes, judgments and so on that might occur as consumers go about their daily lives and one way or another come into contact with a brand.

Some of those contact points are influenced by marketers, through the design of the product or service, how it performs, where and how it is sold, how it is priced, all the communications that are sent about it, and so on. Many of these contact points, however, are out of the control of the marketer, in terms of what a consumer sees, hears, or reads from others. Online and offline word-of-mouth and media exposures have become increasingly important determinants of what consumers learn and experience with brands. 
Regardless of the source of the contact - marketer controlled or otherwise the information contained in it and the rational and emotional responses that it evokes are a function of the psychological make-up of consumers. Brand meaning is shaped by what consumers think, feel and act towards life in general, as well as brands and products in particular. A consumer's life experiences create a perceptual filter that shapes brand meaning in profound ways. The same brand and how it is marketed can be interpreted very differently, depending on the type of consumer involved.

A fundamental determinant of these life experiences is the culture in which the consumer lives. Consumers learn about and make decisions about brands in a social context of friends, family, and other significant people whose opinions matter. Interpersonal forces can be hard to pin down, but invariably play an important role in the success of a brand. Cultural relevance is often a key success factor for a brand. But brands don't just live in the "here and now" - there is always an aspirational aspect in terms of what they will also do for consumers in the future. One of the most fundamental tenets of branding is that the power of a strong brand is its ability to set expectations with consumers: consumers often buy brands as much for who they want to be as who they actually are.

One of the fascinating issues with regard to globalization is how consumers in different countries choose between the old and the new in their brand choices - the history, heritage, and cultural experiences from domestic brands with which they grew up versus all the new, exciting, foreign brands that have only recently become available. A whole host of factors will affect which brands consumers choose, such as: How important is nostalgia to them? Family ties? How do they feel about their own country? Other countries?

With respect to globalization, perhaps no country offers more contrasts than China. With a long, rich, and unique history, China is moving quickly to the top of 21 st-century marketing priorities as companies all over the world target the biggest market around. But how will consumers in China respond to these international forays? How will the meanings of domestic and foreign brands be shaped in China over time? What types of brands will be successful in China, and why? This is the multibillion dollar question. And besides the obvious applied interest in branding in China, there are intriguing theoretical issues about how Chinese consumers - or any type of consumer for that matter - incorporate Eastern and Western values in their brand images and meaning and the types of behaviors that result.

Clearly these questions are challenging, and fully understanding brands and branding in China will require time and significant scholarly analysis. A variety of theoretical perspectives and conceptual approaches will be necessary to capture the richness and complexity involved. Fortunately, an important first step in that journey has been made by Tian and Dong with Consumer-Citizens of China. In this book they offer a careful cultural analysis of how and why Chinese consumers choose foreign versus domestic brands. In particular, they identify the underlying processes by which Western brands become linked to various assertions of nationalism and visions of the future China. They carefully deconstruct the concept of "foreign brands," finding that a "foreign brand" simply means a global brand 
possessing particular traits. Japanese brands, for example, are "Western" brands - not on the basis of geography, but on their global achievements of being high quality, technologically advanced and "world famous."

At the heart of their analysis is the discovery of four cultural narratives that exist with Chinese consumers. These narratives piece together themes from the past and present political and social realities in China, and are found to be employed to enliven imaginings of Western brands. These four perspectives address diverse concepts such as freedom, dominance, competition, political and economic power and achievement, imperialism, expansionism, progress and quality of life, harmony, heritage, and national identity. They offer provocative and sometimes challenging observations that add to our understanding of consumer behavior and brand development in China. If consumers "own brands," as many branding pundits astutely assert, then understanding the manner by which these narratives affect how Chinese consumers choose to define and embrace brands is at the very heart of branding in China.

The authors have made a significant contribution to the field of consumer research in marketing with their work, successfully shining a light on a murky area of branding. Anyone interested in the future of branding in China should read, study, and learn from Consumer-Citizens of China. It offers invaluable insights that are critical to our understanding. The authors should be applauded and thanked for what they have accomplished, and I hope all readers reap the rewards of their efforts.

Kevin Lane Keller

Hanover, $\mathrm{NH}$ April 2010 


\section{Acknowledgements}

We thank members of the Chinese Academy of Science in Beijing, Danrong You, Shuoyang Zhang, Xiaoyong $\mathrm{Xu}$, and Yiwen Chen, for their guidance regarding the language construction and content appropriateness of our Chinese language survey. We also extend our gratitude to the many participants in Beijing, Baoding, Shanghai, and Tianjin who were willing to share with us their views of Western brands, along with aspects of their everyday consumer lives. Throughout this project a number of consumer culture theorists and China scholars have offered insights that informed our analysis. We remain moved by the generosity of Russ Belk, Julien Cayla, Karl Gerth, Jing Hu, David Mick, Nan Zhou, the marketing scholars of Monash University and University of Queensland, and participants at the Cambridge conference of the Academy of Marketing Brand, Identity and Reputation, all of whom offered suggestions that have shaped this report of our research findings.

We asked Kevin Keller to write the foreword for our book, as his research has shaped the direction of brand management research for several decades now. We deem this request a novel move. Marketing scholars who have studied consumer culture have historically avoided the topic of brands, owing to an asserted aversion to producing academic research as a tool for management. In recent years, consumer culture researchers have begun to devise works where brands are focal. This interest in brands has emerged from recognition that brands shape culture and cultures develop around brands. Even so, it remains rare for consumer culture theorists to discuss the managerial relevance of their works. Our view is that transnational organizational brands, collectively considered, are positioned to "do good." We have begun to see more transnational corporate brands engage in corporate social marketing programs at the same time as nongovernmental organizations have evolved to become superbrands wielding consumer marketing practices in the service of humanitarian interests. Given this, we see no inherent conflict in offering our insights into the citizenship meanings of brands in China to brand management practitioners. As our concluding chapter highlights, theorizing in this area holds the potential to be of considerable practical value, as brand managers of both transnational corporations and nongovernmental organizations work to guide individual behavior towards the collective good.

Parts of Chapters One, Five, and Six appeared in the Journal of Consumer 
Research in 2009, (Volume 36, October, pages 504-23) under the title "The Use of Western Brands in Asserting Chinese National Identity" by Lily Dong and Kelly Tian. This paper was accompanied by an online publication and visual appendix posted in March 2009, "Brands of Nation-making in China: A Visual History of the Use of Western and Domestic Brands in Asserting Chinese Nationalism" (http: //journals.uchicago.edu/doi/suppl/10.1086\%2F598970/suppl_file/AppA.pdf). Permission to use this material has been given by the publisher, University of Chicago Press. Eric Arnould served as the Associate Editor for our Journal of Consumer Research publication, and his guidance and suggestions for relevant cultural anthropological works are appreciated. 



\section{Imagining China, imagining brands}

Presiding over the central square in Chengdu, the capital of China's Sichuan province, is a 30-meter white-marble statue of late Chairman Mao Zedong, built during the Cultural Revolution (1966-1976). Chengdu is one of the few cities where such statues of Mao, which were once visible throughout the country, remain. A China Daily reporter offers a rich description of the central square and surrounding area that implicitly renders remarkable the preservation of this historical icon in the face of dramatic cultural change.

Instead of political slogans, the white-marble statue of Mao is now surrounded by huge billboards of advertisements that had been cited as something "capitalist" against Mao's planned economy, in which production and sale of goods were controlled by government plans. Now the venue where Mao's statue stands, at the heart of Chengdu, has become the hot spot for both domestic and foreign investors to show off their corporate images and brandname products. Around Mao's statue, posters or boards with advertisements of home-made products are competing with those of foreign or foreign-funded companies such as Kodak of the United States ... Right behind Mao's statue, a banner streamer [announcing] . . . a large-scale shopping fair for traditional Spring Festival goods is in sight. [Contrasting food rationing during Mao's era, people now] can buy whatever they like ... for the imminent New Year and the ensuing Spring Festival, or the Chinese lunar new year, at this fair. ... The decades old Chengdu Department Store is a listed one [on the stock market] whose building, just opposite to Mao's huge statue across the city's main street, was festooned with varied ad banners atop its roof and buildings. A lottery business ad . . . was especially eye-catching . . . In the past two years, the business made nearly 100 local residents . . millionaires through lottery buying, which was however, unimaginable and banned during Mao's era. ... Around the square are also vivid shops of McDonalds and KFC, whose globally known logos were the best identity for publicity ... On the left of Mao's statue three major Chinese insurance companies, China Life, China Pacific and Ping An, were touting their services in huge enchanting advertisements. [This was something foreign in Mao's planned economy where people] could enjoy housing, medical, and pension benefits from the 


\section{Imagining China, imagining brands}

government ... On the Remin (People's) Road ... South of Mao's statue, advertisements of a dozen real estate developers were competing ... [as] Chengdu witnessed a booming housing market like other cities around China . .. To make way for the construction of a central business district, the Chengdu municipal government, once adjacent to Mao's statue, moved to the brisk and fast-expanding business center three years ago.

(China Daily 2003)

In this imagery of a prospering Chinese city, aspects of the past are retained (such as Mao's statue) and nourished (for example the Spring Festival) in China's new market economy, and coexist in harmony with commercial brands, both domestic and foreign, that together alter consumption experiences and practices from China's past. Past and present are not always blended so seamlessly.

During the 60th anniversary of National Day the Japanese popular press reported that the Beijing City Office of Publicity had requested that television stations not broadcast the scene of Chairman Hu reviewing troops with the Toshiba poster in the background (http://forum.kaiyuan.de/viewthread.php?tid=364558; http:// txbbs.cc/viewthread.php?tid=3095).

The press reports suggested that this was prompted by Chinese viewers who had written to express their anger at seeing the Japanese brand while they were watching the National Day celebrations. After three decades of promotional presence in China, it would be easy to think that global brands have become commonplace to the point of seeming natural. Global brands often try to avoid appearing alien by engaging with local culture and insinuating that they are Chinese (Zhao and Belk 2008b). As this incident reveals, global brands remain foreign in the eyes of many Chinese. Such foreign-ness is also seen as inappropriate to or even contaminating celebrations of Chinese cultural heritage or China as a nation.

It also prompts a number of questions about the presence of foreign brands in China. Why did some viewers react with such strong negative emotions about the Toshiba poster? Why would viewers' complaints carry enough weight to allegedly prompt Beijing City Officials to take action to stop the broadcast of the film-clip? Whereas China scholars might link these reactions to China's history involving civilian victimization during the locally labeled "Japanese War of Aggression," we are left to wonder how such history becomes embodied by the Toshiba brand, and why it is of relevance to Chinese people today. Many were born after this Second World War event, and now live under an administration that apparently does not attach such negative meanings to global brands.

The National Day anniversary is of course not the only incident in which a global brand has been deemed by the Chinese as inappropriately linked to China's celebration of its nation and historical past. In contrast to this unintended linkage are attempts of global brand producers to ground their presence in China's national history. Take, for example, an advertisement we accessed online in 2007 reportedly created by KFC. The filmed advertisement depicted a host of hungry Chinese soldiers who receive and then devour the contents of Kentucky Fried Chicken boxes. With patriotic background music and soldiers clad in World War 
II uniforms, the advertisement's voiceover and text suggest that "Chinese people are passionate about and willing to die for three things: the national flag, the great (socialist) dream, and KFC Fried Chicken wings." Although the exuberance with which the soldiers devour the box of wings perhaps was intended as camp or comic, the Government of the People's Republic of China (PRC) did not see the humor nor feel the promotional pull. The advertising campaign was never broadcast, as the PRC deemed its content inappropriate (The film, posted at http://www.56.com/ u79/r_MTMxNDQ3MTY.html and accessed in 2007, has since been removed). With an infinite number of creative choices, why would brand producers opt for this type of appeal? Although at first this promotion struck us as thoughtless, we would answer "for many reasons."

First, this foreign brand advertisement pursues a strategy of "sinocizing" the brand (Zhou and Belk 2004, 71) by imposing a specific favorable historical context that fosters a sense of the United States and China as allies. That the KFC brand is represented as a gift to an ally might be read as this brand producer's attempt to counter an imagined oppositional meaning - a foreign brand as the Trojan-horse gift of an enemy. Second, the ad rhetoric mimics the structural format of well-known political guidelines proposed by cultural political icon Dr. Sun Yat-sen (18661925). Dr. Sun is known for promoting the selective adoption of management systems from foreign countries as a path toward China's empowerment during early confrontations with foreign countries. The guidelines are called "san min zhuyi" or the three-min system (Three Principles of the People), namely minzu (nationalism), minquan zhuyi (democracy), and minsheng zhuyi (socialism or populism). Third, in playing off of Dr. Sun's rhetoric, the ad references the founder of the Guomindang party, which is the ruling party of Taiwan today. Dr. Sun is one of the few historical political leaders honored in both Taiwan and China. Thus, this selection sidesteps the controversies that have erupted between China and Taiwan over Taiwan's claims for independence.

The unaired KFC ad suggests several fundamental premises: that Chinese nationalism is important to consumers; that some consumers imagine East-West conflicts rather than alliances; that consuming foreign brands from the West is potentially at odds with Chinese nationalism; and that this conflict can be navigated through selective invocations of history. All in all, this brand producer seems attuned to cultural anthropologists' assertions that in the age of globalization, nationality and cultural history are all the more relevant in the lives of individuals and shape the meanings they attach to consumer goods (Friedman 1996, 1997). Yet the global brand icon KFC, for all its well-intentioned efforts to localize its appeal, was viewed as shui tu bu fu (not acclimatized to the water and soil) in China (Zhou and Belk 2004). Although the promotion of the foreign brand may have attempted to capitalize on the local cultural system, it nonetheless appeared alien and offensive (Zhao and Belk 2008b). Among other aspects of the ad, in China expressing hunger leads to a loss of face. After all, prior to the economic reforms Chinese consumers suffered decades of limited food supply. The depiction therefore not only causes embarrassment but also revives unpleasant memories. Further, the traditional value system in China has always praised people who 


\section{Imagining China, imagining brands}

would rather die than accept jue-lai-zhi-shi (food offered from pity mixed with contempt). So, although there is more thought behind this failed brand promotion than at first meets the eye, we would say knowing "quite a lot" is nonetheless not enough.

Even global brands invited to join in China's celebration of heritage have found themselves at the center of a controversy in which China's sovereignty, cultural heritage, and future are debated. An apt illustration here is the opening of a Starbucks storefront café in the Forbidden City in fall 2000, following Starbucks' 1999 debut in China. The almost 600 year old Forbidden City encloses the imperial palace, which was home to 24 emperors until imperial rule ended in 1911. In the burgeoning tourist industry spawned by gaige kaifang, the invitation extended to Starbucks to open a café in the Forbidden City was part of the museum administrators' attempts to improve service in China's top tourist attraction (People's Daily 2000). Whereas some reports suggest that the invitation was a strategy whereby administrators could raise money to maintain the 178-acre complex of villas and gardens, palace management claims the decision was driven by a desire to meet consumer demand, and not by profit (China Daily 2007). Almost immediately after its opening, website debates emerged, with some Chinese bloggers protesting the presence of Starbucks on the grounds that it was damaging to cultural heritage (People's Daily 2000).

In January 2007, six years after the opening, a China Central television host, Rui Chenggang, aroused resentment in a blog where he pronounced the Starbucks in the Forbidden City to be a joke among western tycoons (China Daily 2007c). Email exchanges between Chenggang and the CEO of Starbucks, Jim Donald, reveal that the Starbucks presence was contested as insensitive and even disrespectful of China's cultural heritage (China Economic Times 2007):

[email letter to CEO of Starbucks from Chenggang] Jim, how are you doing? I'm the Chinese anchorman you met last year at the Yale CEO Summit. We talked about why Starbucks should move its shop out of the Forbidden City. And I really appreciated it when you told me you yourself were not in favor of that. Am curious to know if you have a plan to have it removed. It's still there. Did your Chinese partner agree with you?

All the best.

Chenggang

原文[original email] Reply via email)

Dear Mr. Rui,

Thank you for your note and for your concern regarding Starbucks Coffee Company's presence in the Forbidden City.

When Starbucks was invited by museum officials to open a store six years ago, we did so with great sensitivity to, and respect for, the historic and cultural heritage of the Forbidden City. We have shown and continue to show our respect for local history, culture and social customs, and have made serious efforts to fit within the environment of the Forbidden City. 
We are honored and humbled to have been invited to offer customers a place to relax and enjoy a cup of coffee with their local Barista.

Connecting with our customers and the communities in which we operate is important to us. Ever since our entry into China, we have been involved in the local community and its culture. An example of this can be seen in our China Education Fund activities.

Thank you again for reaching out to me. Should you have any additional questions, please do not hesitate to contact me. In the meantime, I have asked Eden Woon, vice president of Starbucks Greater China, to reach out to you personally.

Sincerely, Jim Donald

The email letters can be found on the blog of Rui Chenggang (http://blog.sina.com. cn/s/blog_4adabe27010008zk.html). Whereas some bloggers held that Starbucks was an instrument of further interjecting capitalism into China and called for cultural protection, others questioned the essence of "cultural protection," anticipating that Starbucks would be replaced with a local coffee (rather than tea) provider. Others questioned the cultural independence of Rui's argument, as he seemed much concerned with Westerners' opinion of the Starbucks in the Forbidden City.

In short order the Starbucks closed following the January 2007 blog protests and debates. The blog debates were followed in March by a motion submitted to the National People's Congress by a member of parliament, Jiang Hongbin, to close the outlet. Jiang filed the motion on the grounds "As long as it stays in the imperial palace it poses a challenge to our traditional culture" (China Daily 2007b). The prospect of a host of tourists attending the heritage cite during the 2008 Olympic Summer Games in Beijing perhaps also elevated concerns for showcasing the palace as traditional culture untainted by global forces (see Belk 2003), as the ongoing renovation of the palace more generally involved toning down commercial symbols. In July of 2007, Forbidden City managers decided that all shops on its grounds would operate under the palace's brand name. While, given the debates, one might presume that a tea house would replace the Starbucks, in 2008, on the same site, the Forbidden City Café opened its doors to provide coffee and other drinks (China Daily 2007a).

Current knowledge of Chinese consumers' meanings and motives that guide their responses to foreign brands amounts to the pinhole in a black sheet of paper held against the sun; there is an abyss of lacking knowledge. Our contribution to this abyss is guided by the foundational premise that just as brands are no longer product trademarks but rather live in the consumer's imagination, so too has the nation been freed from a fixed physical time and place. The nation is also imagined, drawing from the past and from expectations of the future to assert collective identity present day (Friedman 1992a, 1992b). As suggested by the three cases of the Toshiba-framed National Day celebration, the web-posted KFC patriotic-themed promotion, and the Starbucks café in Forbidden City, imaginings of brands are interwoven with imaginings of the nation. 
This book aims to demystify the tensions regarding the presence of foreign brands in China that emerge at such moments. It offers insights into the complex responses of the state and its citizens to global brands in China by showing how these responses are interwoven, mutually shaping, and multipositional. This multipositionality reflects that different views of Chinese nationalism offer different prescriptions for foreign brand consumption, and emerge from both globalization and more micro-level processes of individuals asserting their autonomy. The depth of cultural knowledge shared in Consumer-Citizens of China facilitates sensitivity to the potential for a proposed foreign brand signage, promotional campaign, or storefront presence to become the latest cultural gaffe in the eyes of Chinese State Officials or consumers.

The insights offered here are the culmination of our research into the meanings that underlie Chinese consumers' motives for responding to foreign brands. To date, inquiries into the meanings of foreign brands in China have not attempted to understand foreign brand meanings from the perspective of Chinese consumers and in the context of their daily lives. This lack of information is repeatedly lamented by CEOs of transnational corporations attempting to introduce their brands into China (Knowledge @W.P.Carey, 2009), as it holds the potential to inform promotional campaigns, product design, distribution, brand positioning, brand pricing, and handling of customer complaints. Such insights might help alleviate the current high rate of Western brand failures in China (Croll 2006).

We show how nationalism is perceived and used by Chinese consumers to infuse foreign brands with meaning, rendering them useful in articulating a reaction to the West, and materializing imaginings of the future China. Whereas "nation-building" implies that a top-down construction by political, military, and intellectual leaders, "nation-making" emphasizes broader social participation by citizens in the course of their everyday lives (Gerth 2003, 4). Our work reveals the underlying processes by which Western brands become linked to various assertions of nationalism and visions of the future, which motivate choices between foreign and domestic brands. An understanding of consumption motivational practices must start with an understanding of the consumer's world of subjective meaning and a discovery of "how it is divided into units" (Campbell 1994, 45). That is, is the concept of "foreign brands" meaningful to Chinese consumers? Not entirely, as "foreign" is deemed to refer to global brands possessing particular traits.

\section{Foreign brands as global brands from the imagined West}

We began our inquiry into Chinese consumers' meanings and motives for "foreign brand" consumption as a category of significance in China's history (Gerth 2003). We found that foreign brand meanings are formed by local cultural understandings of China's historical relationship to the forces of capitalist globalization, along with current discourses on China's future in the global economy. Our Chinese participants disclosed that "foreign brands" is an "otherness" that is selectively imputed to brands associated with the "West." This finding converges with those emerging from the study of the meanings of foreign advertisements, where 
consumer culture theorists suggest that the term "global" has come to mean "Western" in people's minds (Abbas 2000; Zhou and Belk 2004).

This "West" is not a geographical entity but one of the imagination. It includes nation-states that constitute dominant powers in the globalization of capitalist ideology and which have shaped China's position in the global economy: the United States, Western European nations, and also Japan. Chinese national narratives which seek to forge a collective national identity through discourses that place China in opposition to the West also include Japan (Gries 2004). As Gries (2004) notes, Japan is not west of China, but Chinese often include Japan in both the noun and the adjective "Xifang" - "the West" and "Western" - reflecting that it is through Japan that the Chinese have sought knowledge of the West. Participants' responses to our questions mixed references to brands from the United States and Western Europe with those from Japan, and excluded those from other nationstates. This phenomenological view of Western brands emerges from their historical use in the construction of Chinese nationalism (Gerth 2003; Friedman 1992a; Zhao and Belk 2008b).

Whereas most Western brands comprising our Chinese participants' discourses qualify as global (that is, most claim $20 \%$ of their sales from foreign nations; Business Week 2001), the concept of Western brands is more narrow. Apart from those from Japan, global brands from Asian-Pacific nations were rarely mentioned. This exclusion may reflect the effectiveness of brand campaigns that cultivate a regional Asia-Pacific identity and market (Cayla and Ekhardt 2008), operating in the absence of cultural memories of conflict. Indeed, whereas one design goal of these campaigns is to elide past military conflicts (Cayla and Ekhardt 2008), our participants' inclusion of Japan as "Western other" suggests that memories of past national humiliations are not easily glossed over. The National Day incident mentioned above suggests as much.

Although Western brands are associated with selected nation-states, consumers do not identify them by an objective assessment of their country of origin. Rather, the participants' concept of Western brands reflects localized attempts to deal creatively with the country-of-origin confusion produced by outsourcing practices and complex international chains of assembly and cross-national joint ventures (O’Cass and Lim 2002; Thakor and Kohli 1996; Zhou and Belk 2004). Resolving this confusion, they find that the legitimacy of Western brands resides in their global status: that is, Western brands also must be "world famous" - guo-ji-mingpai. Drawing from local knowledge of quality control measures demanded of exports in post-reform China and survival-of-the-fittest notions of capitalism, some of our Chinese participants insisted that Western brands must be of higher quality and technologically superior to domestic brands if they have gained access to China's market. From some participants' perspective, owing to China's protectionist history very few domestic brands are global, and thus have not passed the same product standards of the international marketplace. The significance of Western brands' global stature is highlighted even if challenged by local media stories, noted by our participants, that draw attention to cases where Western brands exhibit lower quality in China than the same brands in developed nations (Yu 2007). Brand 
names aid the designation of a Western brand but are not as defining as attributes of global fame, quality, and technological superiority. This reflects local experience of encountering a proliferation of domestic goods branded to convey Western-ness and capitalize on presumed positive associations (Zhou and Belk 2004). Chinese consumers' discussions of translated brand names reveal a practice that Gerth $(2008,41)$ labels "nationalistic visuality, centered on training the eye to identify visual clues and to distinguish between the foreign and the domestic across social life." In semi-colonial China of the early 20th century, the goal of this visual practice was to buy China-made goods (Gerth 2008). Today some of our participants engage in this practice to screen out counterfeit Western brands, and others lament the shamefulness of consumers' fascination with Western brands which has forced quality China-made goods to pass themselves off as foreign.

In our work, when we speak of brands we are for the most part speaking of product forms of the brand. The vast majority of Western branded products discussed by our Chinese participants also refer to corporate brands, for example Coca-Cola, Jeans West, KFC, Nike, and Mercedes. In China, where many Western brands are sold from similarly branded storefronts, as in the case of KFC, Jeans West, and Gucci, for example, the product form of the brand is more visibly linked to the physical presence of the corporate brand. Through logos, labels, and promotional campaigns, Western brand producers have attempted to infuse these product forms with the identity of the corporate brand; each product contributes to the corporate identity as well as basks in its reflected glory (Balmer 2006). This is in contrast to a strategy whereby the corporation crafts a distinct brand identity through separate brand names and brand campaigns for each product in its portfolio. The move by marketing managers to target customers with corporate brands has been motivated by macro-level forces, particularly internet technology, which renders corporate acts visible and inseparable from their product brands (Fog et al 2005; Trentmann 2007). Corporate brand identity is built from communications that articulate who the company is and what it stands for that distinguishes it from other organizations (Schultz and Hatch 2006). The values and beliefs of the corporation shape the brand identity and serve as the basis for securing consumers' affinities towards, identification with, and emotional attachments to the brand.

Whereas the brand traditionally targeted only customers, it is increasingly being used by corporations in dealings with their various stakeholders, including employees, shareholders, the financial community, suppliers, and regulatory bodies (Schroeder and Salzer-Mörling 2006; Ind 2001; Schultz and de Chernatony 2002). Consumers and employees in particular are encouraged by brand corporations to "be the brand" or "live the brand" (Schultz and de Chernatony 2002). Croll $(2006,45)$ notes: "It has become a world-wide marketing truism that brand names are not only about product choice and quality but also about the appropriation of new identities and lifestyles." Our findings suggest that the more specific, distinctive, or niche-oriented identity and lifestyle positions that corporate brands from the West seek to cultivate may to some extent become conflated in the eyes of Chinese consumers, for whom the branded product's association with "the West" is the most distinguishing feature of its identity. 


\section{Western and domestic brands as materials for realizing an imagined future China}

Our findings reveal that Chinese individuals engage the past to imbue Western brands with national identity meanings tied to four different imaginings of the future China. As Wilk (1994) asserts, objects play an active role in constructing images of collective futures as they represent aspirations and create directionality; they make a given future seem concrete. In contests for desired futures, groups engage goods in different ways to "stake their claim, map their route, and convince others of its inevitability . . Just as people use objects to invent tradition, they also use them to invent the future (Wilk 1994, 98)." This perspective is different from the suggestion that confidence in the future, as dictated by conditions of employment, healthcare and retirement, determines Chinese consumers' spending on global brands (Croll 2006). Reversing the direction of influence, our extension of Gerth's (2003) theorizing highlights consumers' agency and citizenship in attempting to direct the future of the nation through their brand choices. Closer to our conception, Watson (2006b) notes how local-born youths in Hong Kong were driven by their vision of a more cosmopolitan Hong Kong than existed in the past to disapprove of consumers' abuse of public facilities (such as taking napkins and condiments out of the McDonald's establishment). They tied such practices to the past when an influx of immigrants with no stake in the local economy took a "take money and move on" attitude, and when a climate of economic insecurity prevailed along with fears of a Red Guard takeover. A different vision of the future shaped these youths' consumption behaviors in the present.

Here we outline the four imaginings of the future China materialized through reactions to Western brands. We offer selections from our data to illustrate the ways in which these imaginings were expressed by Chinese consumers. Reactions to Western brands are revealed as linked to different national cultural narratives (Gries 2004), each of which appropriates China's past to inscribe Western brands with selected meanings. The narrative of the West as experiential venue represents Western brands as instruments of freedom and new experiences. A narrative of the West as imperialistic oppressor imbues Western brands with the capacity for cultural domination of China. In a third narrative, in which China seeks redemption from humiliation at the hands of the West, Western brands take on the meaning of tough market competitors which, if defeated by national brands, will redeem China in the eyes of the world, recovering an interrupted destiny as a world leader. In a narrative of the West as economic partner (Gries 2004), Western brands coexist with national brands in harmony through mergers and distinctive competencies. We more fully analyze these narratives, their prescriptions for Western brand consumption, and their use in imagining the future China over the course of the book.

Briefly here, each of the four cultural narratives which are used to make meaning of Western brands reflect temporal poaching of and leveraging from ideologies manifested in nation-state governing practices. These include various means of asserting state ideology that comprise and serve to realize the official vision of 
the future nation-state, such as political speeches, published discourses, policies such as those to curb or stimulate consumption, and state-sponsored programs of education. Each of the four cultural narratives pieces together themes from present and former nation-state administrations and uses them to enliven imaginings of Western brands. Once Western brands are imbued with "historicized" meanings (Martin 2004) that align them with select ideologies of China's relationship with the West, consumers' responses to them become a means of materializing various preferred imaginings of the future China.

In the preparation of this book we spent the past year presenting our findings to colleagues in China as well as at academic conferences and seminars in the United States, the United Kingdom, and Australia. A recurring reaction was fascination with the rich responses provided by our Chinese participants. Although our research, conducted in four Chinese cities, involved multiple methods, including interviews, focus groups, and surveys, it has been data from our survey-administered projective tasks that audiences have found most intriguing. This involved asking consumers to write a dream about a foreign brand. The dream could be either a good dream or a bad dream. This choice was also informed by recognition that critical expressions and sentiments tied to Western foreign brands, or the domestic Chinese brands that compete with them, would be more likely to be aired under indirect and masked forms of inquiry (Gries 2004). This methodological choice was deemed useful in eliciting free commentary on whatever imaginings the participant considered relevant (Hilgard 1980; Holbrook and Hirschman 1982). The survey responses form the focal voice of our research narrative; other voices from interviews and focus groups are used in ways that harmonize or contrast (Price and Arnould 1998).

One vision our Chinese consumers sought to realize through consumption practices is that of a future China characterized by greater freedom, conceived as more choice, enhanced convenience, more information, and greater plurality of views. This vision draws from a national narrative of the West as experiential venue and Western brands as instruments of freedom (Gries 2004). This narrative theme of freedom manifested in a host of dreams:

[The more foreign brand products I have], the more confident I would feel about myself. [Dream] In my dream, I drive a Benz car, wear a Swiss watch, freely walk all the way to my friend's home to chat. The two of us have such a good talk: how comfortable Nike tennis shoes are, how successful Samsung and BMW are, the Piao-rou (meaning "flying gently" in Chinese, known as Rejoice or Pert in English) shampoo really has made my hair smoother... After that, we go to eat KFC, and while wiping our mouths we praise foreigners for coming to China and bringing convenience to our people.

(20 year old female survey participant, Beijing)

Microsoft turned into a young, energetic, and knowledgeable wise person. He took me into the Microsoft world... I wanted to see the sea, he would... 
give me a virtual experience of being there. Then I wanted to know about the universe. He could give me totally new thoughts and feelings.

(23 year old male survey participant, Tianjin)

By engaging the narrative of the West as a route to new experiences, consumers reconstruct the past in the present (Friedman 1992b). This appropriated narrative capitalizes on present-day official discourses that espouse the depoliticized nature of Western brands, rendering their consumption constitutive of "the spirit of nationalism" and essential to promoting the national economy and elevating citizens' standard of living. It draws Western brand meanings from 19th-century historical movements which embraced Western goods because they brought with them ideological insights pertaining to democracy (Liu 2004). Summoning this past lends meaning to Western brands as instruments of freedom, voice, and choice, not only in the current economic realm (Coulter et al 2003) but also as tools to create an imagined future China transformed by access to experiences and ideologies from the West. Contrary to a notion that nationalistic narratives are synonymous with discourses of protectionism and domestic brand loyalty (Wang and Wang 2007), this nationalistic narrative encourages global exchange and Western brand consumption. Although it calls upon Western nations for transformational insights tied to improving national circumstances, it is not lacking in nationalistic concerns and sentiments of patriotism. Rather, it reflects a different view of the process of gleaning and asserting political and economic power for the nation-state.

A second vision is a future China that returns to Mao-era protectionism. This vision draws from a Chinese national narrative of the West as imperialist oppressor (Gries 2004), as reflected in the following survey responses:

In the dream, I saw myself wearing Beaty clothes, holding a Chanel handbag, wearing Red Earth cosmetics on my face, Shi-si shoes. Suddenly, it started to rain, I ran forward, then my shoe sole broke along with the tearing sound of the clothes. I tried to run home, looked into the mirror, found the "waterresistant" cosmetics ruined by the rain, and I became a big colorful cat. Thus I threw them away, never sought after foreign brands.

(18 year old female survey participant, Beijing)

I'm driving a BMW, listening to Sony music, drinking Coca Cola, and come to a wild and empty place. With Nike shoes on my feet, I run like crazy, running, running. On the grass, beside the tents, there are many red flags with five stars [Chinese national flag], around them are herds of cows. Many workers are milking the cows, they milk like crazy. Up in the sky, floats a slogan "Bright Dairy" (a Chinese dairy brand) ... The workers are dying one after another... I have sold all my foreign brand products including my BMW and Sony video camera etc.!!! Then I buy "Bright" milk to feed pandas.

(23 year old male survey participant, Baoding)

The Chinese national narrative of the West as imperialist oppressor projects China's past subjugation of the semi-colonial era onto the future, thereby 


\section{Imagining China, imagining brands}

heightening the fear of a territorially dominated China. It links marketplace invasion to an immanent threat of military invasion, through a logic in which profits from Western brands fund Western military operations. Within this narrative, Western brands are demonized as encouraging the practice of individualistic, conspicuous, and leisurely consumption, echoing past criticisms levied in Mao-era socialist discourses. The elevation of Mao Zedong as a heroic cultural figure by post-reform administrations renders this past accessible. On this basis, this narrative emphasizes that present-day consumer practices mark a divide-and-conquer strategy by Western powers. As this narrative asserts an agenda of protectionism, ownership claims to physical territory become essential. It represents China's territory as being marked by Western brand dominance, as exhibited in homes, on store shelves, and retail centers within heritage sites. Such images create a serious and compelling image of an invaded China, thereby facilitating an imagined invasion of China's less tangible spaces, cultural, economic, and political. The narrative resolves the invasion fears by calling for a return to Mao-era trade protectionism, where domestic brands once again become the staple of lived experience. Abstinence from Western brand consumption is a nation-making act, marking a call to create a future China whose physical borders are not transcended by foreign trade.

This vision seems to be the one most likely held by the National Day celebration viewers who complained of the background image of the Toshiba advertisement. In the eyes of these viewers, the Toshiba brand may have embodied past Japanese military aggression, which can be conjured as a current threat, given that economic power (delivered through global brands) offers the means to fund national militia. This meaning makes the Japanese brand particularly disruptive to the National Day celebration, which featured a Chinese military ritual.

A third vision is a future China that rises to a dominant position in the global market economy, as illustrated in the following responses of Chinese consumers who dream of introducing Chinese brands to Western nations. This vision draws from a Chinese national narrative in which conquered Western brands symbolize China's redemption from past humiliations at the hands of Western powers (Gries 2004).

[The more foreign brand products I have], the less money is left in my pocket. [Dream] Chinese products' quality improves very fast, and the post-purchase service goes up, too. They push foreign products out of China's market, and I would feel gratified if I could see this point. Everybody in China buys Chinese products. Then I dream that I come to Las Vegas of America, taking Chinese products with me, hold a "Chinese product news release", and compare them with American products on the spot. I immediately beat the foreign products, winning honor for China. Then I wake up from the dream.

(24 year old male survey participant, Beijing)

One day, streets of foreign countries are running Chinese Red Flag (a car brand), foreigners all wear Double-star (a Chinese shoe brand) and Pu-dun pants (a Chinese brand).

(survey participant, no demographics, Baoding) 
Emerging from a narrative in which China subjugates the West, this imagined future China guides a reconstruction of the past in terms of the present (Friedman 1992b). The envisaged capitalist expansion of China via the global spread of China-made brands is grounded in a selective cultivation and creative combination of China's pre-communist, capitalist period with Mao's (socialist) expansionist aspirations. Here there is also a call to buy China-made goods, yet no protectionism is sought, as this constrains the realization of the imagined future China ascending in the global economic order. The West-as-subjugated narrative also revitalizes the cultural memory of past Western military aggression, yet it transforms the meaning of these losses in terms of present-day circumstances and values (Friedman 1997), blaming these aggressions for China's failure to rise to the top of the global economy. Western brands in China that are inferior to the same versions sold in other countries, or whose local representatives offer poor service, are reminders of the semi-colonial period of humiliation in which China's ports were forcibly opened to foreign trade. In envisioning a future China pre-eminent in the global economy, Western brands are a potential target for close censorship. Chinese consumers screen those Western brands that attempt to reimpose past humiliations through double standards in the treatment of Chinese consumers compared to their Western counterparts. These include culturally offensive ads such as the web-posted ad featuring Chinese soldiers and KFC food, which may be read as appropriating Dr. Sun's "Principles of the People" in a trivializing manner. They also include Western brand practices of being unresponsive to customer complaints, placing inferior-quality Western brands in China, failing to recall unsafe brands in China, and setting up high barriers to the return of Western branded goods once concerns for product safety are publicly reported (Yu 2007). Viewers possessing this vision of China were unlikely to be among those complaining about the Toshiba ad at the National Day celebration - although perhaps these viewers would have found it more appropriate to see one of China's global brands, promoted in the background. Further, bloggers who challenged the "cultural invasion" arguments that led to the closing of Starbucks in the Forbidden City, perhaps would have preferred to see a domestic coffee brand claim the space as a result of higher consumer demand rather than cultural heritage controversy.

The fourth vision of the future China is an existentialist nation that is constantly changing through contact with global forces while remaining distinctively Chinese due to its grounding in indigenous ways and values. This vision emerges from a popular national narrative of the West as harmonious economic partner (Gries 2004). Projective survey responses reflecting this fourth vision were common:

[The more foreign brands I have] it shows the richer I am. Dream: I imagine that foreign brands and Chinese brands are two people with high quality, optimistic and positive attitudes. They walked together, and became best friends! They learned from each other and helped each other to make up for each other's weaknesses. The Chinese brand was down to earth, and the foreign brand was gorgeous. The Chinese brand drew on the foreign brand's advanced technology and management experience, and at the same time, it 
entertained the foreign brand and made the foreign brand benefit greatly from the Chinese brand. Hand in hand, and shoulder by shoulder, they worked hard together for mankind's happiness.

(29 year old female survey participant, Beijing)

The more foreign brand products I have, the more ... I I feel successful, however, it's better to own Chinese famous brands. [Dream] In a quiet mountain village, everything was so pure and clean. One day a traveler came, trying to sell to those simple and innocent villagers a kind of good drink, Coca Cola. The first time I was exposed to it, I tried it. It tasted bitter. "It tastes so horrible!" I said. This time, grandma walked over. "Wrong. You should not drink it this way. You should drink it as if you were drinking Chinese herbal medicine. Add water and sugar." Then, grandma took over the Coca Cola mixed a big cup for me. She put in a lot of sugar. I drank some. "Wow! It tastes great!" Thus, I cheered, "Everywhere is home!"

(23 year old male survey participant, Beijing)

This vision comprises the narrative of the East and West as partners in elevating the conditions of all mankind. Accented here are the value-added components brought to the table by each partner. Balancing the West's contribution of technological know-how, this narrative conjures a Chinese heritage ground in harmony with nature, and an appreciation of the elderly and their wisdom. This heritage has been iconized in practices of traditional Chinese medicine, notably a pre-modern practice and one of China's most renowned exports globally. As a practice that emphasizes harmony with nature, it reflects an attempt to revive aspects of the pre-modern world which have value in the present by way of contrast (Friedman 1997). This practice of locating social identity in eco-friendly or rural pasts which have become valued in the present has also been identified among movements that seek to reinstate indigenous identities (Hawaiian, Native Americans; Friedman 1992b, 1996; see also Manning and Uplisashvili 2007). Leveraging from this heritage, the envisioned future China is one that makes its own distinguishing contributions to the world economy while creatively engaging products from abroad in a manner that is uniquely Chinese. This partnering view of East and West seemed pronounced in the China Daily reporter's description of the commercial landscape surrounding Mao's statue in Chengdu square. The reporter notes that the economic prosperity following foreign investment in China's manufacturing plants that produce Western branded goods also allowed for richer celebrations of Chinese Spring Festival and lunar new year. A partnering view can also be seen in the assertion that Western brands generated enough excitement to bring together Chengdu's citizens in the square.

In the partnering narrative, the historical cultural style of consuming and using goods rather than buying China-made is the basis of social identity. Much like the official vision of the nation-state, where protectionist policies that impede trade are not overtly promoted, this narrative works to unify categories of Western brands and domestic goods. This manner of asserting nationality through consumption 
also calls attention to the lack of realism regarding a divided market, given that Western brands are often made in China. Yet, its proponents find themselves reacting defensively against other nationalistic narratives. Their ambivalence towards Western brands is decided, a self-conscious choice that reflects awareness of the national identity politics at stake, and the seriousness of brand choice in the eyes of fellow citizens (compare with Friedman 1997).

\section{Obscured state influence and consumer autonomy}

Consumers' temporal poaching of nation-state ideologies by endorsing selected national narratives is revealed throughout this book as obscuring whether Western brand meanings (and marketplace responses) reflect state influence or consumer autonomy. This obscurity is not inconsequential in light of Friedman's (1992b, 854) suggestion that, throughout history and across cultures, the emergence of a competing view of cultural identity "implies the fragmentation of a larger unity and is always experienced as a threat." The threat resides in the inherent use of cultural identities to lay claim to visions of the future nation-state (Friedman 1992b; Wilk 1994). The legitimacy claimed by linking to discourses of past administrations perhaps reveals a cultural adaptation to avoid social penalties for violating national consumption norms, as occurred in China's semi-colonial history (Gerth 2003). Further, anthropologist Elisabeth Croll recounts that during her ethnographic field work in China during the early years of economic reform (the 1980s), consumers shared with her that they were reluctant to show off their acquisitions to neighbors. They were concerned that government policy might change, so that they would "become the object of political criticism rather than admiration" as occurred during the Cultural Revolution under Mao Zedong's administration (Croll 2006, 37). The Chinese government did exhibit ideological reversals during the early years following the launch of economic reforms (Zhao and Belk $2008 \mathrm{~b}$ ), when the consumerist lifestyle was accused of undermining the official ideology of socialism, leading to new campaigns championing socialist ideals of sacrifice, simple living, and trust in party leaders (Baum 1994; Zhao and Belk 2008b). By the spring of 1992, however, slow reform progress led Deng Xiaoping and the Party to encourage and celebrate consumption (Ci 1994; Zhao and Belk 2008b).

As differing visions of the future China are similarly legitimated through links to the past (Friedman 1992b; Wilk 1994), they contend with each other. Notwithstanding rural/urban differences in proffered national narratives and envisioned futures, we do not see this contention as emerging from a hierarchy of social order where some visions of China and their constitutive identity and brand meanings are privileged, as emanating from a group of cultural elite (Friedman 1997). Belying such a hierarchy, our multiple narratives emerged from a homogeneous cohort with respect to age and educational/professional status. Rather, a metaphor used by Wilk (1994) to describe the Belizean neocolonial order seems suitable. Referencing individuals' differing visions of the future Belizean state, he refers to them as "a puddle of different colors of paint, with little vertical 
order ... [that] only blend at their margins. Any attempt to rise out of the puddle is met with opposition."

The puddle mitigates or perhaps even pre-empts selected nationalist narratives from routinizing responses to Western brands as something of a civic ritual. Nationalist narratives, if uncontested, may serve much like "a ritual script" in that they offer prescriptions for individuals' marketplace behavior (Rook 1985, 253). As "ritual repeats received ideas" (McCreery 1995), an individual reacting to a Western brand offering in a manner prescribed by a nationalist narrative is, in a sense, engaged in a ritual performance which makes use of brands as ritual artifacts. However, in the face of competing national narratives that prescribe different responses to Western brands, the performance does not become routinized to the point that political meanings atrophy and behavior becomes habitual or reflexive, either a goal in itself or dominated by other motives (Campbell 1994). The most striking voices indicative of this tension were participants who spontaneously defended Western brands as good for China and the Chinese people. In the absence of narratives that disseminate values of national self-sufficiency, protectionism, and domestic brand loyalty, such defenses would be unnecessary. These defenses suggest that a heightened drama becomes attached to Western brand consumption through the tensions posed by competing narratives.

This drama is further accentuated through narrative discourses that seek to heighten the seriousness of brand choice by highlighting its social consequences. Previous consumer research has often treated assertions of national identity as experiences of solidarity with fellow citizens, achieved by expressing similar tastes and values. In illustration, Mick and Buhl's (1992) participants held that distinguishing aspects of Danish identity included living for the future, avoiding ostentation, and the cultural principle of Danish beer drinking. In academic discourses treating marketers' attempts to promote their brands as national brands, the goods are treated as "central emblems" of resurgent national industries after socialism (Manning and Uplisashvili 2007, 626). For our Chinese participants, Western brands were not mere symbolic identity-markers: rather, they were seen as important to the cultural, economic, or militaristic security and survival of the nation-state. Echoing Friedman's (1996, 128) view, consumers' choices of narratives to historicize Western brands shape brand decisions as assertions of social identity. These assertions are "deadly serious, and often seriously deadly" contests. This is because the historical conditions in which social identity is grounded are deadly serious matters (Friedman 1996). Chinese consumers see their consumption practices involving branded goods as a domain for directing the fate of their nation.

In summary, our emergent theory is that the meanings of Western brands are shaped by China's sociohistorical conditions to motivate brand choice as an everyday act of nation-making. Nation-state governing practices influence consumers' meanings of Western brands and are guided by a particular vision of the future nation-state. In China, this "official vision" is a nation that remains open to capitalist markets, encourages conspicuous consumption, and does not promote protectionist policies or laws (Croll 2006; Gerth 2008), but rather forges national unity 
through reviving iconic images and social events from the past (Liu 2004). This official vision is not uncommon among nations enmeshed by global market forces (Wilk 1994), so it is understandable if the event planners who staged Chairman Hu's review of military troops on National Day did not take special notice of the Toshiba advertisement in the background.

Threats to the official vision of the nation-state prompt governing administrations to use historical referencing practices to legitimate power and amass support (Liu 2004). In China, however, this revived past is one where anti-Western values were officially sanctioned by former administrations (Gerth 2003).

Faced with state influence over the imagined future China, consumers nonetheless possess autonomy, which is exercised by engaging national narratives to historicize Western brands (Martin 2004). These cultural histories, which Chinese individuals use to construct and ground their social identity (Gries 2003), embed Western brands in systems of meaning that draw selectively from past moments and historical referents. Through their engagement with these national narratives, consumers reinstate consumption categories that mark brands as Western versus domestic, reorganize their meanings in terms of present-day local logics, and wield these categories as instruments for materializing visions of the future nation-state that differ from the official vision (Wilk 1994). Each narrative reconstructs a viable Chinese history, appropriating official governing practices from selected moments in the past such that they all claim legitimacy (Friedman 1992b) and obscure whether given responses reflect state influence or consumer autonomy. This legitimating process is critical to the survival of these identity positions, which otherwise might be construed as challenges to state sovereignty and risk censure and penalty. These reconstructed cultural histories reflect Friedman's (1992b, 853) view of social identity as a "game of mirrors," involving "a complex temporal interaction of multiple practices of identification external and internal to a subject or population." Competing national narratives of East-West relationships are revealed as promoting different nationalist identity meanings of Western brands and prescribing different marketplace responses to them.

The tensions stemming from these disputed nationalist identity meanings render the decision to acquire Western brands "meaningful" and a form of everyday nation-making, rather than behavior which at a conscious level is politically "meaningless" (Campbell 1994). Constituting political action, the imagined social legitimacy of consuming Western brands, as opposed to actual experience, is sufficient to constrain or propel future responses (Campbell 1994). Our theorized process is qualified where consumers' visions of the future nation align with the official vision. In the absence of intervening challenges to brand meanings, tensions are mitigated, political meanings atrophy, and Western brands become an end in themselves (Campbell 1994). Drawing again from the Toshiba incident, those of the viewing public who hold a view of the future China that is compatible with the official vision, such that they do not classify brands into domestic and foreign, might negotiate Toshiba's meaning on grounds other than national identity. 


\section{Organization of the book}

With this summary as our overview, we now elaborate and contextualize our theory, drawing from the voices of our Chinese participants. We interpret their comments in the light of insights from political science scholars, historians, consumer culture theorists, and anthropologists whose works examine the effects of capitalist globalization on local (nation-state) cultures. In Chapter Two we return to the state of knowledge of Chinese consumers' motives for Western brand consumption at the time we began our study. Our analysis of the emerging literature on branding in China revealed that presumed motives for responding to Western brands had not been informed by Chinese consumers' voices. Rather, most studies invoke explanations from single-motive universal theories, such as Veblen's (1925) theory of conspicuous consumption, which posits that desire to imitate higher-status others drives the acquisition of branded goods. In this regard, the field of marketing and consumer research exhibits a tendency which Anne Tsui (2007) notes of the field of management. Works tend toward homogeneous use of a model based on Western culture, such that "researchers inadvertently depress the development of novel ideas and theories that may prove to be useful in advancing knowledge in different national and emerging economy contexts" (Tsui 2007, 1354). Views challenging this emulative theory are rare in available works on Chinese consumers' responses to Western brands. Those that present alternative views emphasize that some Chinese consumers reject Western brands because of nationalistic sentiments. In rethinking the applicability of the emulative-motive theory, we address a set of four popularly held notions of Chinese consumers' responses to Western brands that suggest 1) the desire to emulate Westerners drives the purchase and consumption of foreign brands; 2) consumer nationalism is manifest solely or predominantly through foreign brand boycotting rather than other uses of these material goods; 3 ) Chinese people are mere consumers of the foreign brand meanings disseminated by foreign brand marketers, rather than active meaning makers; and 4) desiring and acquiring foreign brands while claiming strong nationalistic sentiments represents a paradox. The latter notion is reflected in the publicized "Patriot's Paradox"- a label attached by global advertising agency Ogilvy \& Mather to their finding that Chinese consumers reporting the highest levels of nationalism were no less likely to assert a preference for Western brands (Wang 2008). By airing challenges to these popular notions and expanding the frames within which we have come to think about Chinese consumers' responses to Western brands, Chapter Two paves the way for open listening to the voices of Chinese consumers to discern their meanings and motivations for branded consumption.

Chapter Three offers a historical perspective on brands in China, drawing from selected moments, namely late imperial China, semi-colonial China of the early 20th century, and post-reform China, from 1979 to the present. A selective review of these moments draws heavily on more comprehensive historical and ethnographic reports - of Gary Hamilton with Chi-Kong Lai (1989), Karl Gerth (2003, 2008), and Elisabeth Croll (2006), respectively. This brief review reveals aspects of national history, the traces of which can be discerned in present meanings of 
Western brands and their relationship to Chinese nationalism. A glance at history also reveals that the state's role in shaping the meaning of Western brands differs across these moments, reflecting different responses to the forces of globalization. This chapter reconciles the views of historians who hold that brands existed from as early as late imperial China, to views of cultural anthropologists and communication scholars that brands were introduced into China from the West during the semi-colonial period, banned during Mao's administration, and then reintroduced with the economic reforms promoted by Deng Xiaoping. Reconciling these two different assertions requires an appreciation of differing academic traditions. Whereas historians provide compelling evidence for the assertion that brands emerged in China independently of Western influence, this history does not represent the lived experience of many Chinese today, who date their consumer experiences with brands to the economic reforms of the late 1970s and early 1980s. These experiences are the consumption meanings that interest cultural anthropologists. With this recognition, it remains possible for nation-making and nationalist narratives in the future to appropriate a China-made brand history that pre-dates economic reforms, as has already begun in China brand reports that recognize a category of "time-honored" Chinese brands (Yu 2007, 2009). We note that among our participants, some talk of not recognizing China-made goods of Mao's administration until economic reforms introduced brand competition. In contrast, others spoke of China-made brands present during Mao's reign as if they had always been acknowledged as such. Thus Chapter Three, consistent with our findings in Chapters Five and Six, highlights the plurality of lived experiences of brands among Chinese citizens.

Elaboration of our theory begins in Chapter Four. We introduce this chapter with details of our data collection method and sites. We then present the voices of our Chinese participants to substantiate our finding that the terminology "Western brands" is meaningful to Chinese consumers. More importantly, we highlight how Chinese consumers identify or distinguish brands as "Western." We note that we found considerable homogeneity in the perceived attributes of Western brands, which, apart from their relative high price, are generally positive. This renders our findings in Chapter Five somewhat surprising, as despite their rather homogeneous views regarding the positive attributes of Western brands, Chinese consumers attached not only positive but also negative meanings to them.

The process of contextualizing our theory continues in Chapter Five, where we elaborate the ways in which Chinese consumers imbue Western brands with meanings of Chinese nationalism. Building from Gries (2004) work on popular notions of Chinese nationalism, we identify four meanings of Western brands, with each meaning linked to a particular national narrative of East-West relations: 1) the West as experiential venue and Western brands in China as instruments of freedom; 2) the West as imperialist oppressor and Western brands in China as instruments of domination; 3 ) the West as subjugated and conquered Western brands as symbols of Chinese redemption from past national humiliations; and 4) the West and East as economic partners, and Western brands as harmonious partners of Chinese national brands. We base our identification of these meanings 
on our participants' imaginings of Western brands. As these different imaginings emerged from same age cohorts, we discount the notion that age-based socialization is the sole source of variation in Chinese consumers' responses to Western brands. We conclude this chapter by calling attention again to the purpose served by embedding Western brands in historical contexts suggested by particular nationalist narratives. By doing so, Chinese consumers render these goods meaningful in materializing their preferred imaginings of the future China.

In Chapter Six, we turn from an emphasis on the shaping and negotiation of the collective imagining of the nation to look at individual-level processes of imagining Western brands. Chinese consumers' use of national narratives to give meaning to Western brands is revealed as consistent with theories of how individuals enliven consumption fantasies through their imagination. Applying a recently introduced theory of fantasizing consumption (Martin 2004), we offer insights into how the different national narratives operate to shape the meanings of Western brands as resources for materializing imaginings of the future China. We also draw from this theory to posit ways in which the national-narrative shaping of Western brand meanings may influence individuals' processing of Western brand promotions and promotional stimuli. We offer examples from interviews with Chinese consumers to illustrate these imaginative processes.

We conclude with a brief epilogue that positions our findings in the broader context and theorizing of consumers' efforts to realize the imagined future of collectives through consumption choices (Trentmann 2007). Citizen-consumers are those who undertake consumption choices and practices with an eye toward the multiplicative effect of their decisions if many others respond or behave similarly (Trentmann 2007). Beyond our present work, we note emerging research using other nation-states as focal contexts that feature the consumer-as-citizen engaged in the practice of materializing the future nation. Pushing the theoretical ground that is being developed in this area to move beyond the nation, we suggest that the brands of transnational corporations, whether foreign or domestic, face another category of global band - that of non-governmental organizations - that seek to shape brand categories and meanings through new notions of citizen-consumers that challenge the domestic brand-foreign brand dichotomy that has heretofore characterized research into brand meanings. We see this as the future of brand competition in the imagined future China, as global brands, whether Western or China-made, must begin to deal with issues of the alleviation of poverty, environmental protection, and the quest for human rights guarantees. 


\section{Rethinking popular notions of Chinese consumers' motives for responding to Western brands}

International news stories and popular business books in the West are often slanted to awaken an old dream that China's market will make fortunes for Western brand producers (Croll 2006). This dream is encouraged by the mesmerizing potential of 1.3 billion customers, who constitute the "golden goose," the "magic market," "the mother of all new markets," or "the biggest market for everything" (Croll 2006, xi; Knowledge@W.P.Carey 2009). China represents the "last market," the "last great frontier" (Croll 2006, 8). Elisabeth Croll, Professor of Chinese Anthropology, illustrated this slant in the report of the 2003 new development strategy outlined at the Communist Party's Third Plenum. The strategy placed the expansion of domestic consumer demand as a priority to shift from investment-led to consumption-led economic growth (Croll 2006). Whereas national news reported the strategy in terms of increases in jobs and salary levels, international news dramatized the announcement as an exciting development for Western brand producers interested in the promise of the Chinese consumer market. Likewise, during the global economic crisis of 2008 international news depicted China as a "bright spot" for producers of Western luxury goods whose sales had declined in other developed nations (Voight 2009).

Translating China's large population into market potential for Western brand producers is the premise of a host of business-oriented books such as Garner's The Rise of the Chinese Consumer (2005). Concretizing the expansionist dreams of Western brand producers and legitimizing the strategic plans such dreams propel, similar books offer compendiums of market analyses, replete with sales forecasts for automobiles, televisions, mobile phones, personal care goods, fast food, and various categories of beverage. With top-down estimates based on growth in gross domestic product (GDP) and estimates extrapolated from survey reports of product ownership or ownership intentions, these works map China's consumption landscape in terms of the anticipated density of acquired consumer goods in given cities and regions (Garner 2005). Estimates extend to projections that by 2014 China will surpass the United States as the largest market for consumer goods, to become "the engine of growth for the global economy" (Garner 2005, 3). Popular and academic reports herald China not only as the last great frontier for the expansion of Western markets, but also as a buffer against shrinking demand as the restrained credit of American, British, and Australian consumers hampers their spending (Croll 2006; Fong and Shirouzu 2009; Ratner 2009; Voight 2009). 
Despite the promise, failures of Western brands in China's market are common.

... realizing China's market is a long-held dream that has been perpetually postponed and is likely to remain so in the foreseeable future. Analysts supporting this view note the recurring pattern of hope or dream followed by disappointment or disillusionment and suggest that "a pendulum metaphor" best represents the rise and fall of foreign expectations of and experiences in the China market over past decades or even centuries.

(Croll 2006, 14)

Such failures stem partly from the complexity of the market (Croll 2006; Wang 2008), which has been neglected in the oversimplification of the motives driving Chinese consumers' responses to Western brands. Translating China's large population into a large market for Western brands has involved dismissing the competitiveness of China's domestic brands in the belief that Chinese consumers prefer Western brands so as to imitate the lifestyle of wealthy Westerners. This presumed motive dominates the vast majority of discussions on the demand for Western brands in China. The exceptions are works suggesting that Chinese consumers find Western brands undesirable, resisting them out of patriotic motives. In this chapter, we examine both of these motives more carefully, concluding that they probably do not tell the whole story.

\section{The emulative motive for Western brand consumption}

Imaginings of China as the next great market for Western brands are bolstered by frequent claims that the "taste among the upper-middle class . . . is increasingly converging towards that of the Western consumer," as a trend driven by Chinese consumers' desire to display their "sophistication" (Garner 2005, 84, 85).

Changes in consumer habits have now rendered some old stereotypes rather dated, especially where it concerns China's rising upper-middle class in the first-tier cities. Sophistication has become more important and taste among the upper-middle class is increasingly converging towards that of the Western consumer, especially as many international magazines are publishing local editions in China (fashion magazines and even Elle Décor). International designer brands are now increasingly hosting high-profile promotional events in first tier cities [that is, Beijing, Shanghai, Guangzhou] . . .

(Garner 2005, 84)

U.S. Companies have been so successful in China because "Chinese consumers have a 'look up to the rich' attitude and the United States is the world's top developed country in their eyes."

(Gao Tao, consultant for International Brand Association in Beijing, quoted in the Washington Post, Cha 2008) 
This presumed desire to imitate Western lifestyles by choosing Western brands is not limited to luxury brands such as Mercedes Benz and Gucci. As those who herald the burgeoning Chinese market note, brand stories can be retold such that brands tied to mundane consumption in the United States are quite upscale and symbolic of cosmopolitanism in China. Wrangler jeans are not the work clothes of rural ranch hands, but are sported by successful urban professionals; Wal-Mart's can be the social activity of the year; KFC and Pizza Hut can be places to impress dates (Cha 2008); and the American fast food icon McDonald's can become a place of leisure and relaxation, as well as a transnational adventure special enough to celebrate momentous occasions (Yan 2006).

Further, reports asserting that Chinese consumers are driven by a desire to display their sophistication by imitating Western lifestyles disclose, for instance, that sales of Western-brand automobiles are double those of Chinese models; demand for the Western skincare brand Olay exceeds that for the domestic brand Dabao; and Coca-Cola outsells Nongfu Spring (Garner 2005). In reports targeting Western brand producers it seems that only in the category of beer do Chinese consumers prefer Chinese brands (Garner 2005). These reports are not inconsistent with the general findings of the 2007 China Brand Report. Contributors to the report, which is produced by Chinese scholars and published by the Brand Research Centre of Shanghai Jiaotong University and the Shanghai Brand Promotion Centre, lament the fact that none of China's domestic brands are in the world's top 100 (Yu 2007).

In positing that Chinese consumers seek to advance their social standing by imitating Western lifestyles and consumption choices, popular Western discourses of "the rising Chinese consumer" adopt an emulative model of consumption (Friedman 1994; Veblen 1925). They revive an old notion that emulation of classbased taste is the key to consumer demand (Campbell 1994). Veblen's (1925) theory of conspicuous consumption emerged to explain the success of the capitalistic economic system which revolutionized consumption in eighteenth-century England (Campbell 1994; Friedman 1994). In China, the veracity of this model draws from the early nineteenth-century colonialist era (Wang 2000), when European expatriates living in China's port cities imported Western brands (Wang 2000). The observed adoption of these goods by local elites who could afford them has often been attributed to their desire to elevate their social standing (Wang 2000; see also Wilk 1994). According to popular and academic reports, this envy of expatriates and their Western consumer goods was presumably disrupted by the advent of communist rule in China under Mao Zedong (Wang 2000). Since the economic reforms of 1979, which opened China's market to Western brands, Veblen's theory has re-emerged to explain or incite belief in the growing demand for Western brands in China; or, to borrow Croll's $(2006,16)$ catchphrase, the transformation of China's citizenry from "comrades to consumers" of Western brands. Often accompanying this celebrated transformation is the presumption that postreform Chinese consumers are like Western consumers, driven by similar motivations, particularly individualistic pursuits of class status. Today, this presumed envy-driven desire to imitate Western lifestyles is attributed to the influence of 


\section{Rethinking consumers' motives for responding to Western brands}

promotional media from Western brand producers, particularly magazines, billboards, and consumer spectacles that offer a glimpse of Western lifestyles (Garner 2005; Wang 2000). Collectively, these attributions echo Veblen's (1925) view that the emulative motive is a pervading and persistent trait of human nature (Campbell 1994).

Popular business reports of Chinese consumers' attraction to Western brands, such as Garner's The Rise of the Chinese Consumer (2005), are also largely depoliticized, as their target audience comprises executives of corporate capitalist brand producers in the West. Political conflict is, however, acknowledged in some academic discourses on globalization. Here, the emulative model carried to its logical conclusion portends a homogeneous world culture based on Western (predominantly American) culture (Wilk 1994; Zhao and Belk 2008a). This theory of homogenization via the instruments of foreign brands presents developing nations as "under siege," leaving citizens as the "uncomprehending dupes of transnational corporations" who are being "stripped of their cultural heritage" (Watson 2006b, 108; Yan 2006, 79). It is against this imagined future that resistance to Western brands emerges as a nationalistic or patriotic gesture.

The competing theory, which we embrace, holds that globalization produces cultural hybridization or glocalization (Hannerz 1990; Robertson 1994; Wilk 1994; Miller 1998; Watson 2006a, 2006b; Yan 2006), whereby consumer goods introduced through globalization are appropriated by local cultures and infused with meanings that serve local cultural interests and values (Kjeldegaard and Askegaard 2006; Wilk 1994; Zhao and Belk 2008a, 2008b). Yan's (2006) ethnographic work at Beijing's first McDonald's, where the Chinese partner owned 50 percent of the business, offers an example of the depth to which foreign brands are appropriated and localized. Yan $(2006,39)$ elaborates how the American fast food icon has been localized to create a "Chinese version of Americana." Treated locally as window to the world or a "microcosm of the transnational," where customers can imagine they are in a Western city, or educate their children about other cultures, the McDonald's store where the Chinese national flag was also raised daily became a place to languish over food for an hour or more, meet friends and family on special occasions, and develop personal relationships with store hostesses, referred to as "Aunt McDonald." The eat-and-leave-quickly model so ingrained in the West was subverted in this early Beijing McDonalds. Despite such vivid ethnographies that attest to consumers' appropriation of global brands to serve local interests, it has so far been the homogenization theory that has had the greatest influence on reported motives for rejecting Western brands. Chinese consumers are held to reject Western brands for patriotic reasons.

\section{The patriotic motive for rejecting Western brands}

Some China scholars suggest that Chinese consumers' resistance to Western brands is driven by nationalistic motives as a symbolic gesture of loyalty to the nationstate (Wang and Wang 2007). Inherent in this view is a challenge to the rhetoric of popular news stories depicting Chinese consumers salivating over Western 
brands. Explaining such rejection as symbolic of nationalism among non-Western peoples has become a reflex in business and academia. This is illustrated by the work of some researchers who formalize concepts of "consumer nationalism" in terms of rejecting the brands of other nations. International corporate communications scholars, for instance, emphasize this linkage.

Consumer nationalism could become a barrier to multinational companies as they expand into overseas markets ... By highlighting their respective national origins and identities, consumers impute a form of undesired "otherness" to international brands. . . . Two types of negative impact . . . are likely. One is that companies suffer immediate financial loss as a result of consumers' withholding consumption through boycotts; and the other is the damage to corporate image and reputation in light of the public unmasking of their (perceived nationality) and the negative associations with the issues of contention. While the first impact scenario is direct and dramatic, the second is subtler but equally perilous ... Since the economic reform in the late 1970s ... China is now re-discovering its national identity . . Consumption, once again, becomes an important platform for self-expression.

(Wang and Wang 2007, 136-8)

Another apt illustration of the linkage of consumer nationalism to rejection of foreign brands emerges from research carried out by a transnational advertising agency. In 2003, Ogilvy \& Mather conducted a survey of the brand patronage behavior of Chinese youth. Their findings revealed that Chinese youths who are the strongest patriots used Western brands almost as much as those with lesser feelings of nationalism (Wang 2008, 19). Executives perplexed by the finding dubbed it the "Patriot's Paradox." Both popular and academic coverage of the finding focus on the implications for age-based segmentation, noting that desire for Western brands among China's youth is sufficiently strong to override patriotic sentiments, whereas the same does not hold for older consumers (Wang 2008; Hong Kong General Chamber of Commerce 2004). News coverage has not challenged the presumed paradoxical nature of patriotic people liking foreign brands.

This book enhances the understanding of Chinese consumers' motives underlying their response to Western brands. At first, we were not convinced that the door should be closed on the study of such motives. For one reason, assuming that Chinese consumers seek to emulate Westerners through brand purchases denies non-Western peoples the creative capacity to use Western goods for their own purposes. At the same time, we questioned why the rejection of foreign or Western brands should be inherent in notions of nationalism, particularly for nation-states such as China, where reigning administrations endorse participation in the global economy. This perspective has been aired from different viewpoints. Zhou and Belk $(2004,64)$ suggest that Western brands that attempt "to play the [Chinese] nationalist card may now be considered as bi guan zi shou (closed-minded) since China has become a part of the World Trade Organization." Wang $(2008,2)$ likewise comments on how China's entry into the WTO has prompted debate on what the "new China" is. 
Opinions are sharply divided on what the "new China" is like now that it is a member of the WTO. Some predict the "demise of the authoritarian state"; others consider China's ascent to the world stage to be a global self-promotion that will hardly put a dent in the state's capacity to control ... With few exceptions ... critical literature on the WTO challenge is prone to reinforce a mentality dating from the Cold War in its treatment of the globalizing China either as the Communist "other" or as a foe involuntarily losing its own identity to become one of "us." Post-2001 China is neither. It is heavily influenced by the ideology of global partnership while struggling not to become a mirror image of the United States. "Country branding" is more challenging than ever, and the emerging brand "new China" eludes ideological preconceptions.

We concur with Wang's (2008) observation and provide our findings on how China's consumers play a role in nation-making. This can be accessed by studying their responses to Western brands in China. The stereotypical Western view of Chinese people as the puppets of a PRC propaganda machine has given way to recognition that Chinese citizens play an influential role in shaping government practices in China (Gries 2004). The protests over the Toshiba ad in the background of the filmed National Day celebration, and those contesting the presence of Starbucks in the Forbidden City, suggest both agency and expected effect. Given this nation-making potential, we begin our inquiry by rethinking popular notions of Chinese consumers' responses to Western brands.

\section{Rethinking the primacy of the emulative motive for consuming Western brands}

In rethinking the primacy of the emulative motive for Chinese consumers' responses to Western brands, we identified the few works that challenge this thesis, either indirectly or directly. Some challenges may be described as indirect - that is, without critiquing the emulative thesis they suggest that other motives may drive the attraction to Western brands. Alternatively, these works suggest that other motives dominate decisions, rendering Western brands unattractive. Illustrating the former, Yan (2006) and Wang (2008) call attention to the importance of safety concerns in Chinese consumers' attraction to Western brands. As for the latter, a small body of works suggest that Western brands are losing their appeal as Chinese brands become more attractive, as consumers respond to their improved quality and lower price, endorse "buy domestic" campaigns by government and private industry, or become disenchanted with foreign brands because of the problem of counterfeits (Cui 1997; Li 2004; Weng 2002; Zhou and Belk 2004; Zhou and Hui 2003). More recently, in debates over whether China's consumer market can rescue the world economy, CNN reporter Kevin Voight (2009) noted that "even as Western companies clamor for the China market it's an open question of whether Chinese consumers - be they nouveau riche or just emerging from poverty - are interested in foreign goods." Voight (2009) further quotes from Frederic Neumann, senior economist of HSBC, that "We see a lot [of penetration] 
in the auto sector and the top end of the luxury market, but if you look at broad Chinese consumption trends, Western companies don't have the cachet of local Chinese brand names." Unfortunately, the source of this cachet was not identified in Voight's report.

There are, though, direct challenges to Veblen's (1925) emulative theory of consumption, more commonly known as the theory of conspicuous consumption. These challenges render the continued propagation of its basic assertions surprising (that is, the claim that "Chinese consumers are attracted to Western brands driven by status-envy of wealthier Westerners"). Criticisms of Veblen's theory of conspicuous consumption emerged in anthropological discourses of the early 1990s (Friedman 1994a; Campbell 1994). Veblen is classified as working from the "instinct school" of social theorists because of his tendency to explain human conduct in terms of simple drives or innate tendencies assumed to be common in human nature (Campbell 1994, 32). For Veblen, the drive to enhance social standing by emulating elite others was human nature. The "instinct school" references those whose theories grew out of a behavioral psychology perspective to view motive as a "temporary energy system" or a "force" that "drives" action from a state of apathy (Campbell 1994, 24). Among cultural anthropologists, the "instinct school" also perhaps holds a double meaning. Notably, Veblen's (1925) work does not incorporate insights from eighteenth-century English people (Campbell 1994), although advocates of the theory sometimes sidestep this criticism, noting that the conspicuous consumer will rarely admit to such intentions (Mason, 1981).

We agree with those critics who challenge Veblen's theory as a single-motive or universal theory and who instead seek to understand motives by discerning the meaning that actors attach to their actions (Friedman 1994; Campbell 1994). Motivational understanding requires more than mere observation of actions, but rather placing acts in the context of meaning in which actors are embedded. A contextualized understanding of actions shows how they connect with actors' goals, desires, and outcomes, which are sometimes outcomes hoped for in the face of fears (Campbell 1994). Motivational understanding deals with what a person is striving towards and the meaning these goals possess (Campbell 1994, 29). We can observe whether a Chinese consumer at the counter in a retail store is buying Western brands. But we might ask "Is this motivated action or is it routine behavior?" "What is the importance of acquiring these brands in this person's life?" "What meanings of Western brands make them significant?" "How have the meanings which the Chinese consumer attaches to Western brands been shaped by local cultural forces"? and "How have these local cultural forces that shape brand meanings been influenced by broader global forces?" By addressing these questions we can develop a sense of Chinese consumers' motives for acquiring Western brands. A prerequisite to all of these questions is ground work to determine whether "acquiring Western brands" is a meaningful category of action to Chinese consumers and not merely an arbitrary "observer-invented" category (Campbell 1994, 46). Our notion of motive aligns with that of cultural anthropologists who suggest that the study of motive cannot be separated from inquiring about general patterns of meaning shaped by local cultural forces, 
which assist in understanding the observed behavior in the context of individuals' hopes and fears (Campbell 1994).

With motives so conceived, invoking explanations regarding conspicuous consumption from observations that Chinese consumers window-shop or acquire foreign brands may amount to speculation. This is because the explanation is not informed by these consumers' subjective viewpoints and their cultural systems of beliefs and attitudes, which give meaning to the consumption of Western brands (Campbell 1994). Chinese consumer culture theorists Zhou and Belk (2004) note how the absence of Chinese consumers' voice characterizes much academic research concerned with the homogenization of culture. In particular, they stress that the literature has emphasized either content analysis of themes in foreign ads or advertisers' disclosures of how they created such ads, and carry with them an implicit assumption that consumers take from the ads the meanings that advertisers intend. They conclude: "thus the presence of global images and foreign appeals are [erroneously] taken to mean that local culture is becoming globalized and that consumer values are changing accordingly" (p. 63). This underlying perspective is reflected in discourses on the rising Chinese consumer suggesting that Chinese consumers' taste is becoming Westernized (Garner 2005).

Inferring Chinese consumers' desire to emulate Westerners from observations that they acquire Western brands amounts to a process of labeling their actions (Campbell 1994). In a harsher indictment, Wilk (1994) suggests it amounts to labeling less affluent people in developing cultures as inept or intellectually incapable of taking an active hand in manipulating symbols. Rather, they are presented as emulating a small elite group who are deemed the cultural meaning-makers (Wilk 1994). In assuming an emulative motive for consumption, this negative labeling can become compounded. When people of small economic means go to considerable expense to acquire consumer goods which are more affordable and abundant in the West, it is commonly seen as "some kind of mistake" by people who succumb to shallow, material constructions of identity because they "do not fully understand what ought to be their proper priorities" (Miller 1994, 74). Recognition of such negative social labeling should lead researchers to seek alternative motives informed by cultural knowledge.

Western cultural bias also is held to underlie the emulative model's generic modern form of individualism (Friedman 1994). This flaw in the emulative thesis is emphasized by research findings that attention-getting displays in other cultural contexts are pursued for the symbolic value conferred upon the collective to which the individual belongs, and with an eye toward how conspicuous consumption influences collective outcomes (Miller 1994; Rowlands 1994; Wilk 1994). As well as challenging aspects of the emulative thesis, Zhou and Belk (2004) show that status-seeking via branded consumption manifests differently in China, being shaped by local cultural values, and cannot be equated with Western status-seeking practices. Employing a reader-response method in which they asked Chinese consumers to react to global and local advertisements, Zhou and Belk $(2004,69)$ found that "a global orientation [meaning 'Western'] increases face for successful people in China and is consistent with the Confucian idea that 
a gentleman lives a lifestyle reflecting his high social status." They distinguish this type of face as mianzi (prestige face), derived from a desire a for success-based reputation, as distinct from lian (moral face) (p. 64).

Beyond culturally determined notions of status, understanding Western brands in terms of Chinese consumers' quest for status or preservation of face requires close study of their lives. It is interesting that the popularity of Beijing's first McDonald's has been attributed in part to Chinese consumers' beliefs that, unlike in Chinese restaurants, here they would be less susceptible to losing face (mianzi) in front of guests (Yan 2006). The Chinese consumers disclosed that banquets in Chinese restaurants involved competitions among customers to outdo one another by offering guests expensive dishes and alcoholic beverages (Yan 2006). Because it is common for the host to worry about losing face if customers at neighboring tables enjoyed better dishes, many sought to avoid this embarrassment by paying to secure a private room in the restaurant. As Yan (2006) discovered from the Chinese consumers he interviewed, McDonalds' standardized food and the limited number of menu items promised an egalitarian environment in which one could not lose face. At the same time, a degree of face could be gained through the cosmopolitan identity the host could claim by entertaining guests in an exotic transnational venue. One Chinese consumer we interviewed also discussed his preference for Western brand restaurants. In contrast to Yan's (2006) participants, our participant asserted that this was to avoid a showy display of having spent a considerable amount and thereby making guests uncomfortable: "I like the manners in which the waiters served us, especially when he came with the bill. Instead of reading out loudly how much the meal cost, he quietly presented me the bill, pointed to the total cost . . That way, the guests at the table wouldn't know how much I spent. Sometimes when I treat friends at a Chinese restaurant, the guests would feel kind of uncomfortable when they heard the price . . . because they didn't want me to spend too much. I really like the Western style restaurant, not for their food, but for the service." In short, the meanings and modes of asserting status are grounded in culture, such that Western notions cannot be transplanted to observations made in China.

Still other scholars have called into question the supposed persistence of emulative motives as presented by Veblen (1925). That conduct and motives can change over time was the focus of Weber's Protestant Ethic (1930), which rejects Veblen's thesis that capitalism could be explained in terms of acquisitiveness (Campbell 1994). In Campbell's (1994) review, Weber notes that the first capitalists acted from "revolutionary motives." That is, they overcame the traditional value system in which work was a means of satisfying the goal of enjoying leisure, to assert that work is a goal in itself, showing "virtue and a proficiency in a calling" (Campbell 1994; Weber 1930, 61). Weber shows how meanings attached to activities erode and fade away, such that "originating motives" are replaced by "perpetuating motives" (Weber 1930, 41, as reviewed by Campbell 1994). In The Protestant Ethic, Weber argues that the work motives of Protestants in Germany shifted from religious (working for the glory of God and for salvation) to economic (working for necessities and leisure time), and then to "sport" (working for the pursuit 
of wealth; Campbell 1994). Each shift involves shedding the ethical basis of the previous motive (Campbell 1994), so even if one accepts that emulative motives characterized the underlying drive towards Western brands in the early years of reform for many Chinese consumers, there is no reason to assume such a motive will persist indefinitely.

Another challenge to the persistence of emulative motives emerges from critiques of the center/periphery models of globalization found in studies of colonialism. Here, according to Wilk (1994), the colony was considered backward because of its timeless, isolated, and pervasive traditions, whereas the flow of time became the domain of well-traveled local elites who represented themselves as agents of "progress." These elites deemed progress, symbolically represented by style and fashion, to be the movement in time from the unchanging past of rural areas to the dynamic future of the city (Wilk 1994). A colony's progress was measured in terms of how far behind it lagged in displaying the fashions and styles of the metropolis deemed the center of culture. As Wilk $(1994,103)$ notes,

The flow of fashion requires the colonies to keep running faster to catch up ... [it] serves the social and political interests of the colonial elites as well as the metropolitan powers ... On the global scale colonial time affirms the political dependency of the undeveloped and developing on the developed and keeps the colonial elite in a subordinate position.

This colonial time operated through the medium of travel. Local elites visited the metropolis and brought back new styles and fashions to legitimate their status. Today the time lag has been eliminated by satellite communications and the internet. With time differences eliminated, only distance and culture, set locals apart from the West - or more specifically the United States (Wilk 1994). Wilk (1994, 106-7) further suggests that the significance of this diminished or erased time lag is that it frees material goods from carrying temporal messages, so that they can now acquire new meanings.

Local foods that were once tainted with connotations of backwardness and lack of sophistication can now be reinterpreted as "roots" (traditional) food, or ethnic food, or national cuisine. Objects can acquire historical or cultural referents that are truly in the present. Different interest groups can contend to appropriate them and attach new connotations - both positive and negative.

Croll $(2006,46)$ likewise notes how the flow of time in China, beginning with the 1979 economic reforms, differs from that of semi-colonial China in ways that bypass former mediators of meaning.

... the presence of persons and things Western in China was not a new phenomenon given the previous century of contact prior to 1949 but that presence, significant though it had been, was very much limited or bounded by treaty port and mediated by missionary and merchant. Without fast media 
communication and a mass market, contact had been largely conducted via persons rather than goods and not much beyond the largest cities and communication routes. Now it was television screens and shop counters which constituted the main points of encounter and reduced the distance between China and the Western other.

Although the persistence of the emulative motive in China has rarely been questioned, a few scholars do comment on changing motivations for consumers' attraction to Western brands. Yan $(2006,76)$ speculates that the "Chinese version of American culture" as experienced by consuming hamburgers at McDonald's may be seen by the next generation as ordinary and local, as has occurred in Hong Kong and Shenzhen (Watson 2006). Croll (2006), in documenting the radical changes in material acquisitions made by Chinese consumers in the early years of reform, makes the interesting point that "most consumption was still conspicuous." This resulted from the rapid shift from a production-oriented economy that manufactured limited categories of uniform-style goods towards a market economy, in which rising incomes and the availability of imports introduced variation. The iconic representation of this shift is the transformation of workers' appearance. The standard blue work clothes of the Cultural Revolution gave way to rapid changes in fashion that introduced a host of Western branded clothing styles and colors (Croll 2006). In an environment in which almost all consumption is conspicuous, explaining that Western brand consumption occurs because consumers notice and acquire what others have seems a fairly safe assertion. In early years of the reform, however, many product choices were predominantly Western (Croll 2006). This suggests that the acquisition of Western brands at that time may not have been driven solely by admiration/emulation. It also does not rule out that such acquisitions may have been arrived at through complex identity negotiations. Further, since the early years of reform, domestic brands have emerged that compete in quality and international status with brands from the West. Given this, although initially the reform government's bid to modernize and "catch up with the West" may have prompted consumers' assertions of modernity through their display of Western brands (Croll 2006, 47), present-day Chinese consumers may deem that China has caught up, and assert this through loyalty to domestic brands. Notably, this motivation is quite different from fears of Western hegemony. Rather, it may reflect something akin to the collective pride noted by Zhou and Belk (2004), whereby consumers may bask in the reflected glory of successful national brands, gaining face at a national level of the extended self (Belk 1988).

Perhaps most damning to the emulative thesis is the recognition that a motive which operates the same everywhere ceases to be an explanatory variable, leading researchers to look for other explanations (Friedman 1994; Campbell 1994). These scholars remind us that historical and cultural variations produce different motives for consumer action, as well as different actions for the same motive (Campbell 1994; Miller 1994; Wilk 1994). This is not to suggest that emulative motives are unimportant. A rare cadre of anthropologists who have immersed themselves in China's consumer culture over the course of economic reform have 


\section{Rethinking consumers' motives for responding to Western brands}

noted the meaningfulness of emulating Westerners to some Chinese consumers (Croll 2006; Zhou and Belk 2004). Rather, following Weber (1930) and Campbell (1994), we suggest that motives during the early years following reform may differ from present-day motives. Where emulative motives exist, they may be less individualistic and more collectively oriented. Further, emulative motives may comprise broader overarching goals (Campbell 1994) or superordinate meanings that legitimize and moralize particular stances toward Western brand consumption (Kozinets and Handelman 2004) which have not been recognized. In light of a fuller inspection of Veblen's theory of conspicuous consumption, we see emulative desire as one plausible motive among many, the relevance of which requires delving into the meanings of Western brands held by Chinese consumers.

\section{Rethinking "consumer nationalism" as synonymous with Western brand boycotting}

Academic discourses which assume the assertion of nationalism in the context of consumption as occurring exclusively through domestic brand choices and the boycotting of Western brands (Wang and Wang 2007) strike us as something of a myth. This myth emerges from neglected areas of study within the field of consumer culture and globalization, often featuring the influential role of Westernbased transnational corporations and their brands. In pursuit of this focus, studies erroneously treat the nation-state as static rather than dynamic. They also deny the influence of domestic producers on Western brand meanings. As we elaborate, these omissions leave the myth of the exclusive linkage between nationalism and Western brand boycotting unchallenged. These same omissions underlie the unquestioned contrary assertion that Western brand choices reflect emulation of Western lifestyles and hence ambivalence about nationalism (Pecotich and Rosenthal 2001).

If we take nationalism to be "that outlook which gives absolute priority to the values of the nation over all other values and interests" (Hroch 1996, 62; Wang and Wang 2007, 136), at what point after a nation-state begins to participate in the global economy do we alter our conception of nationalism as a value manifested in resistance to Western brands? It seems simplistic to assume that the governing body of the nation-state is able to assert open trade policies without contending with past discourses that cast Western brand consumption as emulating Western lifestyles, unpatriotic, or "treasonous" (Gerth 2008, 42). We would not expect governments to lie dormant in the expectation that citizens will catch on to the ideological changes; nor would we expect their efforts in shifting citizens' values to go uncontested (Gries 2004; Liu 2004). Yet, the static treatment of nation-state governance prevails because consumer research and globalization studies have emphasized the structuring of consumer motives and brand meanings by transnational corporations and their market ideologies (Kjeldegaard and Askegaard 2006).

Leaving the ideology of the nation-state as the backdrop against which Western brand promotions operate results in two misrepresentations that contribute to the 
notion of Chinese nationalists as boycotters of Western brands. One misrepresentation involves fixing the nation-state's influence on brand meanings and motives in the past. Here, the nation-state is recognized as the purveyor of past socialist ideology (i.e. prior to rapid globalization) now embodied within the consumer as part of their personal memory. Consumers' meanings for brands reflect a negotiation of their socialist memories in light of the current influence of corporate brand marketers (Coulter et al 2003). We recognize that any single work emphasizes certain study phenomena to the exclusion of others, yet by way of omission these works represent the nation-state's actions as fixed in the past; that is, they represent the nation-state as currently uninvolved in shaping the meanings of and responses to consumer goods.

There is ample evidence to the contrary. Here we offer a brief example that illustrates how nation-state governments shape the meanings of Western brands. Our example involves a national project to build domestic brands inspired by the former Minister of Commerce of the People's Republic of China, Bo Xilai. The initiative resulted in the 2006 "New Long March of Commerce: Ten-ThousandMile Journey of Brands" (Yu 2007). This was an extravaganza that targeted the promotion of Chinese brands both domestically and internationally in an elaborately orchestrated campaign trail covering 51 cities and 14,290 kilometers in 129 days (Yu 2007). By mimicking to some degree the planned Olympic torch relay tied to the 2008 Beijing games, the Brand Journey might be interpreted as an attempt to invoke brand rankings as a competitive international sport. There is a subtle undermining of Western brands that rival emerging Chinese brands, yet this does not leverage from China's Mao-era past in which socialism was wed to protectionism. Rather, it draws from China's more recent participation in the global market economy and its aspirations to become a dominant player. Our findings suggest that in the eyes of some Chinese citizens this ascent in the global order is motivated by a desire for redemption from humiliations that date back to the semicolonial era. Chinese consumers responding to this campaign would probably not claim that they "boycott" foreign brands as being instruments of Western imperialism, but rather choose domestic brands because they are superior.

A second misrepresentation emerges from treating the transition to a market economy as the critical moment, whereas what comes before and what happens after is (erroneously) deemed stable and unproblematic (Wilk 1994). This implied post-reform stability also contributes to a biased view of transition in terms of "a switch" or "changeover" to a Western-style capitalist market system which opens the way to full fruition of the emulative model's predictions - a homogeneous world culture (Wilk 1994). Here, too, the image of China is fixed, but fixed as an instant replica of America's consumerist culture following the transition. That a switchover is presumed in notions of "transition" is captured in titles such as Pei's China's Trapped Transition (2006). Pei (2006) considers China's reform (compared to the more radical reform attempted by the Soviet Union), noting that China's political framework traps the state in transition. Pei argues that the gradualist approach has been taken because progress toward a more modern economy would effectively curb government action and power. Orientation towards a 


\section{Rethinking consumers 'motives for responding to Western brands}

switchover goal of transition denies more open-ended terms of "change" or "evolution" that suggest creative possibilities. This representation likewise denies the present role of nation-state governing practices in shaping brand meanings and motives. As a result, Chinese consumers' rejection of Western brands has been interpreted as a symbolic gesture of national loyalty (Mick and Buhl 1992). In the absence of a presumed "switchover" to Western-style capitalism, Western brands may be assumed to hold a greater variety of meanings beyond Western globalization's "instrument of hegemony."

Exceptions to the inert post-reform treatment of the nation-state's influence on Chinese consumers' brand meanings have recently entered consumer research discourses (Croll 2006; Zhao and Belk 2008b). In a semiotic analysis spanning the 25 years since China's initial transition from communism to consumerism, the work of Zhao and Belk (2008b) reveals that brand producers constantly adapted their advertising strategies to accommodate shifting government practices. Whereas commercial producers remain focal, the work is singular in recognizing that nation-state governance is organic, responsive to global forces with which it contends, and influential in shaping representations of consumer goods. Croll's (2006) report of her ethnographic fieldwork is likewise replete with recognition that nation-state governing practices shape the meanings of consumer goods. Our work offers a complementary extension by further revealing the nation-state's influence on consumers' meanings and nation-making uses of Western brands.

By including nation-state governance as a constitutive part of the "culture industry" (Abu-Lughod 2005), we may gain a greater understanding of the historical and cultural shaping of the meanings and motives of brand consumption. Abu-Lughod (2005) suggests that nation-states can be analyzed as models for ordering consumers' everyday life. Nation-state governing practices entail speeches, published discourse, policies, and state-sponsored education programs used in the assertion of political ideologies which comprise the official vision of the future nation-state. Transition toward a market economy, or toward greater participation in the global economy, is followed by periods of negotiation and adjustment during which the administration attempts to amass public support through their governing practices (Liu 2004). This often entails attempts to shape the citizenry's imagination of the nation - past, present, and future. The imagined nation is bound to neither geography nor time, but exists in people's minds. As cultural anthropologist Jonathan Friedman suggests (1992a, 1992b), political institutions, including governments, may selectively conjure and reframe the nation's historical past to serve present needs, or amass support for projects tied to an imagined future nation. The government of a nation-state steeped in a socialist past need not discard its cultural history when it changes to a market economy, but rather may draw from it aspects that serve its present political positions and economic aspirations. Demonstrating the reshaping of history, albeit from the private sector, restaurants themed to reflect the time of the Cultural Revolution via the name, décor, and simple menus, have become popular among Chinese who suffered the deprivations of this Mao-era movement (Zhou and Belk 2004). Even a socialist history can serve this political/economic position under a creative state administration (Liu 2004). As such, nationalism or patriotism need not 
be wed to boycotting foreign brands. Rather, meanings of nationalism may vary in ways that suggest different relations to foreign brands. Consumers may hold favorable meanings of Western brands while still holding patriotic sentiments (Zhou and Belk 2004). Following from their study in which Chinese participants in Shenzhen were shown advertisements with both local and global appeal, Zhou and Belk (2004, 71) conclude that Chinese consumers valued global advertising elements, but that this did not involve "an abandonment of feelings of national pride, patriotism or Chinese values. Nor does it imply that participants embrace Western values and disparage local and traditional values." Thus, rethinking the notion that represents consumer nationalism as synonymous with foreign brand boycotting, there may well be no paradox in the findings that Ogilvy \& Mather labeled "The Patriot's Paradox" (Hong Kong General Chamber of Commerce 2004).

\section{Chinese consumers as active meaning makers}

The emulative motive and the patriotic resistance motive for Chinese consumers' responses to Western brands do not tell the whole story. If there is cause for critical analysis here, it resides in the absence of voice given to consumers (Askegaard 2006; Campbell 1994). Studies offering these explanations entail estimates of branded consumption based on China's gross domestic product, observations of Western brand purchases or purchase intentions (Garner 2005), interpretative analyses of Western brand advertisements (Wang 2000), case studies of Western brand producers operating in China (Wang and Wang 2007), and advertising executives' views of Chinese consumers' motives (Wang 2008). Although these methods produce insights into market practices emerging in China, they often require researchers to infer consumers' motives. Behavior can of course have many motives, and a given motive may be asserted through various consumption practices (Campbell 1994). Inferring motives in the absence of the consumer's viewpoint and an understanding of their experience of the world leads to a suggestion that such motives are universal (for example Veblen's 1925 theory) rather than challenging them (Campbell 1994; Friedman 1994a). In popular press reports this condition is often amplified where there is no elaboration and hence only a limited understanding of the cultural context (Miller 1994; Tsui 2007). Efforts to understand motives for exotic behavior are often lacking for consumption activities that seem commensurate with Western norms (Miller 1994), such as consumption of Western brands (Askegaard 2006).

It is not the obligation of any single author or work to attempt to understand motives, but rather is the aspiration of a field of inquiry. Brand research in the past has rarely taken a consumer perspective, which involves obtaining consumers' responses to or ascertaining their relation to the brand. Most often the consumer is treated as the background against which brand management tools are tested (Askegaard 2006). Consumer culture theorist Søren Askegaard suggests this results partly from the orientations of researchers, who introduced more culturally oriented and social constructivist approaches into consumer research. These researchers were inspired by a mission to free consumer research from its bonds to managerial practice so that it might become a discipline in its own right (Belk 
1986). "Brand research might have been judged to be too closely associated with the primacy of managerial purposes" (Askegaard 2006, 93). This has changed. Since the mid-1990s more and more studies have highlighted consumers' symbolic use of brands in their construction of group identity and the meanings of everyday practices (Schroeder and Salzer-Mörling 2006). The sociological and social psychological roles of brands are "no longer taboo for interpretivist consumer researchers" (Askegaard 2006, 93).

Cultural perspectives of the role of brands in people's lives (Schroeder and Salzer-Mörling 2006) have challenged the presumption that Western brands are everywhere objects of desire, driven largely by aspirations to emulate Western lifestyles (Arnould and Thompson 2005; Belk et al 2003; Coulter et al 2003; Kjeldgaard and Askegaard 2006; Mick and Buhl 1992). These challenges are highlighted by an emerging stream of consumer culture research in the context of developing economies, transitioning economies, and those on the periphery of the global economy. These works reveal that motives for consuming Western goods are more complex than mere emulation, and are shaped by notions of identity grounded in local cultural history (Bonsu and Belk 2003; Belk et al 2003; Coulter et al 2003; Kjeldgaard and Askegaard 2006; Mick and Buhl 1992). They have in common the pursuit of what Campbell (1994) terms "motivationalist understanding" of the consumption of Western brands, as each seeks individuals' subjective meanings of these consumption objects. All recognize that subjective meanings derive from larger social processes that cannot be grasped in acts of exchange and consumption, but rather require accessing the psychological states of consumers and how these are shaped by local cultural forces, which are themselves shaped by global forces. Their findings emphasize that consumers rework identity meanings of consumption practices to fit their local contexts, such that they become inscribed in local, historically constituted cultural discourses (Kjeldgaard and Askegaard 2003). All offer theoretical insights elaborating the shaping of identity meanings and motives of Western brands and consumer goods. Our inquiry builds on this cultural perspective and seeks Chinese consumers' meanings of Western brands and the ways in which they are shaped by local cultural history.

Social theorists argue that because the social emulation hypothesis appears applicable, it is accepted with little or no attempt to consider alternatives (Campbell 1994, 46). We echo this argument for the proposition that rejection of Western brands is a symbolic gesture of national affinity. This book highlights the local cultural shaping of the meanings of Western brands to Chinese people, and in doing so it reveals the meaning-making processes engaged by Chinese consumers, and how the processes themselves are culturally conditioned. These meanings and meaning-making processes reveal varied motives, all of which are directed towards the same goal: materializing imaginings of the future China. This higher goal is absent in popular and academic discourses on present-day responses to Western brands. Before turning to how Chinese consumers imbue Western brands with meanings such that they are useful to materializing the future China, we offer a brief historical perspective of branded goods, both domestic and foreign, in China. 


\section{Highlighted moments in the history of branded goods in China}

In the fervor to promote China as the "last great frontier" for Western brand producers seeking more territory (Croll 2006), the popular press in the West, as well as some academic works, often suggest that brands were introduced into China from the West during the early 19th century (Wang 2000). Corresponding with this view is one in which communist rule beginning in 1949 under Mao Zedong disrupted the presence of brands, which were reintroduced in 1979 under Deng Xiaoping's gaige kaifang, a policy of economic reform which opened China's markets to branded goods from other countries. Challenges to this narrative, albeit few, have emerged to suggest a different historical relationship of China to branded goods (Gerth 2003, 2006; Hamilton and Lai 1989). In particular, these works challenge the notion that brands emerged out of a capitalist economic system in Western nations.

This history informs our study and interpretations of the meanings of Western brands held by Chinese consumers. Our review features brief sketches of moments in China's history: late imperial China, late 20th century semi-colonial China prior to communist rule, and post-reform China from 1979 to the present. It draws from book-length works and research programs by historians, cultural anthropologists, consumer culture theorists, and brand scholars to integrate these and highlight the role of state governing practices in shaping brand meanings.

\section{The emergence of branded goods in late imperial China}

Contrary to the view that brands were introduced into China from the West (Wang 2000), Hamilton and Lai (1989) document that in late imperial China (a period from the tenth to the 19th century), brands were common and used to facilitate the distribution of products beyond their places of production. Here, we highlight those aspects of Hamilton's and Lai's (1989) analysis that carry forward to presentday brand meanings and practices in China.

Hamilton and Lai (1989) suggest that the state had little to do with the vibrant commercial activity that existed in late imperial China. Rather, their analysis attributes this growth to a dominant private sector comprised of complex distribution systems which enabled the sale of goods outside their area of production. Although the state did not influence the growth of this consumer economy, it does seem that 
the reigning imperials influenced the meanings that Chinese consumers attached to branded goods, albeit perhaps unmotivated or unintended.

Brands were used in a variety of product categories.

We have found either biaoji or hao labels [identifying producers and sellers, respectively] on the following late imperial products: cotton cloth, items of clothing, porcelain, boots, tea, wine, medicine and herbs, scissors, needles, copper locks, copper mirrors, gold and silver bullion, hair ornaments, jewelry, jade items, writing brushes, writing paper, ink sticks, ink stones, lacquer ware, books, and bank drafts. In no case was the brand name a signature affixed to a one-of-a-kind product; instead it was the means of differentiating an entire line of products from that of competitors. And in all cases the brand names were on products that were distributed interregionally for sale. . . . A clear indication of the widespread promotion of differentiated products is found in the many lists of famous products that were published in late imperial times

(Hamilton and Lai 1989, 258).

Lists of "famous products" emerged from various sources, including local gazetteers who devoted a section to "famous local products," and government officials who reported to the throne on the variety of products available in local markets (Hamilton and Lai 1989). Hamilton and Lai (1989) suggest that the most important lists were those compiled by the imperial household, as the lists contained those branded goods judged to be fit for imperial consumption. Being on the list meant success for the producer or manufacturer. As illustration, Hamilton and Lai (1989) offer the case of a drugstore in Beijing, the Tongrentang, which became the supplier of drugs and medicines to the imperial household. Using a hao label to indicate the quality and reliability of the product being sold, the store began to market its product outside the region. The store first leveraged from its imperial endorsement to attract candidates for the civil service examination to the store for free samples, hoping they would spread the word of the brand when they returned to their respective provinces. Later, the owners opened branches in large cities. The case illustrates that although most Chinese medicines are natural products, the hao of the selling firm became an important indication of quality and reliability.

Hamilton and Lai's (1989) analysis further documents that metal goods such as needles and scissors were likewise branded using hao labels, along with pictures akin to logos, to convey quality steel. For goods such as cotton fabric some manufacturers wove advertisements directly into the fabric, whereas merchants made their own mark known as a jitou (loom-head) at the end of each bolt of cloth they acquired for resale (Hamilton and Lai 1989).

Hamilton and Lai (1989) also recount incidents of brand pirating, whereby competitors in a given market used the mark of a highly successful brand to confer upon their lesser-known goods the high-quality associations of the more famous brand. Brand imitation and pirating continued throughout China's history, resulting in consumers' heightened sensitivity to the presence and discernment 
of counterfeit brands, as has been noted for China's semi-colonial period (Gerth 2003). This discernment involves the use of attributes beyond labels to distinguish brands in the marketplace.

In late imperial China, producers or sellers could be active in promoting their goods towards famous brand status by associating them with quality or prestige, which meant they could command a higher price (Hamilton and Lai 1989). Hamilton and Lai illustrate this process with the case of tea - a process that they suggest also applies to brands of wine, silks, and fine cotton cloth. Tea books spread the demand for tea while elevating the status of specific brands by discussing various types of tea and advising which were appropriate as gifts for officials (Hamilton and Lai 1989). In short, the work of Hamilton and Lai challenges a widely held view that brands grew out of a Western capitalist economic system and were subsequently introduced into China. Hamilton's and Lai's (1989) historical work suggests that England was not the world's first consumer society and that consumerism did not emerge only under capitalism.

There is no evidence from their analysis that branded consumer goods conveyed meanings of nationalism; rather, affiliations to towns, cities, and regions were used in branded labels. Even for exported goods these labels are noted, rather than national ones (Hamilton and Lai 1989). After the collapse of the Qing Dynasty, the meanings of branded goods were shaped by multiple institutional forces, both state and domestic private industry, to convey positions of nationalism.

\section{Branded goods in semi-colonial China of the early 20th century}

If late imperial China is characterized as a period in which the ruling body was ambivalent about shaping the meanings of branded goods, in semi-colonial China the governing body was constrained in its methods of doing so. During this period the Chinese state lacked tariff autonomy. "Unequal treaties" that "opened" China to trade following the Opium Wars (1840-42) denied China the ability to restrict imports by raising tariffs (Gerth 2003, 5). Gerth (2008) also elaborates the institutional and discursive processes that emerged during this period to demonstrate that consumption became a primary means for the Chinese people to conceptualize themselves as citizens of a modern nation.

... a Chinese nation did not precede the notion of "Chinese products." The two constructs evolved together. Nation-making included learning, or being coerced, to shape preferences around something called the Chinese nation and away from items deemed foreign.

(Gerth 2003, 17)

Although the origin of Chinese nationalism has been debated, the dominant view is that China as a conscious national entity was not created until the 19th century, when the nation was confronted by Western powers, beginning with the Opium Wars between 1839 and 1842 (Gerth 2003; Zhao 2004). This war was precipitated by a trade imbalance, as Europe sought Chinese goods, particularly tea, silk, and 
porcelain, whereas Chinese consumers found few goods from Europe attractive apart from opium. When China banned the importation of opium, the British responded with gunboats (Zhao and Belk 2008a). The defeat by the British during the Opium Wars and the imposition of the Treaty of Nanking marked the beginning of confrontations with the West. By the turn of the 19th century Germany was occupying the port city of Qingdao in Shandong Province, claiming railway rights in nearby areas, and the British had forced the Qing government to give them a 99-year lease on the Kowloon Peninsula, north of Hong Kong. During this time, Japan and Russia also made claims to Chinese territory or trade access (Zhao 2004).

The lack of tariff autonomy that followed the Opium Wars provided the impetus for and guided the methods of a diffuse movement that Gerth $(2003,2008)$ labels the National Products Movement. This movement, which began at the start of China's industrial revolution, cultivated the practice of dividing consumer goods into China-made, deemed "patriotic," and foreign, deemed "treasonous" (Gerth $2008,3)$. In this section we briefly summarize Gerth's (2008) analysis of this movement, along with additional points of contextualization from other scholars. The movement's main players were unified by a desire to halt the influx of imported goods and an inability to secure direct state intervention owing to the lack of tariff autonomy. Interested actors included politicians worried about trade deficits, Chinese manufacturers faced with inexpensive and superior imports, and intellectuals concerned with loss of sovereignty. Tariff autonomy was not recovered until the late 1920s, and in the interim these parties created other ways of containment.

Integral to this was the effort to make product nationality the salient meaning of a commodity, more so than price, quality, style, or brand loyalty. By the time the National Products Movement was under way, Chinese consumers had had considerable exposure to Western brands, and brand loyalty was deemed an impediment (Gerth 2003). These imported goods entered port cities such as Shanghai and gradually spread to other parts of China (Zhao and Belk 2008a). Historical analyses document the presence of such global brands as Flying Eagle (condensed milk), Kodak, GE, Colgate, American Standard, and Quaker Oats, as well as Western-made products such as pharmaceutical goods, cosmetics, soaps, electric fans, Browning guns, high-heeled shoes, beauty parlors, and Japanese and Swedish watches (Gerth 2003; Zhao and Belk 2008a). These goods were supported by advertising, introduced by Western missionaries, which appeared in magazines and newspapers or on radio programs, neon signs, billboards, posters, cigarette cards, department store displays, and yuefenpai or poster ads in the form of calendars (Zhao and Belk 2008a, 46). Foreign brands in pre-communist China (i.e., before 1949), were often new products of which consumers had no previous experience. As such, they were clearly marked as "foreign" (by adding the word yang to the product name) and promoted with advertising tied to Chinese folklore and local culture in order to encourage adoption.

As Gerth's $(2003,2008)$ historical analysis of semi-colonial China elaborates, appeals to patriotism were the National Movement's means of asserting product 
nationality as the foremost important meaning of a commodity. The patriotism of consuming China-made goods was advanced through advertisements, exhibitions, nationalistic commodity spectacles, and organized rallies. Honoring product nationality above other criteria was represented in the movement's promotional literature as the ideal patriotic, nation-saving sacrifice. Further, the movement suggested that powerful Western nations and Japan had already established product nationality as the dominant consumption criterion. Campaigns educated individuals into the practice of visually distinguishing foreign products from Chinese products which varied in purity as contaminated by foreign components and workmanship. Notions of pure Chinese products and a pure economy were promoted in movement literature that often represented China-made goods as "the national blood" and invoked eugenics slogans (2003, 8). Campaign discourses promoted the negative social labeling of those who bought foreign-made goods, announcing that authentic Chinese people did not consume imports lest they betray their nation $(2003,299)$. To do so would be "an immoral act" and "an unsurpassably shameful thing to do" $(2003,296,285)$, marking the consumer the equivalent of an "inferior product," "drifter," or "prostitute" (2003, respectively $306,301,305)$.

Receptivity to the movement's campaigns intensified the need for explicit standards that identified which products to buy and which to boycott. National product (China-made) certification standards emerged first in non-government organizations, but in 1928 were formalized by a new national government that made them law and institutionalized incentives for their application. Beyond appeals to patriotism and the use of legal institutions, the movement's influence was wielded through "brute force" $(2003,20)$. Unlike other efforts to nurture affinities toward the nation-state, such as the creation of national opera and a national anthem, the National Products Movement rendered every person a participant, who with everyday consumption decisions could choose to support or reject the movement.

As Gerth $(2008,49)$ further points out, the notion of national products probably abetted the Communist Revolution and Mao Zedong's ensuing reign by legitimizing the abolition of private enterprise: if China-made products were "national" and Chinese people should make sacrifices to consume them, then why should the profits be private and benefit only a few capitalists? Cultural continuity across early capitalist and the communist period under Mao was experienced in the practice of dividing products into domestic and foreign and attaching respectively positive and negative nationalistic meanings to them. Gerth's (2003) work challenges two common assumptions, namely, that consumerism is a uniquely Western phenomenon (see also Hamilton and Lai 1989), and that the Communist Revolution and the reign of Mao represented a total cultural break with China's former capitalist period (Wang 2000). As Friedman (1996, 132) notes, "transformations of structure do not imply a total cultural discontinuity unless former life strategies are replaced by new ones." As Gerth's (2003) analysis makes apparent, China under Mao was experienced in valuing domestic-made goods and devaluing foreign goods to express Chinese nationalism. 


\section{Branded goods since gaige kaifang - China's economic reform}

In contrast to late imperial China, where governing bodies appeared ambivalent to shaping brand meanings, and semi-colonial China, where governing bodies faced constraints on the practices with which they could shape brand meanings, administrations that introduced or supported gaige kaifang, or China's opening up to trade with other nations, have made ample use of practices that shape Western brand meanings (Croll 2006).

We draw our review here from Croll's (2006) work on post-reform China, supplementing this with events and trends reported by international management scholar Anne Tsui and China brand scholar Yu Mingyang. Gaige kaifang, introduced by Deng Xiaoping in 1979, marked a move away from China's centrally planned economy, where state-owned enterprises produced three-quarters of China's goods. During Mao's three decades of rule, the types and prices of goods produced were determined by state plans which were not driven by consumer demand. These plans offered employees of state-owned enterprises a package of social benefits known as the "iron rice bowl." That is, they were given solid guarantees of lifetime employment, pensions, and services, which included lowrent housing, schools, healthcare, and recreational facilities. Croll (2006, 31, 36, 39,42 ) offers the following impression of the available consumer goods and the commercial landscape in pre-reform China.

During the Cultural Revolution of the 1960s and 1970s the most popular items are said to have been bicycles, sewing machines and wristwatches. . . . Apart from these goods, there had been virtually no durables or appliances available for purchase ... During the socialist revolution, general trading and department stores were few and specialized shops rare. Even the main shopping street in Beijing, Wangfujing, boasted little more than a large book shop, a several storied department store, a covered market and a tourist arts and handicraft store. The one department store ... was dark with bare concrete walls and had heavy brown plastic padded blinds flapping at the door. Below and behind dusty glass counters was a narrow range of tired or faded goods, mostly small and made up of limited ranges of utility shoes, clothes, stationery, toys, plastic and other hardware daily necessities including the ubiquitous thermos flasks and old-fashioned alarm clocks . . . During the revolution any promotion on billboards was limited to political slogans, perhaps a Mao Zedong thought or government propaganda for productivity and political education, as well as family planning in late 1980 s.

Although, as has been observed in post-socialist nations in Europe (Manning and Uplisashvili 2007), state-owned trademarks in China are now revived as "timehonored brands" (Yan 2007), China scholars suggest that brands did not exist in China between 1949 and 1978, and that even after the reforms the market from 1978 to 1990 was dominated by state-owned trademarks rather than brands (Croll 2006). Our participants' stories, like the one below, concur with Croll's 
(2006) analysis that the concept of "brands" was not meaningful to some Chinese consumers until after the economic reforms.

PARTICIPANT: There was hardly anyone wearing make-up until the 1980s. The only thing women used for their face, as I remember was a cream called Xue-hua-shuang [meaning "snow flake cream" akin to vanishing cream]. It was a very basic care for the facial skin. I mean more for the purpose to protect against cold wind in winter than to make ourselves look more beautiful. Make-up was only used on occasions of stage performance. That was a great moment because we looked so great after the make-up, though the make-up had to be exaggerating for it had to go with the effect of the strong stage spotlights. I do not remember if there were brands for the cosmetics used for make-up. To get lips red, a cream was used. It was not in the shape of a stick but in a small box and looked like Tiger Balm, even the texture was like that-more oily than creamy. It was made from animal fat-very natural. We never heard of anything chemical or had the fear of being hurt. To make red cheeks, yanzhi [rouge] was used. I was too young to remember whether it was the same thing used for lips, they were similar. However, one thing I remember clearly is that they both smelled so good, sweet and delicious.

INTERVIEWER: Were there branded cosmetics?

PARTICIPANT: I do not remember if there were brands at that moment. Even if there were we did not talk of them by using the brand names. We tended to mention products by their function more often than by manufacturer or the name the manufacturer had given it. Even Tiger Balm, at that moment we called it "qing-liang-you" [meaning "cooling oil"]. Nobody called it "Tiger cooling oil" though we did see this tiger printed on the box. The first time I made the connection between the product and its brand was later when I started to work in Shenzhen in 1986 with those people from other countries. They asked me where to get Tiger Balm so as to bring some souvenirs back to their countries. I was lucky because my reaction was quick enough to immediately think about the tiger image on the box. Cosmetics for make-up were generally named by yan-zhi (to make red), fan-shi-lin (to prepare the face for or clean up after make-up, like Vaseline).

In the three decades following gaige kaifang, the emphasis on production and work shifted to consumption and lifestyle, facilitated by the rising incomes of employees of foreign joint ventures (Croll 2006).

Croll (2006) identifies three waves of consumption, each marked by income and retail trends, categories of available or desirable goods, and demand cycles stimulated by distinct government practices that shaped the meanings of consumer goods, particularly Western brands. These practices include policies that altered credit, taxes, the state provision of homes, education, and other social services (toward privatization), along with state-initiated or approved brand spectacles. 
The first wave of consumption, as detailed by Croll (2006), took place during the 1980s. China's cheap and abundant labor supply drew foreign investment, further encouraged by government policies. Disposable income increased rapidly in the early years of reform, and because rent and utilities were still government supported, increased wages meant increased purchasing power. Consumer spending, previously dominated by food purchases, expanded to include non-food items. Durable goods were commonly purchased items during this period, including bicycles, color television sets, electric fans, cassette players, refrigerators, and washing machines. Spending on new food and clothing also increased during this period. Western brand producers were committed to heavily promoting their brands in China, prompted by the success of global brands in Hong Kong, Japan, Singapore, and Taiwan.

In the 1980s the economic reforms were followed by the introduction of Western brands, the emergence of retail sites, and awareness of fashion. The former image of the West as exploitative was "transformed into an image of a desired destination fostered by the new reform government's bid to modernize and 'catch up with the West"' (Croll 2006, 47). Croll's (2006) ethnographic account recognizes the following brand-related developments. Leading foreign fashion designers set up shop in Beijing and Shanghai and included Pierre Cardin, Elizabeth Arden, Louis Vuitton, Christian Dior, and Gucci, as well as less expensive stores such as Giordano, Benetton, and Gap. Elle and Cosmopolitan fashion magazines introduced women to Estee Lauder and Christian Dior, and Avon and Mary Kay introduced health and beauty aids using direct marketing. Beijing's Wangfujing was one of the first of the country's main shopping streets to be opened up to joint-venture retailers. The first KFC opened in China in 1987 in Beijing. By the mid-1990s KFC had opened 21 more stores in China, six of them in Beijing; McDonald's entered China in the early 1990s in Shenzhen; Hardrock Café opened in Bejing in 1993. Western brands were supported by the growth in television programming, as the most widespread form of popular entertainment. Promotion of foreign brands was not only facilitated by television advertising but also by how-to programs on dressing fashionably, applying make-up, and displaying home furnishings. The advertising industry grew from 10 people in 1979 to 11,000 agencies employing 128,000 employees in 1989.

As Croll (2006) reports, not all consumers during this first wave of consumption were comfortable with displaying their Western brand acquisitions. This period was characterized both by policies to increase consumption and by movements to contain the new trends, such as the 1983-84 "Anti-spiritual pollution" campaign in support of the "habits of simplicity," and the 1986-87 "anti-bourgeois" movement. These created concerns that a reversal of policy might shift values back toward those of the Cultural Revolution, when many consumer goods, particularly Western goods, were vilified. By the end of the 1980s, the government was more directly promoting consumption and new policies aimed at encouraging spending.

The second wave of consumption recognized by Croll (2006) ran from the early to the late 1990s, and is marked by Deng Xiaoping's 1992 Southern Tour talks. These talks promoted the economic reforms and endorsed individuals' 
accumulation of wealth as providing a trickle-down service that would elevate living standards in China. The following October, the Fourteenth Party Congress pledged that the Party and government would build "a Chinese-style market economy by the end of the century" (Croll 2006, 31). As further chronicled by Croll (2006), disposable income continued to rise during this second wave of consumption and peaked between 1992 and 1995. The elevation in consumption and material possessions is evidenced in the saturation of consumer durables among urban households. In 1996, of every 100 urban households, 93 owned a colour television, 90 owned a washing machine, and 70 owned a refrigerator. During this wave, people began to purchase additional consumer goods, including telephones or mobile phones, air conditioners, video recorders (VCRs), hi-fi units, and microwave ovens. New public spaces were devoted to the display of retail goods. By the mid-1990s Western brand retailers with storefronts included B\&Q, Carrefour, Metro, WalMart, Printemps (a French retailer), and Yaohan (a Japanese department store).

Other government practices in the mid-1990s reported by Croll (2006) included tax cuts on house and car purchases, new mortgage lending opportunities, interest rate cuts, and the adoption of a five-day working week, with week-long holidays intended to encourage shopping. These policies were intended to stimulate consumption by mitigating a diminishing propensity to consume, given that by the mid-1990s there were fewer customers for foreign brands. As Croll (2006) reports, it was "More common to save rather than to shop despite the government's best efforts to encourage consumption" (p. 53). One such effort was the privatization of housing in the expectation that this would fuel domestic demand for consumer goods.

At the same time, however, other economic reforms threatened jobs and pensions in the state sector and increased the cost of health insurance and education (Tsui et al 2004), leading to uncertainty which inspired saving rather than spending. Job insecurity was created by downsizing state-owned enterprises and government departments. Banks burdened with nonperforming loans made by noncompetitive state enterprises were threatened. In an effort to transform state enterprises into self-managing organizations responsible for their own profits and survival, in 1998 Prime Minister Zhu Rongji introduced a three-year strategic plan guided by the principle of "grasping the big and letting go of the small" (Tsui et al 2004, 110). This allowed larger state enterprises to reform and prosper, whereas smaller ones were to be sold or, if bankrupt, closed. Steps were also taken to reduce the operating costs of enterprises by cutting workers and subsidies provided for social services and welfare (Tsui et al 2004). These reforms meant laying off millions of workers and dismantling the guarantees of lifelong employment, pensions, and social benefits (Tsui et al 2004). While self-employment and employment in private enterprises increased, employment in urban state-owned and collective enterprises fell from 142.9 million to 86.5 million between 1991 and 2001 (Tsui et al 2004).

The effects of practices noted by Tsui and her colleagues (2004) correspond with Croll's (2006) reports that decreased consumer spending ensued from higher 
unemployment and the perceived uncertainty among the employed. The result, as reported by Croll (2006), was numerous closures of Western brand retail centers as consumers turned away from expensive Western luxury brands toward greater price sensitivity. By the mid-1990s, Chinese brands offering comparable quality at lower prices, such as Qingdao (beer), Forever (bicycles), and Legend (Computers), emerged to compete with Western brands (Croll 2006). In this environment, enthusiasm for Western lifestyles began to wane, reinforced by everyday concerns that there were few social venues for displaying conspicuous consumer goods for which people had paid considerable sums of money (Croll 2006). Insights into such concerns were offered by some of our professional-class participants who recalled their purchases from this period.

PARTICIPANT: The Avon perfume I bought is a 9g bottle, which cost over 50 yuan. I bought it in college and I like it, but I haven't found any chances to use it.

INTERVIEWER: What do you mean by "no chances to use it?"

PARTICIPANT: There are too few people around. It's just like my favorite clothes in my closet, like an evening dress, and I can never find a chance to wear it. Working in a hospital, facing patients everyday, there is really no chance. So I just keep them. Only on occasions where image is important can I use them.

(female interview participant, Tianjin)

It seems from this that the imagined identities promised by Western brand promotions are not readily realized by merely acquiring the products.

The third wave of consumption identified in Croll's (2006) analysis bridges the century and continues today. Nation-state governing practices in this phase intended to stimulate and develop domestic consumer demand emerged to counter China's growing dependence on exports and overseas markets. China's export growth rates fell in 2001, following the recessions of the late 1990s in neighboring Southeast Asian economies. The economic decline in America following the 2001 terrorist attack on 9/11 also prompted concerns about a global economic decline. In subsequent years, reports of overspending American, British, and Australian consumers also posed a threat to China, as goods exported to these consumers were the source of China's economic growth. This threat emerged anew in the 2008 recession, dubbed by some "the Greater Depression." Developing China's own markets is deemed a proactive step towards shoring up a worldwide decline in consumer demand.

As further described by Croll (2006), governing practices during this third wave can also be seen at work promoting the size of China's consumer market to the West, the promise of which was deemed to facilitate favorable terms in China's negotiations to enter the World Trade Organization (WTO). The large market potential for Western brands and imported goods was emphasized by China's Minister of Foreign Trade and China's chief negotiator for entry into the WTO, Charlene Brockevsky, as well as in China's business press targeting Westerners, 
Business Beijing. These discourses would be expected to shape favorable meanings, even nationalistic meanings of consuming Western brands in China.

Coexistent with the nation-state governing practices noted by Croll (2006) that promoted China's market as a rising star and potential cash cow for Western brands, other governing practices emerged during the third wave which called public attention to national brands and their prospective success as global brands. Admission to the WTO in November 2001 required China to open its markets and reduce tariffs on imports and exports. Membership also propelled China's formerly protected domestic markets into strong foreign competition. Most markets, however, remained local or regional. Notably, registered names typically begin with a city or province, such as Shanghai Baosteel, and Qingdao Haier (Tsui et al 2004). Tsui and her colleagues (2004) offer the example of the beer industry, where more than 600 independent rival breweries engage in cut-throat competition, resulting in rapid turnover of firms. This has led to a governmentbacked initiative to consolidate these into national brands.

Augmenting these attempts to promote national brands through organizational change have been other government-backed initiatives. A highly visible initiative was the "Ten-Thousand Mile Brand Journey." The story of this consumer spectacle, recounted by China brand scholar Yu Mingyang, holds that on 13 September 2005, Minister Bo Xilai visited Hangzhou announcing that China should plan domestic brand construction and further its brand-building efforts (Yu 2007). The Ministry of Commerce subsequently listed the Ten-Thousand Mile Brand Journey as one of the top 12 tasks of 2006. Planning continued at the 2006 National Conference of Commerce. According to the 2007 China Brand Report (Yu 2007), the Ministry of Commerce deemed the event important:

This is a necessary choice for changing the format of trading growth. At the present less than $20 \%$ of enterprises in the import export industry have trade marks, domestic brands comprise less than $10 \%$ of total export revenue. In 2004, 249 of the top 500 world brands were American brands, 49.8\%. Without brands as a leading force, we will always be at the lower end of the international division and will always be making sweat money based on labor ... We would need to sell 800 million shirts to buy one A380 airplane.

(Yu 2007)

In short, the brand journey was deemed necessary to change the "backward situation of branding in China" (Yu 2007). Beyond acting to celebrate national brands, the public event was designed to establish a brand ranking and evaluation system, a brand promotion system, and a brand protection system. The event's promotional tagline was China's "New Long March of Commerce, the TenThousand Mile Brand Journey." The journey started in Beijing and traveled through key points in the east, middle, west and northeast of China, along with an international route that traversed Britain, the United States, France, and Germany. The journey highlighted developed brands, emerging brands, and the revival of time-honored brands in various industries, including computers, automobiles, 
porcelain, apparel, pharmaceuticals, alcoholic beverages, cigarettes, and heavy equipment, among others (Yu 2007). Notably, many of the featured brands were in product categories that were the new consumer goods in China at the turn of the century: computers, cars, home furnishings that accompanied the acquisitions of private housing, and travel and recreation (Croll 2006). The event did indeed draw international press, as Italian coverage featured it under headlines such as "Style China: A New Silk Road" (Yu 2007). As noted earlier, this parade of brands occurred in anticipation of the 2008 Olympic Games and its iconic torch relay, and mirrored the Olympic structure, where contenders are positioned as national brands in an arena of international competition. China's new era of national brand promotions is distinct in many ways from those of the semi-colonial and Mao-era periods, and as we shall see draws from a new vision of the future China.

Pleas to national pride in creating national brands for global markets are also seen in scholars' continued calls to the Chinese government to stimulate brand innovation.

Chinese brands have begun directly competing with international brands on a larger scale. China's GDP is now ranked 4th in the world, China's foreign trade is ranked 3rd, and China's foreign currency inventory is ranked 1st in the world. However, among the top 100 brands in the world, there is no Chinese brand. This demonstrates that China is a "big" economic country, but not a strong economic country. As China's development is going to be strapped by the constraints of energy, resources, environment, and the labor force, the Chinese government and enterprises will have to seek opportunities through innovation and the added value of brands. As illustrated by the cases of "Telun-su" [a premium dairy milk brand; literally "gold medal milk" in Mongolian language] and "Rong-wei" [a Shanghai based automobile brand], high end Chinese brands with independent intellectual copyright have debuted and will completely change the past situation where international brands take the high ends and Chinese brands stay at middle and low ends. Chinese brands will compete more in the middle- to high-end markets. We have witnessed how Chinese cigarettes, wine and tea successfully entered the market once dominated by foreign cigarettes, foreign wine, and foreign tea. We have also seen the emergence of Chinese appliances, computers, and cell phones under the strong suppression of foreign brands. We are seeing more quantity and better quality and stable prices of the products of the Chinese colored TV, refrigerator, washing machine, computer, and cell phone. Moreover, in the year 2006, we are glad to know that Chinese cars and Chinese equipment manufacturers started to challenge those strong international brands ... We have good reasons to believe, with the talented Chinese people, firm manufacturing base, and growing economic strength, Chinese brands will ultimately become famous in the world.

(2007 China Brand Report, Yu 2007, 4)

The successful entrance of Telunsu's milk into the high-end was considered to bring "morning twilight to the premiumization of Chinese brands" (Yu 2007, 2), 
and Rong-wei's entrance demonstrated a national ability to employ the world's advanced technology to invent and create completely new Chinese global brands without external intervention.

The 2007 China Brand Report is itself something of a momentous event, being the first of its kind in China. It not only records the planning of the Ten Thousand Mile Brand Journey, but also documents and analyzes major events in China's field of branding for the preceding year. Prepared by 19 researchers from top Chinese universities, the report was reviewed by a panel of 68 experts from various universities, professional associations, and media firms. The work documents efforts and trends related to the success and growth of China's national brands. Its scope is comprehensive, with several areas particularly germane to the study of Western brands as they inform brand meanings held by Chinese consumers. The report covers not only state-endorsed China brand spectacles, but also the growing success or obstacles to success of Chinese national brands, and incidents involving Western brand misconduct, organized under the chapter title of "Brand Crisis Incidents." These incidents highlight the "double standards" of Western brands, whereby Chinese consumers are subjected to lower levels of customer service with respect to complaint resolution, inferior-quality goods to similarly labeled brands in Western countries, producers' failure to recall unsafe brands in China, and high barriers for returns of branded goods once concerns for product safety are publicly reported.

\section{Relevance of these past moments to present-day brand meanings}

This brief historical sketch serves several purposes. First, it highlights the early origins of the concept of "famous brands" as residing in late imperial China, where "famous brands" emerged in rankings of quality in city markets. As we shall see, the notion of a "world famous brand" is a requisite status or attribute of goods that Chinese consumers deem to be Western.

Secondly, the history recognizes the long-standing commercial practice of brand pirating or counterfeiting in China that continues today, motivated by similar circumstances. Yet, as our analysis will disclose, brand pirating or the selling of counterfeit brands is not necessarily frowned upon by all Chinese consumers, some of whom argue that such practices have societal value. The prevalence of brand pirating, however, does require special consumption practices geared toward discerning authentic world famous brands. Further, our analysis shows that "counterfeit" takes a second meaning in present-day China, where the sellers are legitimate Western brand producers but leverage from their "world famous" status to offer inferior products in China relative to similarly branded goods in Western countries.

Third, by revealing the presence of branded goods in late imperial China, this history offers a challenge to notions that the West introduced branded goods into China, which constitutes a form of cultural invasion. This history enables an assertion of brands in China as a home-grown cultural innovation by organizations interested in advancing such a position. We also note that some 
Chinese consumers' lived experiences are more akin to the notion that brands were introduced from the West, leading them to recognize comparable practices in Chinese culture that had been naturalized, owing to the absence of competition and promotions among brands. More generally, this history lays the groundwork for demonstrating that meanings and motives of branded consumption arise out of particular reconstructed histories of the specific culture under study.

Finally, we see that city and regional brand names in the late imperial China were used to mark quality and attribute differences which could be discerned from the place-of-origin labels. This practice continues today (e.g. the beer industry) and has given rise to government initiatives to consolidate competing firms into national brands that compete with Western brands in the global market (Tsui et al 2004).

Beyond offering traces of brand meanings and consumption practices that still exist, Gerth's (2003) work on semi-colonial China reveals that consumption choices were instrumental in nation-making. We extend this theory to the presentday context of globalization, suggesting that nation-making in China continues with consumers shaping the meanings of Western brands through various reconstructions of the past to realize their preferred visions of the future (Belk 1992; Friedman 1992b; Wilk 1994). Whereas nation-states strive toward the ideal of the assimilation of its citizens into a common social project, with globalization they are besieged by the fragmentation of their former unity (Friedman 1997; Wilk 1994). Such fragmentation emerges from various groups asserting competing notions of social identity, which are constructed and legitimized by attributing a meaningful past to a structured present (Friedman 1992a, 1997). These researchers deconstruct collective identities not to falsify their genuineness, which as Friedman (1996) argues would be absurd, cynical, and patronizing, as all identity is constructed and authenticity resides in its experienced relevance; rather, the goal of deconstruction is to reveal the structures that perpetuate the existence of the social groups and contexts that motivate acts of identification. Our findings suggest that China's 20th-century history prior to market reforms carries forward a common thread of experience and ways of interpreting the world that become relevant in assertions of national identity (Friedman 1996).

The active role of China's governing bodies in shaping brand meanings is apparent in Croll's (2006) report on the history of China's economic reform. We add to the repertoire of governing practices noted by Croll that of governmentsupported or -initiated brand spectacles. The case of the Ten Thousand Mile Brand Journey reveals a contrast with China's semi-colonial past. Present-day national brand spectacles do not overtly vilify the consumption of Western brands, but nonetheless hold up China's national brands as a source of cultural pride that citizens can share in and support through their consumption choices. This suggests that nationalism asserted by rejecting Western brands in favor of national brands need not follow from China's Mao-era planned economy. Rather, new governing administrations offer new consumption ideologies tied to nation-making that are consistent with participation in a market economy. 


\title{
4 Foreign brands in China as global brands from the imagined West
}

\begin{abstract}
A low threshold for dreams, easy access to sufficient goods to reach that threshold and a belief in objective limits, difficult or impossible to negotiate, to "genuine" needs and "realistic" desires; these are the most fearsome adversaries of the consumer-oriented society.
\end{abstract}

(Bauman 2007, 46)

Perpetual desire satisfied by consumer goods is held to be the driver of a consumer-oriented society, in contrast to a production society oriented toward securing basic needs. Given this, the elicitation of Chinese consumers' dreams of Western brands figured prominently in our research design. We found ample evidence that Chinese consumers' dreams of Western brands are at a high threshold that exceeds basic needs, and often realistic desires. Indeed, it would seem that the financial challenge of acquiring Western brands because of their high prices is one of their distinguishing features. Chinese university students group together the fantasized acquisition of endless access to Coke and KFC as well as of Mercedes or BMWs, suggesting that what is out of reach and perpetuates desire spans a broad spectrum of Western brand product categories.

In this chapter, after describing our data collection sites and methods of eliciting dreams of Western brands, we report our initial findings. We reveal "Western brands" to be a meaningful category of consumption to Chinese consumers. In particular we show how the inclusion of branded goods within this category of consumption is discerned by a set of defining characteristics: 1) attributes that convey "Western otherness;" 2) international fame; 3) guaranteed quality; 4) technologically advanced designs or production; and 5) highly priced relative to domestic brands. This understanding allowed us to progress to another layer of understanding, whereby Chinese consumers imbue Western brands with meanings by embedding them in historical national narratives of East-West relations. Then, drawing from these meanings, they respond to Western brands in different ways to realize preferred imaginings of the future China. These deeper layers of understanding are elaborated in Chapter Five. 


\section{Overview of research method}

In commenting on Western nations or their brands, Chinese individuals' conveyance of praise, affinity, or relational harmony may or may not be taken at face value, depending on the context. In China, indirect forms of communication, such as the use of metaphors, historical allegory, and discourses where the surface reading is contradicted by the interpretive meaning, are the cultural norm for expressing criticism (Gries 2004). In Chinese terms, one must "listen to the sound of the gong" (luo gu ting yin), to discern whether it is rejoicing (announcing a marriage) or mourning (tolling a death) (Gries 2004, 9). Owing to a long history in which indirect language was employed as a symbol of education and class, Western-style direct criticism is considered by many Chinese to be vulgar (Gries 2004). This aspect of culture guided our research design, which combined projective techniques with methods of direct inquiry.

Our interpretive analysis draws from various data forms collected over six months, with three months spent on-site in China. We began our analytic process by identifying consumers' nuanced terminology to refer to foreign brands (waiguo-pin-pai) in initial preliminary interviews. We also obtained a general idea of their perceptions of these brands, including their affordability. We used this to aid in the formation of our research questions and the development of a survey questionnaire. Next, we elicited meanings of foreign brands from university students via a projective survey instrument. The survey, with projective tasks, was administered to over 200 students to permit the identification of recurring themes. It also seemed useful in eliciting the varied content of foreign brand meanings, given that students comprise a life period of "emerging adulthood," characterized by a self-focused exploration of possible identities, which can be enacted with foreign brands (Arnett 2002, 777). Further, with a sample of fourth-generation PRC youth, all socialized during Deng's reforms, we were able to examine whether foreign brand meanings draw from historical contexts that pre-date consumers' lives (Gerth 2003, 2008). We could also assess whether cultural history, if used to imbue foreign brands with meaning, possesses a plurality of meanings even among same age cohorts, leading to varied views of the identity meanings attached to foreign brands.

We then augmented our analysis of survey data with an analysis of interview data obtained from working professionals who could afford more brands. We conducted these 25 Chinese-language interviews in multiple cities, and in participants' homes or in restaurants. All but two of these participants belong to the third-generation PRC, born in the 1960s and 1970s, but varied on gender and income level. They were asked to share their knowledge of foreign brands and translation practices. They were then asked to tell a story of both a favorite and a disliked foreign brand, though subsequently their stories incorporated their views of how the reform changed China's consumer offerings, remembrances of cultural events which prompted reactions to Western brands, and changes in personal attitudes toward Western brands over time.

We tacked back and forth between the data and the literature on Chinese cultural studies and political science which review China's relationships with Western 
nations from the Chinese perspective. Our consulted works include a host of Chinese popular press and scholarly reports on brands. Translated passages from these which appear throughout the book are our own. Immersion in this literature assisted us in recognizing many of the recurring themes in our data as being linked to national narratives of East-West relations. Our Chinese participants used these national narratives to imbue foreign brands with national identity meanings. Following our identification of narrative themes from the collective texts, we return to the interview data, where we present a case-oriented analysis that offers evidence of the relevance of these narratives to Chinese consumers' lives (Friedman 1996).

\section{Data collection sites}

The cities from which we drew our participants vary on factors likely to influence local meanings of Western brands: population, status as a municipality, location, and degree of urbanization as a characteristic related to Western culture exposure (Wang 2008). Beijing, with a population of 12.8 million, hosts a variety of international commercial activities, yet is also a municipality where the nation's military headquarters are located. Tianjin is an industrial (cargo) ocean port city of 10 million people and home to nearly 10,000 foreign firms. Shanghai is China's largest port city with 14 million inhabitants and, comparable to Tianjin, has a high level of exposure to Western culture. Baoding, a rural industrial city of approximately 553,000 , has had the least exposure to Western culture of the four. Considered Beijing's southern gate, Baoding hosts military forces deemed important to protecting the capital city. The cities where we conducted our fieldwork also varied, and include first-tier cities, Beijing and Shanghai, where most "Western watchers" place their emphasis, a city from the second tier, Tianjin, and a third-tier city, Baoding, defined as sizable and relatively affluent (Wang 2008, 3).

\section{Our data collection methods}

We distributed a self-administered Chinese-language survey containing a series of thought generation tasks to students of Chinese universities ( $n=280$ of 285 distributed): 100 from Beijing, 66 from Tianjin, 25 from Shanghai, and 89 from Baoding. Sentence completion items were used to elicit meanings of foreign brands and were presented as the initial task in the survey. The first of these items asked for responses to the statement stem "I think 'foreign brands' mean ..." Participants could choose any or all of the following responses: "made abroad, imported to China," "originated from abroad, made in China," "product of independent foreign business in China," "product of joint ventures of foreign businesses in China," and "other." A subsequent question asked participants to provide examples of foreign brands. The next nine statement stems were adapted from projective survey items used by Mick and Fournier (1998) in their US study of technological goods. These modified items appeared in the following order: 


\section{Foreign brands as global brands from the imagined West}

1. Foreign brands always ...

2. A good foreign brand should ...

3. Foreign brands never...

4. The more foreign brands I have...

5. The biggest advantage of foreign brands is ...

6. The greatest weakness of foreign brands is ...

7. When I bought my (foreign brand product), I never realized. . . .

8. If I lost my foreign brand item, the worst thing is ...

9. If all foreign brands disappeared from China, I would ...

Six additional sentence-completion items elicited examples of "good" and "poor," "best" and "worst" translated brand names, and what about the translated name renders it the "best" or "worst."

Following these tasks, participants were asked to complete a dream elicitation task. Specifically, participants were asked to "Please imagine you or your friend had a dream about foreign brands when sleeping" and to describe the dream, which could be either good or bad. Beyond these simple instructions, the participants received no other specific guidance. We realize that in other works employing projective techniques, like those of Rook $(1985,260)$, participants have been asked to "write creative and imaginatively complete stories." We did not ask for creative or imaginative writing, but simply asked for a positive or negative dream. Even so, the elicited dreams appear amazingly creative. We speculate that the richness of the dream data is due to several factors. First, at the time of data collection, only about 30 percent of China's high school graduates were eligible to attend university, and these are chosen on their academic performance. Thus, relative to the general population they are highly articulate. Second, the metaphorical use of language, as an indirect form of discourse, has been culturally instantiated and pervasive in everyday life, which probably renders participants creative in this domain. Third, the language itself, with characters being pictorial and with each sound possessing a meaning, would seem to engage the practice of visualization, relative to the English language where individual syllabic sounds often have no meaning. And finally, China arguably has been influenced by modernism's rationalist orientation over a shorter period of time and to a lesser degree, perhaps with the result that there has been greater exposure to and practice with imaginative thinking and writing.

The questionnaire was drafted in English, and following refinements suggested by members of the Chinese Academy of Sciences in Beijing, was translated into Chinese. Additional Academy members provided feedback on the Chineselanguage version, until all items were deemed appropriate.

The transcribed Chinese-language textual data were translated into 205 single-spaced pages of English. The survey data contain references to 102 different foreign brands, largely from product categories for which foreign brand ads are prominent: soft drinks, fast food, electronics, and health and beauty aids (Belk and Zhou 2001; Wang 2000). These categories represent "highly symbolic and richly connotative product classes" (Mick and Buhl 1992, 320). The dream elicitation task produced 247 consumption fantasies. 
Responses to selected sentence-completion items, along with the questions regarding what counts as a foreign brand and participants' examples of foreign brands, were used to identify what constitutes a meaningful consumption category to Chinese consumers. In responding to statements such as "Foreign brands always ..." "Foreign brands never . .." "The biggest advantage of foreign brands is ..." and "The greatest weakness of foreign brands is ...," participants revealed how they distinguish foreign brands from China-made brands, also referred to as national or domestic brands. We highlight these findings in this chapter. Other sentence-completion items, along with the data from the projective dream task, aided our understanding of how brand meanings emerge from linkages to local history, and how consumers selectively engage historical moments to enliven their Western brand fantasies. These themes are the focus of subsequent chapters.

After gathering this survey data, we also conducted personal interviews with 25 Chinese consumers who had graduated from Chinese universities and held mainly professional positions. Following initial requests to discuss a recent incident that the participant experienced involving a foreign brand, the interviews flowed much like a conversation. In our presentations of these, we use pseudonyms to refer to our participants.

\section{Foreign brands as Western brands with distinguishing characteristics}

From our Chinese participants' perspective, "foreign" included imported products, products produced in China by a foreign company, and products of joint ventures between foreign and Chinese companies. In a sense, brands that were not purely Chinese in terms of their conception, labor, and ownership of related patents, trademarks, and production facilities were deemed "foreign." This finding is reminiscent of views during China's semi-colonial era, in which "foreign" was marked by not being purely China-made (Gerth 2003).

The meaningful category of branded consumption to Chinese consumers was not, however, merely anything that was not purely Chinese. Five characteristics were perceived as constitutive of the meaning of foreign brands: 1) "Western otherness," as conveyed by perceived country of origin and through translation practices; 2) international popularity or fame; 3) guaranteed quality; 4) technologically advanced design or production; and 5) a high price.

\section{Western otherness}

Foreign brands were considered only those with perceived ties to developed countries of the West. These included the United States (e.g., Nike, Coca Cola, Pepsi, McDonald's) and Western European countries, including Germany, France, Italy, and Finland (e.g., Mercedes Benz, Christian Dior, Pierre Cardin, and Nokia, respectively), but also brands from Japan, as a country through which China has learned about the West and one which was participating in the global economy before China (Gries 2004). 
Among our Chinese participants, designations of "Western otherness" depended less on an attempt to discern the product's country of origin and more on whether the brand name translation reveals deviations from norms of Chinese language and culture. A few illustrations of traditional Chinese brand names may help to appreciate some aspects of brand name construction, such as names that convey product meaning. For Feige bikes, fei means flying while ge means dove, rendering a meaning that the bike flies as fast as a dove. Hudie (butterfly) sewing machine conveys both the transformational process and the ease or lightness of sewing. For Hongxing radio, hong means read and xing means star, and reflects an early norm for many technological goods to bear names tied to nationalism.

We identified three forms of Western brand name translation into Chinese that reflect deviations from Chinese cultural language norms and thus reflect their foreignness. First are cultural deviations suggested by brand names that do not sound Chinese, such as Mo-tuo-luo-la, or Motorola in English. Second, brand names that do not possess a product-relevant meaning are interpreted as foreign. For example, Ka-fu, or Kraft in English, where the Chinese translation literally means "choke husband," forces people to view it as foreign. As other examples, Hao-shi, the translation Hershey, means "good times," and Wan-bao-lu, the Chinese brand name for Marlboro, means "road of ten-thousand treasures." Third, brand names that violate norms of character combinations are interpreted as foreign. That is, the meaning unit $t s^{\prime} u$ or $c i$ in modern pinyin, which may be comprised of multiple words, reflects an atypical combination of words. In illustration, Gu-te-yi or Goodyear, means "solid, special, different." All three characters in Chinese have a fourth tone (all falling). This sound combination is very awkward and thus is read as foreign. Qian-bi, the Chinese brand name for Clinique, has components qian, which means "pretty," and bi meaning "green jade." The meaning is somewhat relevant to the greenish packaging of Clinique, but the sound is awkward. Both characters "Qian-bi" have the fourth tone in Chinese, which breaks the norm of Chinese character combinations.

Not all brand names that exhibited these deviations were viewed as Western. For example, some translated brand names convey a lack of knowledge of Chinese language and culture which suggests foreignness. Yet, the clumsiness of their presentation detracts from their credibility as a famous global brand, with the quality and backing to gain access to China's market. The lack of sophistication exhibited in their brand name translation rendered these outside the category which Chinese consumers considered Western.

I once bought a loaf of bread, which was covered with foreign letters. When I looked closer, it was all Chinese pinyin [a system of Romanization used for transcription of Chinese names and terms]. It was so ridiculous - a big bread called "Chocolate pie." These kinds of names are not so much disgusting as they are ridiculous. They make you want to laugh at them.

(25 year old male interviewee, Tianjin)

Whether the products are good or bad, high-or low-quality, with good or bad packaging, there is absolutely an acceptance issue. For example, crackers, 
why would you want to call them "ke li jia"? I didn't even know what it meant! I thought what the heck am I buying?

(39 year old male interviewee, Baoding)

Participants' comments contextualize Zhang's and Schmitt's (2001) finding that translating a foreign brand name to be semantically meaningful enhances its effectiveness. The latter quote suggests that (high) quality and (elaborate) packaging combine with cues provided by the brand name to convey Western-ness, as we elaborate later.

Also outside the category of Western brands were some with translations possessing such a strong Chinese cultural orientation that they were not recognized as foreign. To illustrate, the brand Pantene was excluded from participants' discussion of "foreign brands." When questioned about specific Western brands, one Beijing participant elaborated: "I knew Lux is an American brand, but I didn't know Pantene is one too. Pan-ting is a very traditional original Chinese girl's name, and the first celebrity who appeared in the Pantene commercial was the movie star Ms Pan Hong. So I thought the Pantene brand was her brand." Brand names successfully localized so that they do not convey foreign-ness or Western otherness forgo any presumed positive associations with Western brands or abilities to trade on their exoticism.

Some brand names, however, were translated to capture nuances of the Chinese language and culture, exhibiting both cultural sensitivity and sophistication while still designating the goods as foreign. In some instances this was effected with a Chinese-language sound but a character meaning tied to foreign-ness.

Ken-de-ji (KFC). I think this name is well made. Ken-de-ji, how should I put it. It's not that much like a Chinese name ... Ji-rou [chicken meat] seems to be used in China.

(24 year old female interviewee, Beijing)

Here, the foreign brand is translated to maintain a sound corresponding with the original ("Ken-de" for Kentucky is meaningful even though the Chinese name is "ken-ta-ji"). Literally translated, the brand means "willing virtue chicken." Ken is also the same sound as the verb "gnaw" or "nibble," which could help visualize the way people eat chicken wings. "Ji" means chicken, which adheres to the cultural practice of conveying product meaning. The "de" component in the middle of "nibble . . . chicken" just does not make sense in Chinese. If it were changed to "ken-ji-dian" (nibble chicken store) it might sound more like a Chinese name. Thus, the KFC brand name in China is obviously foreign as the character combination is unconventional.

As another example following this pattern, Yu-lan-you (Oil of Ulan in Asia in the 1980s, later Oil of Olay) means "oil of orchid flower." The orchid flower has long been used in China to symbolize pure and pretty girls, as it is known for its tenderness. The flower is a symbol of innocence and youth. Thus the translation of the Western brand name possesses points of compatibility with Chinese culture. 
As one of our Baoding participants succinctly put it, Yu-lan-you means "fresh, elegant, and tells it all." Telling it all includes giving away its foreign origins. The translation maintains an element of the foreign. Yulan is a popular name for girls, but the combination of "yulan you" (oil of yulan) is not often used. So a bit of Chinese flavor in a slightly strange combination implies a foreign brand designed for Chinese consumers.

Safeguard has similarly been translated into Chinese to imply it is a foreign brand with local sensitivity: its Chinese brand name "Shu-fu-jai" means "comfort skin nicely." The name conveys the attributes of the product, consistent with norms of Chinese language. As expressed by one of our Baoding participants, "it explains the features and usage of the product, and has some Chinese flavor in it." Yet, as this participant recognizes, there is an atypical combination of characters. The combination of three characters ending with an adverb is not often used in traditional Chinese brand names.

As a final illustration, BMW uses the brand name "Bao-ma" in China, which translates as "precious horse." Many Chinese use "precious horse" as a metaphor for vehicles because precious horses have been known to run reliably fast for a long time. The choice of word definitely reflects a Chinese orientation, but using this word for a brand name is new in China, thus it is obviously a foreign brand. As another Baoding participant commented, the brand name "integrates the notion of modern transportation with Chinese traditional means of transportation." While leveraging from China's cultural system in its recognition of a popular metaphor, Bao-ma nonetheless is obviously foreign because Chinese brands in the same category, such as Hongqi (Red flag) and Dongfeng (Eastern wind), usually bear some mark conveying their domestic origins or political alignments, following precedents set during the Cultural Revolution.

From some Chinese consumers' perspectives, to be considered a well-made Western brand name, the connoted foreign-ness need not accurately convey the brand's country of origin.

I think the brand name Bi-sa-bing (Pizza Hut) is made very well. . . Pizza reminds people of the Leaning Tower of Pisa in Italy. Just by seeing the brand name you can tell its country of origin which reminds you of its cultural legacy.

(38 year old female interviewee, Beijing)

Further, some suggested that a stronger western-oriented brand name translation seemed appropriate for hi-tech products to reinforce their origin in the West, as a place that many deemed produced technologically superior goods.

For daily use products, their names should make you feel nice and genial, and they should be in line with the liking of Chinese people. But for some hi-tech products, including some electronic products, they should have some meanings of hi-tech. Though not absolutely everything, but high tech products such as electronics will be better if they are translated with more Western style.

(38 year old female interviewee, Baoding) 
Brand names aid the designation of Western brands but are not as defining as are attributes of international fame, guaranteed quality, technological advancement, and relatively high price. This reflects local experience of encountering a proliferation of domestic goods branded to convey Western-ness and capitalize on presumed positive associations. Responses to translated brand names reflect a practice that Gerth $(2008,41)$ labels "nationalistic visuality, centered on training the eye to identify visual clues and to distinguish between the foreign and the domestic across social life." As our analysis in subsequent chapters points out, motivations for making such distinctions are varied among Chinese consumers and directed toward buying Western brands, buying national brands, or making comparisons and contrasts between the two in assessments of China's progress in developing globally competitive brands.

\section{International fame}

Participants suggested that foreign brands should be referred to as "famous foreign brands:" "Foreign brands? I think you should call them 'famous foreign brands" because they have to be famous before they can enter China." In the sentencecompletion task, stems such as "Foreign brands always ..." included responses such as "establish reputation all over the world," and "[possess] huge fame." These types of response dominated the elicited data.

Foreign brands always ...

- are very famous,

- have high reputation,

- $\quad$ are quite popular, or

- have outstanding brand image.

The biggest advantage of foreign brands is ...

- the brand is internationalized,

- they are famous, or

- [they are] well-known.

The "fame" of foreign brands is also noted in the dream data. In the following dream, fame is conveyed by a Western brand that arrives as a celebrity at an event attended by Hollywood actors and actresses.

A fine horse wearing a Versace black lace nightgown appeared on the starlit runway of the Oscar ceremony, and flew into the seated audience. Riding on the back of the horse is the immortal young and handsome Versace. Under the bright starlight, wearing striped casual clothing designed by himself, he waves his hand to the people who stand up and salute to him - he is the great master, great master forever.

(20 year old female survey participant, Baoding)

The fame required for products to be deemed Western brands is conveyed by other dreams in which the Western brand is proudly displayed by a celebrity endorser, or 
dreams in which wearing the brand renders the Chinese consumer a global celebrity. Along with celebrity endorsement, Chinese consumers considered famous foreign brands to be only those with strong promotional backing from their producers, manifested by attention to advertising and packaging.

Foreign brands always ...

- have fine and novel packaging, well produced advertisements, and good brand reputation,

- emphasize the brand's promotion and occupation of the international markets,

- have good packaging,

- have pretty packages, or

- have lots of ads and know about packaging.

Foreign brands never ...

- neglect promotion of its image and products,

- forget to advertise,

- are too frugal to advertise,

- casually spoil their image, or

- are ugly.

With the introduction of Western brands beginning with the economic reforms of Deng Xiaoping in the late 1970s, Chinese consumers were exposed to packaging practices that differed from what had been common in China. Similar to the perspective Wang (2008) noted for Chinese advertisements in early years following reform, packaging practice in China was consistent with values emphasizing substance and honesty. Consistent with this, many Chinese would rather have a good and valuable product with simple packaging than an ordinary product in elaborate packaging. Heightened attention to the "look" or "appeal" of the package was somewhat novel at the beginning of the reform, leading Chinese consumers to distinguish Western brands according to style of packaging. Whereas almost all respondents noted the attention to packaging exhibited by Western brands, opinions varied, reflecting differing levels of receptivity to such practices, or to the modernity that they represent.

\section{Guaranteed quality}

A prevailing theme that distinguished Western brands in the minds of Chinese consumers was an attribute commonly referred to as "guaranteed quality." Quality here refers to the durability and reliability of manufactured products and a performance consistent with promotional promises and consumers' expectations. It also refers to the presence of after-sales processes for resolving complaints.

Perhaps this finding is not surprising, given that reports of product quality issues with China-made goods also appear in the Western press. As noted by China scholars led by Tsui (Tsui et al 2004) and Croll (2006), China's industrial revolution occurred concurrently with its consumer revolution. The Western popular press 
often highlights quality shortcomings in manufacturing, rather than recognizing the tremendous progress of a nation whose industrial revolution took off at the same time as economic reforms. More appropriate would be to recognize that much of China's manufacturing sector has evolved in the relatively short period of a few decades since the reform.

Perhaps more novel to Western readers is that, from Chinese consumers' perspective, after-sales processes for resolving complaints were deemed to distinguish Western brands from domestic ones.

Foreign brands have very good reputation. If you say it's not good, it's not good, and they will give you a refund without even checking. Therefore I feel comfortable buying foreign brands. Of course generally there aren't problems like this. Another thing is the brand. My parents' TV is a Toshiba brand, bought a long time ago. It's been 20 years. But until today it's still very clear. But the same product, when we got married in 1988 we bought a Chinese brand, [Chinese brand name] which we threw away in 1998. Why? It turned green, didn't work no matter how we adjusted it. We asked people to repair it for us, they said that the color contrast was bad, so its quality was not up to standard. Therefore, although more expensive, we should buy brands of better quality. Without quality guarantee, they would not dare to come to China without quality. They [Western brands] wouldn't make enough money because there would be few repeat customers. It wouldn't work. Plus tariffs, the prices will be more expensive.

(38 year old female interview participant, Baoding)

Drawing on local knowledge of quality control measures demanded of exports in post-reform China and "survival-of-the-fittest" notions of capitalism, the participant quoted above, like others, insisted that Western brands must be higher quality than domestic brands if they have gained access to China's market. From their perspective, owing to China's protectionist history very few domestic brands are global, and so do not possess the same quality standards of the international market. Branded products must possess quality in order to survive in the global marketplace. The presumed quality of Western brands was expressed in other ways.

[The more foreign brand products I have], it will help improve my quality of life, because their products usually work pretty well. [Dream] Within one night I own many super famous foreign brand products.

(22 year old female survey participant, Tianjin)

The more foreign brand products I have the more peace of mind I have when using them.

(22 year old male survey participant, Shanghai)

Guaranteed quality as a distinguishing feature of Western brands was expressed in various ways in the sentence-completion tasks. 
62 Foreign brands as global brands from the imagined West

Foreign brands always:

- appear to have guaranteed quality,

- have good quality,

- have stable quality,

- have quality that is truly reliable,

- have post sale service, or

- have good credibility.

The biggest advantage of foreign brands is:

- good quality,

- first class quality,

- they are durable and don't break easily,

- good reputation, or

- good service.

Foreign brands never:

- $\quad$ have worse quality than local sellers,

- $\quad$ are made rough and poorly,

- make fake products,

- $\quad$ are disappointing,

- $\quad$ ignore customers' complaints,

- cheat consumers,

- trick consumers,

- deceive consumers,

- have quality problems, or

- $\quad$ neglect applying for copyright.

To elaborate the latter response, cases of copyright and trademark infringement brought by Western brand producers against producers of counterfeit brands in China have received considerable coverage in international news. Resolving these concerns was central to international discourses on China's entry into the World Trade Organization. The response that "Foreign brands never ... neglect applying for copyright" reflects our Chinese participants' awareness that Western brand producers use the brand name to identify the consistent and reliable quality they attempt to provide, and thus attempt to protect it. Yet, as noted previously, because copycat brands with similar but slightly altered names continue to exist, Chinese consumers learn to attend to nuances of the visual presentation of brands to distinguish Western from domestic (Gerth 2003). Data from our projective task reveal the use of quality to discern Western brand status.

[The more foreign brand products I have] the less time I spend on dealing with defective products. [Dream] I just bought a West Data hard disk with $40 G B$ but when I took it home it didn't work. This cannot be possible. It is a Xishu hard disk (Chinese name for West Data). The quality shouldn't be that bad. I took it to be repaired, and the shop was able to fix it. How weird, it stopped working again when I got back home. Heavens, I almost went crazy. What kind of hard disk is this that the quality is so bad. Therefore, I took it 
to be repaired again, but the people at the reception desk said that it had exceeded the warranty period. I had bought it only four days before. "Isn't the warranty period three months?" Thus, he pointed me to the warranty label, I was stunned after looking at it. It was clearly written "three days." "Not possible, Xishu also rips people off?" [The receptionist replied] "What Xishu [West Data], we are Xibu-riqi [West Date]." I looked at their company name "West Date" and looked at the label of my hard disk. It was also West Date. I immediately felt sick, blacked out and vomited several liters of blood. Heavens, why I am always the one to be hurt?

(22 year old male survey participant, Beijing)

Although the data suggest that most of our participants associated Western brands with the offering of after-sales service or processes for addressing complaints, there was not total agreement that such services were unproblematic. Some reported that the greatest weakness of Western brands was "inconvenient repair," "hard to repair if they break," "post sale service is quite complicated," or "when imported from abroad the instructions are not very clear and are hard to understand." Whereas Western consumers are accustomed to the idea of replacing durable goods after a number of years of use, the Chinese consumers' need for after-sales service may have been the result of past consumption experiences with less durable domestic brands and the tradition of frugal lifestyle encouraged by governments until the 1990s. Consumers' experiences with after-sales service suggest too that their usage experiences also involve Western brands that are not durable and reliable. It may be that the use of guaranteed quality to define and recognize Western brands contributes to dissatisfaction, by elevating expectations beyond what some Western brands deliver. We address this theme in Chapter Six.

\section{Technologically advanced}

Most participants deemed Western brands modern and technologically advanced relative to domestic counterparts. The interview data reveal that "technologically advanced" resides more specifically in offerings of greater safety, durability, and comfort, along with enhanced performance and lack of undesirable attributes. There is some overlap here with the feature of quality. Yet, beyond functioning reliably, our Chinese participants commented on the "research," or "scientific processes" that rendered Western brands capable of different, new, or enhanced functions or performance outcomes relative to domestic brands. Western brand electronic equipment such as razors, audio recorders, remote control televisions, and air conditioners were commonly mentioned as being more modern and technologically advanced. Participants also reported that Western brand health and beauty aids, fast food, and sports equipment were all technologically advanced. In addition to responses such as "Foreign brands always ... "have trendy designs" "or "Foreign brands never . . . "become outdated," were ones such as the following. 
64 Foreign brands as global brands from the imagined West

The biggest advantage of foreign brands is:

- they are advanced,

- $\quad$ they are more trendy,

- $\quad$ create the new from the old with rich imagination,

- [they offer] new design, high technological element, and good exterior appearance, or

- $\quad$ [they] fit the market; [they] are compatible with the trend.

For some Chinese participants, Western brands were deemed to function better because of the advanced technology used in their design and construction. Consider the following stories told by some of the people we interviewed.

[A domestic brand] it's been on the market for a pretty short time, and it's not as good as the other ones. Truthfully, I think many things are this way: although made with the same materials and all made in China, I think the others' [foreign] quality and workmanship is better than the domestic ones. Really. Including electronics, I think foreign ones are better than domestic ones. Put foreign ones aside, even the joint ventured products are better than the Chinese products. For example, my family's air conditioner, it's very obvious. The one in my parents' room is Sanyo, a joint venture. Its remote control is finely made, even the corners and edges are very well made, and its buttons felt very nice. The one in my room is [a domestic brand]. You look at the plastic buttons on the remote control, oh my gosh, they are terribly rough. The same with TVS. The TV in my parents' home is a foreign brand. Wherever you point the remote control, you can "remotely control" the TV. You just look, good TV brands are all absolutely the same, including Panasonic, Toshiba, etc. You'll know it as soon as you try it once. But my family's [domestic brand] TV, if you don't point to the reception spot, you can never expect to switch channels. Therefore it's not that I look down on Chinese people, but you have no way to support (national industry) even if you want to. You (Chinese brands) are so much behind the others (foreign brands). Take the example of remote control, the others (foreign brands) can remote control anywhere and everywhere, and you can only point to that spot.

(24 year old interview participant, Beijing)

My younger brother once used a shaving razor, domestically made, [domestic brand name]. As soon as he brought it home he found that it leaked electricity when charging, but he just got by with it for six months. Now he is using Philips. It's very good. After using it for so long, it's still very quiet. The domestic brands are very noisy. Take the audio recorder I bought some time ago for example. I've used a few Chinese brands, and found that the quality is unbearable. The difference (of Chinese and foreign brands) is very big. The domestic products don't usually last very long, either they're broken, or the sound becomes too noisy. I'm very angry about it, but I have no choice. Truly, 
you can't compliment on the domestic products. Whenever you buy them, you end up getting upset.

(26 year old female interview participant, Tianjin)

The perceived technological advantage of Western brands resided not only with electronic goods. Western brand cosmetics and beauty aids were recognized as based on modern science and made with chemicals and manufactured scents. Participants contrasted these with products of traditional Chinese medicine and remedies. Our participants reported that prior to the entry of Western brands, products were "very natural, we never heard of anything chemical or had the fear of being hurt." These participants reported pre-reform practices using natural remedies for enhancing the skin, such as eating almonds, drinking soup of pigs' feet or chicken claws, using eggplant and lemon, or washing with milk. Those for hair care included washing with honey and tea, or with cooking vinegar or with Zao-jiao - that is, honey locust, a fruit presumed to keep hair shiny and healthy. Make-up prior to the introduction of Western brands also involved practices such as painting eyebrows with the dark brown residue obtained from burning plant leaves underneath a wok. The following excerpts from our participants illustrates the use of these natural remedies based on traditional Chinese medicine (TCM) in everyday life.

XIAN: In my hometown in Henan province, there is a kind of plant. It's called "Zhijiahua" (meaning nail flower).

INTERVIEWER: Oh yes, in my hometown in Hebei province, we also had that.

XIAN: My mom would wrap the ground flower paste to my finger nails at night and the color would be on the nails the next day.

JING: The nail flower would be ground together with some alum (a special cooking ingredient like rock sugar) which could give you orange nails. And we would use the leaves of mulberry trees for red fingernails. It was so mysterious in childhood. We would stretch out our hands and say "Look, do you have such colors?" the color would stay for a long time.

Although these reflect TCM's long history of backyard preparation (Go 2003), some remedies are often packaged and sold, like the lip oil made from animal fat described earlier. Both backyard and packaged TCMs have been characterized as "mild but effective remedies causing few side effects" (Go 2003, 8). This was often pointed out when discussing Western brand health and beauty aids. Chinese participants found that owing to their scientific engineering, Western health and beauty aids possess more rapid or stronger effects. Some brands play on this perception in their brand names, for example SK-II, meaning "secret key to beauty."

The biggest advantage of using traditional products is they are without sideeffects. My mother is very much against dying hair with those imported chemical products. She has never done this in her life even though now she has a 
lot of white hair. She believes the products nowadays used to dye our hair are very much chemical and will definitely cause skin cancer sooner or later. One of her former colleagues, who dyed her hair often, did die of head skin cancer some years ago. I've never heard if there is any Chinese traditional way to make hair black but I believe there was in the old times in the Imperial Palace for those concubines. It is true that we have confidence in using anything made of traditional Chinese medicine.

However, as far as body care products and beauty aids are concerned, I give my equivalent confidence to those big famous brands such as Christian Dior, Estee Lauder, Shiseido, Lancôme, etc. These big brand products are not only reliable, nicely presented but also efficient just because they have more scientific research behind them. Traditional Chinese products, though having less chemicals, take longer to see the effect and very often we lost our patience before seeing the result. In a way, on one hand we do have confidence in how they are made-no chemicals are added. On the other hand, we have less confidence in when they will finally bring us a revolutionary result. Besides, at present the quality of Chinese traditional cosmetics products are far from being fine either in the product themselves or their presentation.

(41 year old female interview participant, Shenzhen)

Yes, I would often use Western brands. Their quality is better than our domestic brands. I didn't believe in any anti-wrinkle products before. I know it's not good for you in the long run. They use some growth factors in the product so that your skin would look good for now, but you will lose the radiance once you stop using the product. I tried Dabao eye cream and it's too dry. Lancôme is much better. I don't know if it can prevent you from having wrinkles, but at least I feel good about it.

(38 year old female interview participant, Beijing)

Advanced technology was also noted by our Chinese participants in discussions of Western fast food establishments. The standardization achieved through modern scientific principles that render these branded foods consistent and reliable ("McDonaldization", Rizter 1993) enabled some Chinese consumers to see them as "good foods," as they minimized the risk of stomach or intestinal disorders.

Coca-Cola is what we buy most often for our family. And Sprite is also a foreign brand. We have the peace of mind when drinking these things because we know we won't have diarrhea. When we go out, we often eat in McDonald's, not for its taste, but for the sanitation. We feel we have trust in it.

(46 year old female interview participant, Tianjin)

Watson's (2006b) study of the first McDonald's in Hong Kong details both the distinguishing feature of standardized practices tied to consistently ensuring sanitation throughout the retail establishment and Chinese patrons' favorable response to these standards. 
For others of our participants, the scientific knowledge used in Western brand food production was deemed to result in food with greater nutritional content. One participant who believed American brand fast food was more nutritious than traditional Chinese food and often took her son to McDonalds, nonetheless revealed:

I'm not too concerned with the growth hormones used in raising chickens and cows. But I'm a little worried about the growing body of my three year old. So I let him drink organic milk and try to eat organic grains as much as possible.

(40 year old female interviewee Beijing).

Finally, there was also evidence that Western brand sports equipment was deemed by many to be technologically advanced. This was exhibited less by the characteristics of the exterior form of the branded product and more in terms of the precision and enhanced performance a consumer would experience as a result of wearing Nike or Reebok sports shoes. Indeed, some brand name translations contribute to this perception. For example, the translated Chinese name for Reebok is Rui-bu, meaning "sharp stride."

Also related to the perception of technological advancement is the notion that Western brands are always "new." Technology by definition implies new knowledge or processes such that the application of technology leads to new products. Participants' comments and elicited dreams suggest that newness is a hallmark of Western brands, which sometimes undermine former versions of their product to stay at the forefront of novelty.

The more foreign brand products I have the more depth and breadth of knowledge I have about fashion. Dream. I dream that my Lux shampoo turns into a weird yellow color (it is originally pink), and it can't produce foam anymore. The celebrity of Lux suddenly appears and tells me that she has quit using this product and switched to the new Lux powder hair products. Then I was surrounded by foam and bubbles.

(21 year old female survey participant, Shanghai)

Although many Chinese consumers defined Western brands as technologically advanced, the referent here was what was available in China's market. With access to information on the internet and increased international travel, several participants reported discovering that Western brand producers never "Simultaneously sell the newest product in China that they do in other parts of the world," or never "Put their newest frontline products in China." We find validity to these impressions in reports by high-level Western brand executives that advise other Western corporations not to go to China with their latest products, given experiences of patent and copyright infringement (Knowledge@W.P.Carey 2009). As we elaborate in Chapter Six, such practices do not go unnoticed by China's consumers and create image problems for Western brand producers. 


\section{Expensive}

The perceived high price of most of Western brands was revealed in the sentencecompletion tasks. The following are illustrative of consumers' responses.

Foreign brands always:

- $\quad$ are expensive, or

- $\quad$ are high-priced.

Foreign brands never:

- have lower prices than domestic brands,

- have big discounts,

- $\quad$ are cheap,

- save you money,

- compete on price with Chinese brands, or

- (always) have higher prices than domestic brands.

The greatest weakness of foreign brands is:

- too expensive, or

- high-priced.

The more foreign brands I have:

- the less I have left for my living expense,

- $\quad$ the more money I have spent,

- $\quad$ the less money I have, or

- $\quad$ it proves that a necessity of good taste is money.

If I lost my [foreign brand item] the worst thing is. . . .

- I will never be able to buy again.

Consumers' dreams included winning the lottery to obtain foreign brands, or receiving them for free.

Went to drink Coke, one glass of Coke after another, all free, and even met a beautiful woman! After drinking enough Coke, I would eat in McDonald's. I especially wanted to eat ice cream! As (with Coke) one big cup after another, free!

(25 year old male survey participant, Beijing)

The perceived difference between what is affordable and what is available in the absence of special, fantasized promotions was revealed in other dreams.

Foreign brands are getting cheaper, look better, cell phones are as available as pencils, and they are all miniature models. Buy one get 10 free, there are as many foreign brands as domestic brands. My favorite foreign music products are all very inexpensive. Everywhere there are famous foreign brand cosmetics, they are available anytime you need and they are all free.

(21 year old female survey participant, Baoding) 
I dreamed that Baleno are free to take, KFC are free to eat; Nokia buy the color shell get the cell phone free; Adidas buy shoe laces get shoes free; Panasonic buy earphones get CD player free.

(23 year old female survey participant, Baoding)

The more foreign brand products I have, the more money I spend. Dream: I dreamed that all the foreign brands in the world are free to take, but only for one day.

(22 year old male survey participant, Shanghai)

These dreams reflect that, although foreign brands are of limited accessibility, financial limitations do not pose obstacles to the fantasy of consumption. They also contextualize and underscore Croll's (2006) finding that the proportion of China's population able to afford and acquire Western brands is far from that envisioned by Western brand producers wishing to enter China's market.

We would not expect that the distinguishing features of Western brands in the eyes of Chinese consumers to be stable over time. Owing to competition from well-made high-end domestic brands, even some of these traits (for example, higher price or quality relative to domestic brands) are beginning to lose their ability to define Western brands. Further, as the number of made-in-China brands that become global increases, this characteristic too may be temporally limited as a basis for distinguishing Western brands. This suggests that should the category of "Western brands" remain meaningful to Chinese consumers in the future, the manner in which it is defined may change as shaped by a host of complex macrolevel forces.

Apart from for the exclusiveness or high price of Western brands, all of these distinguishing features would seem to lead to favorable meanings and responses to them. Yet, as we elaborate next, with this core set of attributes intact, meanings were quite varied in the emotional responses and behaviors they elicited from Chinese consumers. As we find, brand attributes, including their identity value promoted in advertisements, are not the sole source of meaning of Western brands. Rather, Chinese consumers employ national narratives of East-West relations to imbue Western brands with various meanings. 


\section{Chinese national narratives and the meanings of Western brands}

The emotional attachment of Chinese people to their national identity is deepseated and evolves from China's dynamic relationship with other nations, constituted largely by stories about the past (Gries 2004). Our Chinese participants' fantasies of Western brands drew from discourses on East-West relationships that form multiple competing national narratives that vie for Chinese national identity (Gries 2004). From this perspective, nationalism may be described as "an ensemble of discursive practices, functioning through interaction between historically changing fields of struggle and 'habitus' of discrete dispositions, in which ideologies are legitimated and delegitimated" (Liu 2004, 68). Our emphasis on national narratives as opposed to stories is deliberate and dictated by our Eastern context. Narrative is a term of rhetoric that encompasses the genre of story (Reissman 1993). Stories, as the dominant narrative form in Western social science research, embody a Western assumption about time marching forward. Other, often overlooked narrative forms include topic-centered narratives, which are stitched together by theme rather than by time, and are expressed as snapshots of past events thematically woven together; habitual narratives, which express events that happen over and over such that there is no peak in action; and, hypothetical narratives which depict events that could have happened (Reissman 1993). As reflected in our analysis, discourses about China's national culture that inform its members about how the group is related to foreign cultures take various forms and combine multiple narrative genres (Gries 2004; Zhao 2004).

\section{The West as experiential venue, Western brands as instruments of freedom}

In some dreams our participants praised the entrance of Western corporations into the Chinese market, imagined becoming more confident upon acquiring their brands, and dreamed of owning them as symbols of achieving a wealthy leisure class status. We return to a further analysis of dreams introduced in Chapter One.

[The more foreign brand products I have] the more confident I would feel about myself. Dream: In my dream, I drive a Benz car, wear a Swiss watch, 
and drive freely . . . how comfortable Nike tennis shoes are, how successful Samsung and BMW are, the Piao-rou [Pert] shampoo really has made my hair smoother . . After that, we go to eat at KFC, and while wiping our mouths we praise foreigners for coming to China and bringing convenience to our people.

(20 year old female survey participant, Beijing)

I became a rich person ... driving my own BMW sports car . . wearing Nike clothes and Nike shoes, I am on the green grass, holding golf clubs, swinging under the golden sunshine, with a happy smile on my face. Actually this is . . one of my earnest wishes. When someone owns all kinds of famous world brands, his life would be incomparably bright.

(20 year old male survey participant,Tianjin)

Compared to other fantasies, these seem to exhibit a historical amnesia. They bear no traces of the Maoist ideology of national self-sufficiency attained by building an egalitarian socialist society through collective self-sacrifice, as do ideological themes carried forward from the earlier National Products Movement (Gerth 2003). There are no nostalgic fantasies of Mao-era collectivism, nor are there any explicit themes of Mao-era suffering against which imagined indulgence in Western brand consumption is celebrated. Absent are the expressions of active remembrance that pervaded Chinese literary and political discourses during the 1970s and early 1980s (Wang 1996). These dreams entail neither reflections on the personal wounds inflicted during the Cultural Revolution nor the repressed memory of the "century of national humiliation" (Wang 1996; Gries 2004).

Despite appearances, these apparently apolitical fantasies of Western brands do reflect historical discourses disseminated under Deng Xiaoping's administration to bolster support for gaige kaifang. Gaige kaifang reintroduced foreign brands which, despite a strong presence in the early 1900s (Gerth 2003, 2008; Wang 2000), had been absent since the inception of Communist government in 1949. Gaige kaifang involved the abandonment of Mao's revolutionary idealism and an elevation of economic development in order to build a modern, marketoriented nation. The effects of Deng's reforms are in contrast to the devastated economic state of China following Mao's Cultural Revolution and the perestroika of Gorbachev that led to the collapse of Soviet-style socialism (Liu 2004). Since 1979, gaige kaifang has succeeded in bringing rapid economic development and material prosperity while maintaining the political status quo under the Chinese Communist Party (Liu 2004).

The absence of identity conflicts or ideological tensions in these stories is notable, as they reveal a desire for the individualized brands of Western capitalist corporations in China, where socialism, with its collectivist focus, is still the statesanctioned ideology. Yet this quality mirrors discourses introduced by Deng's administration, under which the contradictions posed by increased integration into the capitalist world were strategically downplayed (Liu 2004). One such strategy 


\section{Chinese national narratives and the meanings of Western brands}

was the positioning of the reform in terms of pragmatism rather than ideology (Liu 2004; Zhao 2004). During his tenure, Deng made a host of speeches prioritizing economic development while sidestepping debates about whether such development, undertaken via a fuller integration into the capitalist system, undermined and compromised socialist ideology (Liu 2004). Using vernacular language which resonated with both rural and urban workers, Deng condensed the state response to these ideological debates with The Principle of Cat and The Principle of Fumble, which were widely circulated in popular culture (Liu 2004). The first is an aphorism stated by Deng in the 1960s: "As long as a cat can catch a mouse, it is a good cat whether it is black or white" (Liu 2004, 52, quoting from Deng 1993, 105). Applying this to both dismiss ideological conflict and silence ideological debate, Deng reiterated The Principle of Cat in his 1992 Southern Tour talks: "Now the key issue is whether it [the reform] is named "capitalism" or "socialism." . . . the criteria for judging [the success or failure of reform] lie mainly in whether it benefits the productivity of socialist society, and whether it promotes the synthetic power of the state, and whether it raises the living standard of the people" (Liu 2004, 52-53, quoting from Deng 1993, 105). Under Deng's reform, performance legitimacy provided by high-speed economic development has taken the place of the revolutionary legitimacy of Marxism-Leninism (Zhao 2004). The Principle of Fumble, put forth in the 1980s, reflects upon the spontaneous and initially covert act of rural peasants, led by farmer Lao Zhang, to privatize the collective commune which provided the momentum for the reform: "[In launching the reform and opening up,] we've fumbled our way to cross the water" (Liu 2004, 52, quoting Deng 1993, 232). As an acknowledgement of the passivity of the Chinese Communist Party leadership in the economic reform from the beginning, this declaration credits the impetus to rural workers (Liu 2004). This discourse positions and bolsters the reform as emanating from the masses and modeled on their down-to-earth pragmatism (Liu 2004). Reinforcing the persuasive oratory strategy is a second mode whereby, in the spring of 1992, Deng announced a threeyear ban on theoretical discussions of the ideological nature of reform (Liu 2004). Critiquing this act, Liu (2004) noted that, ironically, it made questioning Marxism and socialism in China taboo.

Further reinforcing the public's receptivity to gaige kaifang have been state efforts to reframe and largely diminish historical moments that ran counter to market-oriented economic reforms (Zhao 2004). To illustrate, the late 19th-century Boxer Rebellion, one of the first nationalist calls to boycott foreign brands following Western invasions, had been considered a patriotic movement during the Cultural Revolution. After the launch of Deng's reforms, PRC publications criticized the movement as an "irrational and fanatic anti-foreign movement" (Zhao 2004, 55). Comparably, several of our interviewees highlighted the irrationality of expressing "nationalist emotions" by way of rejecting Western brands. Participants replaced such bases for decisions with judgments based on value, framing this as unemotional and rational.

When we like something, we don't want to involve it in nationalist emotions. 
... If the others' [foreign countries'] stuff is good, one should not consider political factors.

(33 year old interviewee, Beijing)

In the October following Deng's 1992 Southern tour talks, the Fourteenth Party Congress pledged that the Party and government would build "a Chinese-style market economy by the end of the century" (Croll 2006, 31). The announcement was significant in allaying consumers' fears over a possible shift backwards to another cultural revolution (Croll 2006). Whereas Croll (2006) noted that in the early years after economic reform Chinese consumers were reluctant to display and talk about their material acquisitions, we found many of our participants talked or dreamed of them with pride.

The dreams in our data exhibit the effects of the popularization of consumerist values which, Chinese cultural theorists reveal, has ironically been aided by the Communist Party's promotion of consumerism (Wang 1996). Some participants' fantasies appear to be fashioned after Deng's unconventional promotions that "Getting rich is glorious" and his counsel to "Let a part of the population get rich first" (Liu 2004, 62; Kuhn 2000). One participant echoes these themes in his dream where a life of wealthy leisure is his "earnest wish [because] when someone owns all kinds of Western brands, his life would be incomparably bright." Others dreamed of the type of "moderate affluence" which Deng established as the aspirational goal of the masses (Liu 2004, 62), suggesting that this could be attained only after some had achieved wealth (Liu 2004). Dreams of moderate affluence often featured a single Western brand which magically made its owner more cosmopolitan and desirable.

[The more foreign brands I have] the more internationalized I am personally ... Dream: At a clear autumn dusk, I lightly leaned against the big window that faced the open field and blue sky... [when] a Gucci silk scarffloated to me from the universe, and it gently landed around my neck. Extremely excited, I stood up, . . . then a pair of soft but powerful arms held around me from behind, and a sweet kiss fell on my neck.

(20 year old survey participant, Beijing)

As silk has been an iconic domestic product throughout China's history (Hamilton and Lai 1989), ambivalence towards domestic brands is expressed by this participant, who opens her window to "the universe" to receive a Western brand silk scarf, which she greets with excitement and appreciation. Her acceptance is accompanied by a feeling of being enveloped by a powerful but protective and gentle liaison. At one level the kiss and the envelopment represent stereotyped western style boldness and romance, as Chinese tradition makes such an act embarrassing. At another level the envelopment reflects an immediate magical transformation into a more socially desirable self. At a higher level, it conveys a liberating access to a broader world backed by a powerful, friendly supporter. The dream echoes the prevalent 1980s view of the West as a beautiful imperialist that frees Chinese 
consumers from the restraint of traditional values of sacrifice and a simple lifestyle (Gries 2004).

Participants' dreams entailed fantasized freedom in many forms. In one form, the Chinese body (shen ti), which is also the self (Tung 1994), was imagined as being freed by Western brands. For example, a dream of an extraordinary basketball performance aided by Western branded goods transformed Chinese athletes into freely moving bodies. Such dreams highlighted having fast, spontaneous fun, involving continual rapid decisions, made on the spot. The action-oriented bodily movements associated with Western branded goods is perhaps reflective of a broader sense of a freely moving self. This self is experienced from a sociohistorical perspective in which Chinese individuals were restricted to particular geographical regions and where travel outside domestic boundaries was limited. Dreams of traveling freely within and outside China were common. Notably, China's domestic tourism industry was spawned following gaige kaifang as part of government initiatives to stimulate domestic consumption (Croll 2006).

I was driving a Buick, flying fast on an empty road ... We were now fast, now slow, went through city after city, arrived in Tibet of my dreams.

(23 year old female survey participant, Tianjin)

Foreign brands lowered their prices, and they are all authentic brands. Whichever country the brands are from, lucky customers will all have the luck to enjoy traveling to that country.

(20 year old male survey participant, Beijing)

Consuming foreign brands as a symbolic act of crossing the boundary between home and the wider world gives rise to fantasies of a more literal boundary crossing, and also to an experientially freer self. Anthropologists reporting on Chinese consumers' reactions to the first McDonald's in Beijing similarly note that, for many, McDonald's was seen as a gateway to the world (Yan 2006).

As another form of fantasized freedom, participants praised Western corporations and their brands for freeing Chinese consumers from restrictive ways of thinking. Western brands were seen as introducing Chinese consumers to new practices or new ideas. In the following examples, the Oil of Ulan brand (known as Oil of Olay in the Western) is animated as a fashion consultant who offers instructions on how to succeed in the recently created job market (in contrast to the government-assigned jobs of the past). Likewise, the humanly wise Microsoft brand introduces new knowledge, thoughts, and experiences.

I was going to the interview, and I was so nervous at this time, I wanted to try to dress myself appropriately . . . However, I . . knew nothing about cosmetics, and I was really stuck. . . Suddenly my Oil of Ulan [Oil of Olay] turned into a little angel, and she naughtily asked me, "Why are you looking blank? ... Thus I told her my problem. The little angel just said one thing "leave everything to me, the Oil of Ulan little angel. Within a few minutes, I will 
turn you into a beautiful little angel." Then she started applying her skills on my face ... within a few minutes, the me in the mirror was totally a different person: "Youthful, beautiful, white, and flawless." I was very satisfied ... I thanked the little angel, immediately went to the interview place. I believed that, with the encouragement of Oil of Ulan, I would surely be extremely confident and perform well.

(22 year old female survey participant, Tianjin)

Microsoft turned into a young, energetic, and knowledgeable wise person. He took me into the Microsoft world... I wanted to see the sea, he would... give me a virtual experience of being there. Then I wanted to know about the universe. He could give me a totally new thoughts and feelings.

(23 year old male survey participant, Tianjin)

A host of Western brands were imagined as setting free assertions of the self. Some saw the transformative powers of Western brands as rendering them capable of better performances, an esteemed "star," or more cosmopolitan world travelers who gained access to new experiences.

Several major famous brands that represent luxury and extravagance were all owned by me at the same time. While having these, it seemed like I became a star, wearing Rolex watch, dressed in Chanel clothes, driving Benz car ... It may be only a daydream, but I'm still very happy...

(20 year old female survey participant, Beijing)

When I get married, I am wearing a Chanel wedding gown, Christian Dior shoes, DeBeer's diamonds, riding in an extended model Cadillac, and going to Europe for my honeymoon - to Paris, Milan, London, and New York. I go shopping and buy LV handbag, Prada purse, CK [Calvin Klein] clothes, and Poison perfume. And I also go to the longed for Disney Land, European theme parks, and the global movie city [Hollywood] in Los Angeles... Such a beautiful dream.

(21 year old female survey participant, Beijing)

As noted by Croll, this view of Western brands as delivering freedom has emerged against the backdrop of uniformity that characterized the early years following reform.

It was not long before consumption came to symbolize a novel and immediate freedom after years of controlled scarcity so that the defining features and categorizations of the revolution - of work, occupation, blue-trousered comrades and class origins or class labels - soon gave way to new lifestyle practices, perceptions and self-perceptions substantiated by consumption goods and services. 
Jeans were a symbol of independence against a background of blue Mao suits that conveyed the notion of a solidly grounded and conforming citizen (Croll 2006). Difference was also symbolized in that Western fashions displayed the contours of the body in ways that the Mao suit could not (Croll 2006). Although the suits common during the 1950s to 1990s are known as Mao suits in English, they are known to the Chinese as Zhongshan zhuang, named after Dr. Sun Yatsen, the founder of the Guomindang, the ruling party of Taiwan. Although these suits were modern compared to the traditional Chinese robes still worn in the early 1900s, in the postreform period they were considered outdated.

Likewise, clothing, jewelry, and cosmetics were used to construct a new gender identity that contrasted with the image of the Mao-era Iron girls dressed androgynously in the unisex blue suits (Croll 2006). Western brands in these product categories provided a sense of freedom and movement, as consumption represented movement toward a desired identity. They were used to "become [feminized] women," to reject the past, and to move towards becoming more progressive, cosmopolitan, or global (Croll 2006). The quest to transform identity through consumption is the distinguishing mark of a consumerist society that supplants a society of producers (Bauman 2007).

The symbolism of some dreams further depicted Western brands as freeing Chinese from a devastated economy, as exemplified by their offering a foundation that sustained survival and a solid platform to support upward mobility. For others, the presence of Western brands transformed them from desperate seekers in the barren desert into "hopeful" survivors of a plush land.

A person . . is deserted in the desert, thirst and hunger make him feel the threat of death, he is desperate and starts digging in the sand, digs and digs, finally he digs out a box.... there are five cans of Pepsi with a note: wherever you are, you always have my support. He feels the warmest thing in life, and ... finds the green land and regained life and hope.

(survey participant, no demographics provided, Baoding)

On a bright afternoon, my friend and I went to climb the Great Wall. We hiked for a long time, then my friend found that her shoes were broken, the sole was worn out. And my shoes ... weren't ... I proudly told her that I was wearing Nike. Nike adds splendor to my steps.

(23 year old female survey participant, Tianjin)

Shaped by Deng discourses in which wealth and consumption by the few lead to improved living standards for the masses, assertions of individuality and identity transformations in China cannot be compared to those in the West. Rather, they are more akin to findings in other cultural contexts that individual display is also pursued for the symbolic and economic value it confers on the collective to which the individual belongs, and with an eye toward how conspicuous consumption influences collective outcomes (Miller 1994; Rowlands 1994; Wilk 1994). The following survey response to one of our sentence completion items sums up this perspective. 
[The more foreign brands I have . .] the more it shows that our country is emerging in international status and our economy is moving forward.

(survey participant, Beijing)

The view that Western brands offer a source of national pride makes sense in light of China's efforts to gain entry to the World Trade Organization (WTO). In this endeavor China's Minister of Foreign Trade emphasized the large market potential for imported goods, as did China's chief negotiator for WTO entry (Croll 2006, 13). Whereas the notion of a consumerist society has been held to involve the pursuit of individuals' desired futures (Bauman 2007) here we see consumption as the pursuit of visions of a collective future.

\section{The West as imperialist oppressor, Western brands as instruments of domination}

Other dreams reflect a national narrative in which the West is deemed an imperialist oppressor and Western brands are instruments of domination. Although here we trace the history that keeps this meaning of Western brands alive in China, it is important to note that this meaning does not view those who have not "caught up" to the ideological shifts endorsed by the state as "backward" (Wilk 1994). Such "backwardness" is often attributed by a well-traveled cultural elite claiming to be cosmopolitan, to rural dwellers or those less well educated (Friedman 1997). Yet, as Wilk (1994) has noted, these assertions break down with exposure to Western views, values, and fashions, aided by global media. Cultural elitism underpinned by global travel is diminished as access to information becomes widely available. Notably, the "oppressive" meanings of Western brands came from university students and professional workers. Reflections of this can be seen in the writings of China's intellectual elite. For instance, the 2009 China Brand Report described Johnson \& Johnson's acquisition of Dabao, a Chinese skin-care brand since 1985, and its acquisition of Huiyuan, a Beijing-based fruit juice brand launched in 1994, as "national brands falling into enemy hands" (Yu 2009, 44). The acquisition caused concern among Chinese consumers and brand scholars that Chinese brands would disappear. The owners of those acquired Chinese brands are further criticized in the report as "betraying [the national industry]" to "maximize financial gain" (Yu 2009, 46-47).

In our data, the expressed meanings of Western brands as instruments of domination ranged from subtle symbolic implications to explicit pronouncements. The subtler dreams of Western brands as instruments of imperialist oppressors resemble those that draw from the narrative of the West as liberator, in that they too entail imaginings of a self which revels in a seemingly unbounded consumption of Western brands. Yet expressions of gratitude are absent. Without directly challenging Deng's discourses, these dreams convey a longing for iconic Chinamade goods and a more materially simple life, reminiscent of Maoist ideologies of national self-sufficiency and anti-consumption, which echo discourses of the earlier National Products Movement (Gerth 2003, 2008). 
In my dream I come to a palace, where every column is a Western brand name. The words on the columns mean to invite me to participate in a game. So according to the game rules, I devour every brand just like a worm eating beans . . . Then I come to a big door behind the palace, open it, there is the prize for my winning the game. The room is filled with Western brands, for home use, including electronics, basic commodities, cosmetics, expensive clothes. But before consuming them, I hope to make a last request of the game designer: please give me a pure silk sleeping gown made in China, because it is very comfortable, and I believe I'll feel very peaceful in it.

(20 year old female survey participant, Baoding)

My friend dreams that she is wearing clothes of famous foreign brands, using daily life products of Western brands, and she happily goes back home, just to see the low and old house, and her hard-working and simply-dressed parents. It is not realistic to blindly pursue or admire foreign brands.

(survey participant, no demographics provided, Baoding)

In the palace dream above, an image of Western imperialism is detected where Western corporations set the rules of the (marketplace) game. Within the Western palace, consumption is rewarded with further consumption. The dream's moral coda - that comfort and peace can only be found in a silk sleeping gown from China - introduces a subtle renouncement of Western brands. Notably a luxury product, the nightgown is not for conspicuous consumption. This renouncement challenges the perfect image of the West as the beautiful liberating imperialist (Gries 2004). This interpretation can be compared with the earlier dream in which the silk gift from an "open universe" is a Western brand Gucci scarf, which the consumer greets with excitement. Like the palace dream, the dream of happily returning to the materially simple home also suggests an ambivalence toward Western brands. Neither dream, however, contains expressions of anxiety over the absorption of China into the global system which might evoke a revolutionary discourse or a desire for intervention and resistance. Rather, they reflect a surface conformity to a particular nationalist discourse wherein revolutionary legacies are elided with debates in China in order to promote economic development (Gries 2004; Liu 2004). Chinese cultural theorists suggest this silencing of revolutionary discourse is symptomatic of a triumphant global capitalism (Liu 2004). Deng's pragmatic nationalism is not, however, a hegemonic narrative because the state has been unsuccessful in reproducing social cohesion and a broad alliance of the general public (Liu 2004). Greater social and economic polarization, a condition recognized in the returninghome dream of the Baoding participant, has led to discontent (Wang 2008).

The emergence of repressed discontent in these dreams parallels comments from our interview participants who likewise questioned the pursuit of Western brands. Several lamented that "Chinese still believe in foreign things."

I think Chinese are too stubborn in this respect. Everybody thinks this way, that anything Western is good. But I think it [valuing Western brands] will 
have some negative influence on my family in the future. I won't influence them towards these things.

(23 year old female interviewee, Beijing)

Further, some participants responded to the sentence-completion tasks in ways that exhibited a disdain for Western brands.

[The more foreign brand products I have. . .] the less happy I am because I hope Chinese national industry will have greater development.

(25 year old male survey participant, Beijing)

[The more foreign brand products I have...] I don't think this is something to be proud of. Besides, I won't do it.

(19 year old male survey participant, Beijing)

In other dreams imaginings of Western brands as instruments of Western domination were quite pronounced. Many envisioned Western brands as a form of attack from the outside, or as an invasion from within, thereby enslaving Chinese people.

[The more foreign brand products I have] the harder the blow is to domestic products ... Dream: In the world of foreign brands, King Valentino and Queen Lancôme bring their daughters Head \& Shoulders and Colgate, and their sons Nike and HP, to ride a Goodyear airship ... with Coca Cola as fuel. Holding a big flag of Safeguard, cruising on the Fifth Avenue [a fragrance brand], with the help of Angels, Pampers, and Nokia, they are planning to launch an all-round attack on the Chinese market!

(survey participant, no demographic data, Baoding)

Foreign brands swept China's market as if they would block out the sky. Domestic products had no foothold. We had to purchase some of the necessity products with surprisingly high prices. Horrible!

(22 year old female survey participant, Beijing)

[The more foreign brand products I have] it shows that domestic products are not popular. Dream: A certain brand comes to inhabit a person who will destroy us all. Therefore, we cannot "worship Western and fawn foreign."

(survey participant, no demographic data, Baoding)

Last night, I had a very scary dream. In the dream a big department store put out a new type of imported toy, a kind of mini robot. Its size and shape is similar to a Barbie doll, but this kind of mini robot could have simple communication with humans. It could tell stories, sing various songs, more importantly it could walk like a person, and could release electricity to protect its owner at dangerous times. What's more, it constantly releases a light soothing scent. 
Since it had so many advantages, it became very popular in the whole country, especially among teenagers. This kind of robot was seen in all streets, some walking with their owners some standing on their shoulders, some even crawling over their heads, proudly giving directions. Time goes by day by day. The robots had terrible changes. They grew taller and taller, and the purchasers of the robots became exhausted and they grew smaller and smaller. What's worse, while the robots grew bigger in size they started making copies of themselves like cancer cells, crazily proliferating. Finally everyplace was packed with the vicious and plump robots, whereas our poor fellows were enslaved by them.

(20 year old female survey participant, Beijing)

War metaphors were prevalent in the literature of the National Products Movement, which sought to link patriotism to the rejection of Western brands (Gerth 2003). As Gerth $(2003,2008)$ notes, this movement paved the way for Mao's communist rule by establishing the market as a domain within which to assert the collective interests of the nation. In calling for the protectionist principles of the earlier nation-state, these dreams reflect Maoist nationalist sentiments. Contrary to assertions that in Marxist theory nationalism is an anomaly, Mao established a Chinese Marxism that was integrated with nationalism (Zhao 2004). His project of an alternative modernity opposed both Western capitalist modernity and China's old imperialism (Zhao 2004). In Mao's discourse on nationalism, Confucianism also was vilified as it represented the ideological hegemony of the imperial rulers. Rejection of Confucianism became an integral aspect of Mao's construction of nationalism (Liu 2004). In the early 1990s, when the CCP attempted to foster a sense of national unity, Confucianism was revived and celebrated as a common and unifying cultural heritage, at the same time as Mao was resurrected as a national hero (Gries 2004; Liu 2004; Zhao 2004). Mao's vision of an alternative modernity was based on an ideological and cultural revolution grounded in egalitarianism, economic self-reliance, and a one-party political system sustained by democratic centralism (Liu 2004). Mao's attempt to realize this vision has been interpreted as a powerful counter-imperialist movement during the formative years of capitalist globalization (Liu 2004).

Liu's (2004) analysis details the use of Maoist revolutionary ideology as a legitimating force for the CCP as follows. As the pragmatism that epitomizes Deng and post-Deng administration has undermined Marxism and socialist ideals, the CCP has sought new means of acquiring legitimacy. One way has been to use Mao's image as a cultural symbol while separating it from its revolutionary meaning. For example, the Deng administration financed a flourishing revival of Mao-era qunzhong wenyi (folk art). Mao introduced these practices during the Cultural Revolution to encourage the Chinese people to participate in folk arts so as to overcome the superiority of bourgeoise culture. The cohesiveness developed by present-day re-enactments has since been channeled toward Deng's development agenda through discourses of "national spirit" and pride in attaining "moderate affluence" (Liu 1994, 62). The re-enactments emphasize a national identity 
constituted by symbols of nationhood, shared historical experiences, and a common language. Related to this strategy, official CCP discourses which consider the Cultural Revolution a tragedy largely exempt Mao and pass the blame to his advisors ("The Gang of Four") who manipulated him. The use of Mao's image was also evident in some of our participants' discourses.

Our knowledge about brands came from practice. The Chinese Chairman Mao Zedong once said "True knowledge comes from practice." Take the t-shirt my husband brought back from Japan for example, it didn't wear out until after eight or nine years of wearing... I bought a watch from Japan. It had a seven year warranty. And the battery lasted for seven years before it needed to be replaced. Even now grandma is still wearing it. It's been eleven years.

(46 year old female interviewee, Tianjin)

The revival of Mao's cultural legacy holds the potential to awaken protectionist sentiments. Incidents of Western confrontations which pose new threats to the identity, interests, or integrity of China often provide the impetus for the reconstruction of nationalism (Zhao 2004) and invocations of protectionism.

\section{Western brands as weapons of cultural dominance}

Some dream fantasies of Western-initiated war and invasion seem metaphorical and participants' concerns that an authentic Chinese culture is on the edge of demise. The fantasies share a common plot in which the Chinese consumer is seduced by lures of individualism into Western brand consumption and becomes displaced from Chinese culture, which leads to her/his demise. These dreams mirror a narrative in which Western corporations are motivated to dominate or destroy China's culture and undermine its national identity.

[The more foreign brand products I have] the more it marks my own "value." Dream: One day, Lao Zhang was driving a BMW car, and he suddenly entered ancient times, where people were all surprised and wondered: what is this thing, why haven't we seen it before? Then they asked Lao Zhang what it is. Lao Zhang answered, this is my Precious Horse [BMW's Chinese name]. Someone said, I also have a precious horse, why do they look so different? Lao Zhang said, my Precious Horse is very fast, that person said, let's race. Lao Zhang agreed and they got started. . . In less than two seconds, Lao Zhang's Precious Horse was out of sight. Everybody said, it's really so fast. Suddenly he heard a [warning] scream [from them], there's a cliff ahead!

(21 year old male survey participant, Beijing)

This participant reflects ironically on the destruction of the Chinese self with Western brand consumption, which commodifies people (marks their "value"). In the dream Lao Zhang serves as a metaphor for the centuries-old cultural icon Zhang Guo-lao, the Chinese god of immortality, who is known to always ride on 


\section{Chinese national narratives and the meanings of Western brands}

the back of a donkey. The participant reiterates the theme of destruction of the collective self by imagining this god being seduced to give up his traditional transportation, the donkey, and adopt the "precious horse" (the Chinese name of the BMW brand). Adoption of this status good forces him into a perilous and destructive high-speed competition. One of the most common names in China, Lao Zhang stands for the farmer credited with the first act of privatization in China (Liu 2004). Likewise, as an iconic symbol of the masses being drawn towards privatization, Lao Zhang renders the interpretation one of cultural demise, central to which has been the rapid commodification of people. As critiqued by cultural theorists, in the emerging fashion, modeling, and commercial job markets Chinese individuals now position, brand, and sell the self (Brownell 2001; Hoffman 2001). In this dream the consumer as god also recognizes the practice introduced into China's emerging upmarket retail stores during the mid to late 1990s, where management taught their staff a new maxim: guke shi shangdi, which means "the consumer is god" (Croll 2006, 40). News reports of the introduction of Western brand stores in publications such as Beijing Scene quoted consumers who claimed that the "pleasant shopping environment and better service really did enable shoppers to feel like gods" (Croll 2006, 40). The above survey participant warns that although Western brand acquisitions may offer a sense of godliness, they can also lead to demise.

In some dreams, the loss of culture at the hands of Western brands was conveyed as a loss of self for the Chinese consumer.

One day, Ronaldo drove a Benz to my home and said, "The car is yours. Bye." Then I arrived in a grand stadium in France. I suddenly turned into an Adidas ball, and Trezeguet kicked me against the post again and again.

(21 year old male survey participant, Shanghai)

In this dream, overt seduction through the offer of high-status luxury goods is followed by abandonment, cultural displacement, transformation of the self into a commodity, and then torture. Still others convey a sense of being drawn into Western brand consumption, with faint suspicions that the Western brand seducer is a thief or a bandit. Nonetheless, they imagine being unable to resist an ironically involuntary sense of freedom.

[The more foreign brand products I have] the higher standard of living I have. Dream: Clear and bright moonlight beams into the room through the open windows, sprinkles all over the room, and sprinkles all over my bed. My body feels like flying up, I know that I'm flying with help from someone. The fragrance of Chanel is floating in the air, I want to resist, but can't, because I like flying in the perfumed rain. I don't care whether that someone is a thief or bandit, I like flying like this, on and on.

(20 year old female survey participant, Beijing)

As symbolized by the mistrust and hesitancy that belie the pleasure and freedom of "flying in the perfumed rain," for some, the promises of freedom embodied in 
Western brands is an artifice to charm Chinese consumers from their traditional culture. Such themes are reminiscent of a popular film of the mid-1990s, "Ermou." The film featured a young woman village entrepreneur who sold noodles and her blood to save for a large television set. The television is so large that it displaces the family from their bed and, "still with its price tag visible, is watched by the whole family and admiring village neighbours" (Croll 2006, 51).

Still other dreams recognize the entertainment industry as a significant force fueling capitalist globalization in China. Yet, abandonment and loss of self nonetheless ensue.

One day, a man fortunately was chosen to be the celebrity of several different Western brands. Having a large number of fans, he could also enjoy using those Western brands. . . Just when he was enjoying life so much, bad news came, [the foreign companies] . . terminated their contract with him . . . Therefore, within a night, he became a common person, nobody wanted to talk to him anymore, he became so lonely and scared, running with no direction.

(19 year old male survey participant, Beijing)

In numerous dreams participants imagined the domineering force of Western capitalist corporations and their insistence on material acquisitions. In the aftermath of such acquisitions, Chinese cultural life was often imagined as eroded to a narrow preoccupation with the disposition of accumulated Western brands.

[The more foreign brands I have] it shows I have some trust crisis towards domestic products. Dream: A sales representative from Adidas sent me a truck load of basketballs. I didn't want them, because I don't like playing. They said no (I can't refuse), if I didn't accept the truckload of basketballs, they would bury me alive with those basketballs! . . Since then, my family has been living nervously in a basketball flood: a basketball placed on the TV; a couple of basketballs would jump out when opening the fridge; even when we eat, we would sit on basketballs instead of chairs! How to get rid of the basketballs has become the main goal that my whole family tries to achieve.

(22 year old female survey participant, Beijing)

Other participants conveyed concerns that Western brand promotions altered cultural notions of what was aesthetically pleasing.

I think media has some influence on our aesthetic judgment. When I was a child I read a story called "What's Beauty?" It said a pale skinned good looking boy didn't do any work, so he wasn't beautiful at all but an iron-molding young man was working under the sun and exposed his bronze color skin. That is the beauty of working people. It had a very deep impression from a young age. But as time goes by, we've been exposed to Western ads. We've seen the beauty of Miss Globe, Miss Hong Kong, we know, "Oh, that kind of look is beautiful." Media has an unobtrusive influence.

(25 year old female interviewee, Beijing) 
Concerns expressed in these dreams parallel popular press reports that the presence of Western brands is corrupting, contaminating, or diluting Chinese culture and cultural space. In Chapter One we recount the controversy that followed the opening of Starbucks in the Forbidden City, which was deemed by many to be damaging to China's heritage (People's Daily 2000). In the burgeoning tourist industry spawned by gaige kaifang, Starbucks was part of the Forbidden City administrators' attempts to improve service. Since the 1990s culture has repeatedly been a battleground in popular discourses, as clashes between Deng's development strategy and China's espoused socialist ideology have become more apparent (Liu 2004). These clashes have been attributed to the absence of a clear vision of the social and political values of gaige kaifang (Liu 2004). Such ambiguity initially aided the acceptance of economic policies (Liu 2004). Subsequently, in a reversal of the 1980s fascination with the West, this ambiguity intensified the legitimation crisis of the Deng administration (Gries 2004).

Dream imaginings of a Chinese culture under attack and invaded by Western brands reflect a historical embellishment of brand fantasies (Martin 2004) with what Chinese political and cultural studies scholars call China's re-emergent "victimization narrative" (Gries 2004; Liu 2004). This narrative is reportedly popular among China's fourth-generation "revolutionaries" (Gries 2004), who grew up during the 1980s and 1990s under the relatively material prosperity that followed gaige kaifang (Gries 2004). Each preceding generation had suffered a form of vicitimization. The Red Guards of the third generation were sent to the countryside during the Cultural Revolution of the 1960s and 1970s; the second generation suffered the Great Leap Forward of the late 1950s; and, the first generation suffered the anti-fascist and civil wars of the 1930s and 1940s (Gries 2004; Liu 2004). Encouraged by a number of popular nationalist diatribes (Song et al 1996a, 1996b), some fourth-generation Chinese see the takeover of China's culture as their generation's victimization (Gries 2004). Not incidental to the formation of this narrative were the Chinese Communist Party's 1990s campaigns of education in patriotism, launched as a response to US sanctions which followed the 1989 conflicts. Tied to a narrative in which China was presented as besieged, the Party's campaign called for national unity under one-party rule and territorial integrity (Zhao 2004). These patriotic values were fomented by a shared Chinese history. Through this campaign, Chinese tradition, which the Communist state had attacked for years, became an essential value of nationalism; the Communist Party restored ancestor worship, celebrated the Great Wall as a patriotic symbol, and revived Confucianism (Zhao 2004). Government efforts to revive and preserve Chinese tradition continue today, as evidenced by the addition of two traditional festivals (Mid-autumn and Qingming) as national holidays, beginning in 2008 (Croll 2006). These national holidays serve a dual purpose, as they are often declared to promote leisure time and occasions for consumption (Croll 2006). 


\section{Western brands as weapons of military dominance}

In concert with our dream data's more explicit expressions of "attack" and "invasion," the victimization narrative also entails the traditional militaristic meaning.

[The more foreign brands I have] the less I am like a Chinese. Dream: The Western brand turns into a person and he is Napoleon or Hitler, holding his iron rod and marching over the earth. Wherever he passes, dead bones are scattered all over the ground. White bones fill the streets, not even a chicken is left within thousands of miles...

(21 year old male survey participant, Shanghai)

The concerns apparent in this dream and others were fueled by the 1999 NATO bombing of the Chinese Embassy in Belgrade, the 2001 US-China standoff over the American spy plane which collided with a Chinese jet fighter, US arms sales to Taiwan, the deployment of the National Missile Defense, and US reports that China poses a threat to world order (Gries 2004; Liu 2004; Zhao 2004). These incidents, which are often publicized as threats to national security, prompt more overt attempts by Chinese institutions and individuals to politicize Western brands and their consumption. Following the 1999 American bombing incident, for example, public protests challenged American media reports that the bombing was an accident, framing it instead as an intentional act aimed at undermining China's international image and power (Gries 2004). Public protests further framed the bombing incident as linked to China's semi-colonial past, to suggest that China would not allow the long series of Western aggressions to continue (Gries 2004; Han 1999). Blog postings on the Guangming Daily website criticized the consumption of a host of Western automotive, clothing, fast food, electronic, and computer software brands and called for Chinese companies to revoke contracts with American corporations (Gries 2004). In concert, Chinese corporations pledged online promises to halt business relationships with companies such as Microsoft (Gries 2004; Liu 2004). In protests which erupted in over two dozen major cities, Chinese individuals carried signs saying "Kick American hamburgers out of China," alongside placards declaring "Punish the war criminals!" (Gries 2004, 14).

In some discourses, American goods were seen as the ultimate source of funding for the US military (Liu 2004). Calls for boycotts made much of the large numbers of Chinese upon whom Western corporations relied for profits, and called for Chinese unity in order to amass power in numbers (Liu 2004). Some Chinese consumers' discomfort over the presence of the Toshiba ad at the National Day ceremony (see Chapter One) can be better understood in the light of this linking of foreign brand success with foreign military power.

In our participant's dreams parallel themes exist that call attention to the power of individual choice when replicated across the nation. Some dreams linked individual choice of Western brands to an imagined apocalypse for the population of China. A fuller analysis of the apocalyptic theme of one of the examples in Chapter One follows. 
I'm driving a BMW, listening to Sony music, drinking Coca Cola, and come to a wild and empty place. With Nike shoes on my feet, I run like crazy, running, running. On the grass, beside the tents, there are many red flags with five stars (Chinese national flag), around them are herds of cows. Many workers are milking the cows, they milk like crazy. Up in the sky, floats a slogan "Bright Dairy" (a Chinese dairy brand) ... The workers are dying one after another ... I have sold all my foreign brand products including my BMW and Sony video camera etc.!!! Then I buy "Bright" milk to feed pandas.

(23 year old male survey participant, Baoding)

In his fantasy of renouncing Western brands in the interest of the common good, this participant clarifies the values of gaige kaifang while alleviating the threat of the undesired identity transformation it poses. Mao's revolutionary discourses called attention to the exploitation of individuals at the hands of global capitalists (Liu 2004). From this perspective, individualization through the accumulation and display of Western brands resulted in a loss of face, that is, a loss of social esteem. In his dream of "Bright milk," the Baoding participant pre-empts this loss of face by renouncing Western brands and taking up production with the collective. His goal of aiding the survival of the indigenous culture with domestic production is embodied in feeding "Bright milk" (a domestic brand) to the panda, an iconic endangered but protected species. In other dreams, the loss of face or esteem is somatic, symbolized by disfiguration of the physical face (Tung 1994). May Tung's (1994) analysis of the meanings of the body and its parts in Chinese culture notes that the face is closely related to social honor and position, as well as one's self-respect.

In the dream, I saw myself wearing Beaty clothes, holding a Chanel handbag, wearing Red Earth cosmetics on my face, Shi-si shoes. Suddenly, it started to rain, I ran forward, then my shoe sole broke along with the tearing sound of the clothes. I tried to run home, looked into the mirror, found the "waterresistant" cosmetics ruined by the rain, and I became a big colorful cat. Thus I threw them away, never sought after Western brands.

(18 year old female survey participant, Beijing)

In this dream the storm that follows consumption of the Western brands makes returning "home" a challenge, as the consumer's face has been ruined. The loss of face expressed here as becoming a "big colorful cat" implies social embarrassment as a result of consuming Western brands. The term "colorful cat" has long been used by Chinese to describe the dirty face in a loving tone. As a discursive text, the dream offers parallel images to those comprising Deng's Cat Principle. Such parallels lead to speculation over whether or not the dream implicitly contests this principle, which dismisses the color of the cat as insignificant, and by association also dismisses the debate about whether gaige kaifang is capitalist or socialist in nature (Liu 2004). Whereas the Cat Principle delivers the moral that if the cat catches the mouse it is a good cat, regardless of its color (Liu 2004), this 
participant sees that the performance criterion (that is, an outcome-driven assessment) can have an undesirable impact. One interpretation of the colorful cat image is that it depicts gaige kaifang as individualistic, capitalistic, and undesirable. In other dreams, somatic symbolism was expressed as the loss of sweat and blood "sucked out" by Western brands, or as contamination or deterioration of the body, as representation of the self (Belk 1988; Gerth 2003; Tung 1994).

The market is glutted with foreign products and the packages are all covered with foreign languages. . . Many domestic products are overstocked, national enterprises bankrupted, and workers laid off. Horrible, too horrible. I can't determine my nationality while in the sea of these foreign products.

(survey participant, no demographic data, Baoding)

I use L'Oreal moisturizer . . Sassoon for my hair, and . . . Lforeign brands for hair color, underwear, sweaters, and perfume] slowly I walk into Starbucks. My boyfriend is wearing Adidas . . our faces . . . so obviously possessing Chinese characteristics - yellow skin, black hair, black eyes. Is this an inevitable outcome of the world's grand assimilation, or is it the sadness that we have forgotten about our own national industry and blindly crave foreign brands.

(23 year old female survey participant, Tianjin)

After Microsoft escaped from disintegration, it expanded with a faster speed and learned its lessons, started to control the government so that it would not be sued again. . . Not long afterward, governments of all countries in the world are under its control . . . Political imperialism was established.

(20 year old male survey participant, Beijing)

Notably the vast majority of those who drew on a narrative of the West as imperialist oppressor for their brand fantasies were residents of Beijing and Baoding. Certainly, the presence of military forces in Beijing would be expected to heighten attention to militaristic discourses of East-West relations. Further, the presence of numerous heritage sites there which benefit from an international tourist trade would render this city's cultural space more frequently contested. The relatively rural and smaller Baoding possesses both of these characteristics. As "the southern gate of Beijing," Baoding has been an important military center since Beijing was established as the capital of China in 1421, and now hosts one of the most important military bases. Baoding later became the home of the first Military Training School in China, which was founded in the late Qing Dynasty (1902) and many of whose graduates were key players in China's recent history (for example Chiang Kai-shek). Later, from 1949 to 1958, Baoding was the capital city of Hebei province. In addition to the military significance, like Beijing, Baoding is also a city of historical cultural significance, as half the tombs of the Qing Dynasty emperors are scattered in the surrounding hills. Unlike those from port cities, residents in these two cities have more exposure to and knowledge of China's recent history, 
and have adapted to competition, drawing from military experiences as the only accessible, relevant history tied to foreign competition (Kuhn 2000).

\section{The West as subjugated, conquered Western brands as redemption}

In many dreams, participants fantasized scenarios of restoring national pride by conquering Western brands in the market. Underpinning such fantasies is the revitalized cultural memory of China's century of humiliation at the hands of Western imperialists (including Japan). This remembrance draws from a victimization account in which the Chinese plight is often referred to as luohou aida, interpreted as "the backward will be beaten" (Gries 2004, 50-1), which explains China's defeat as resulting from economic and technological backwardness (Gries 2004). The legacy is one which many Chinese individuals seek to erase (Gries 2004; Zhao 2004).

Foreign brands turn into rows of soldiers with knives, and pour in fiercely. But with the resistance of superior equipment of domestic brands and the nationalist spirits of Chinese people, they are defeated and withdraw.

(survey participant, no demographic data, Baoding)

[The more foreign brand products I have] the more I feel lack of national self-esteem. Dream: . . . Domestic brands enter into the international market and achieve good results. Chinese people hence no longer look down upon themselves. The Chinese economy soars. Every Chinese voluntarily supports state enterprises and Chinese enterprises. Our reputation gets better. What Westerners can do, Chinese can also. What Westerners cannot do, Chinese can also. We have been suppressed for too long.

(survey participant, no demographic data, Baoding)

Chinese products' quality improves very fast.... Then ... I come to Las Vegas of America, take Chinese products with me, and hold a Chinese product press conference. I compare them with American products on the spot, and immediately beat the foreign products, winning honor for China...

(24 year old survey participant, Beijing)

Narratives that seek to redress China's past humiliations draw from national discourses of victimization which emerged at different historical moments, spanning the 1894-95 Sino-Japanese War until the British return of Hong Kong "to the Motherland" in 1997 (Gries 2004, 49). Following the Sino-Japanese War, humiliation was experienced by the Japanese imposition of the Treaty of Shimonoseki, which forced China to cede Taiwan, the Pesadores, and the Liaodong Peninsula, as well as opening up a specific section of the Yangtze River and the Ports of Shashi, Chongqing, Suzhou, and Hunkou to Japanese trade (Zhao 2004). Although this victimization narrative was slightly diminished by Mao's China-as-victor 
discourses, Gries (2004) suggests it has been revived by bestsellers such as The Rape of Nanking (Chang 1997). This work and others documented World War II atrocities committed against Chinese civilians at the hands of the Japanese military, which the Japanese government did not acknowledge (Gries 2004). Also woven into cultural accounts of humiliation are Chinese allegations of disrespectful treatment by the WWII Allies, the failure of the West to fully acknowledge China's contribution to the Allied victory, and Japan's refusal to acknowledge China's victory despite acknowledging that of other Allied nations (Gries 2004). National humiliations of the 1950s and 1960s have been interwoven with earlier incidents of victimization. These included stories of America blocking the PRC's entry into the United Nations, delaying it until 1971 (Gries 2004). Further plaited into the victimization narrative are other incidents deemed a national dishonor, such as the 1993 loss of the bid to host the Olympics due to alleged American intervention (Gries 2004). As Gries $(2004,51)$ noted, the more popular interpretation of "backwards/beaten" has become "backwards because beaten" (luohou yinwei aida), implying that Western aggression has kept China backwards.

Post-reform assertions of victimization include humiliation inflicted upon the Chinese people by Western corporations that price their brands too highly for the masses. In Chinese popular culture, anti-ads have emerged to dramatize this form of humiliation. One depicts an aggressive Ronald McDonald forcing a Chinese consumer to bow at the base of the golden arches, while refusing the consumer's pleas for a discount (SOHU.com 2005). Our participants also found it humiliating that some Western brands in China were of inferior quality to similar brands offered in Western nations.

What is thought in dreams, is actually the wish to make up what is missing in reality. . . In any country, the commodity concept a brand represents is unchanged, there shouldn't be any quality discrimination based on country or region.

(24 year old female survey participant, Beijing)

These depictions of Western brands also mirror reports of the 2007 China Brand Report (Yu 2007). The reported brand crisis incidents highlight the double standards of Western brands, whereby Chinese consumers are subjected to lower levels of customer service, goods that are inferior to similarly labeled brands in other Western countries, producers' failure to recall unsafe brands in China, and high barriers to the return of branded goods once concerns for their safety are publicly reported. Carrefour, Toyota Reiz, P\&G's SK-II cosmetics, and Chivas 12-Year are all reported examples of Western brands that engaged in practices deemed disrespectful to Chinese consumers (Yu 2007, 323).

Many of the brand crisis examples reflect the data in our paper where Chinese consumers are concerned that foreign brands may dump defective products onto China's market and that Chinese consumers might be treated with less respect by foreign brands ... With the prevalence of internet and easy access 
to information about the outside world, Chinese consumers are more aware of various brands and consumers in other parts of the world, and desire and expect equal treatment from companies (especially those of famous brands) including product quality (e.g., Chivas and Toyota Reiz) and related return policy (e.g. Bausch Lomb and SK-II). Any perceived difference in product quality or "double standard in return/exchange policies" would be interpreted by Chinese consumers as a lack of respect and would invoke a sense of humiliation from the past. This is another illustration of Chinese consumers' viewing foreign brands as oppressors.

(Yu 2007, 323)

Redemption was imagined in our participants' dreams, not in terms of protecting cultural icons and heritage sites, nor in terms of protectionist exchange policies, or boycotting Western brands. Rather, participants fantasized that Chinese products would be sought by Chinese consumers because of their international competitive superiority while the status and prices of Western brands in China decline.

Foreign brands are defeated completely by domestic brands overnight. Chinese people are proud of buying domestic products, and Chinese products are recognized by the world, like Haier.

(survey participant, no demographic data, Baoding)

One day, streets of foreign countries are running Chinese Red Flag (a car brand), foreigners all wear Double-star (a Chinese shoe brand) and Pu-dun pants (a Chinese brand).

(survey participant, no demographic data, Baoding)

$B M W$ rushed in front of me, and invites me to sit in. I'm so surprised that I throw up. Me, of a salary income class deserving to sit in such famous car in this lifetime, I won't regret it even if I die. I shout, "It does not feel as cool riding you as riding my electric donkey [nickname for motor cycle]!" You should change your name to "wild donkey brand" . . " All right." Going country is the destined route for aristocrats to become common people.

(survey participant, no demographic data, Baoding)

Chinese products will someday fill people's thoughts and lives all over the world. On that day, I will have a dream, Western brands will no longer be arrogant. Just like that I throw out a few coins, wow, foreign goods all my way!

(survey participant, no demographic data, Baoding)

Similar sentiments were also evident in the sentence-completion responses.

[A good foreign brand should ...] adapt to the reality of China instead of standing high above humanity.

(survey participant, no demographic data, Shanghai) 
[If all foreign brands disappeared from the Chinese market I would . . .] feel glad because many Chinese products have quality that match international standards.

(survey participant, no demographic data, Baoding)

In contrast to the former narrative, which is driven by efforts to shape nationality as an inward-directed sentiment that seeks to hold a nation together and guard against alien rule, this narrative operates by discourses that direct effort outwards (Gries 2004, citing Comaroff and Stern 1995). In the redemption narrative, the view of Western brands as instruments of aggression produces expansionist attitudes, with victory sought in international market dominance (Gries 2004).

A historical trace of China's outward expansion can be found in the 30-year Foreign Affairs Movement (Yangwu yundong) during the semi-colonial period following defeat in the Opium Wars. A group of ministers headed by Zeng Guofan proposed to the Qing Emperor (who rejected foreigners as teachers) that China should learn from foreigners to strengthen her power, acquiring skills that would allow China to defeat them in the future. Officials were sent to North America and Europe to learn about and purchase technological equipment, which was then incorporated into Chinese education and military bases. The persuasive line used by Zeng Guofan to appeal to the Emperor has been widely disseminated, "learn from foreigners to defeat them" (shi yi yi zhi yi). Also contributing to this view was Lu Xun (1881-1936), another prominent litterateur. In his article "Na lai zhuyi" (Appropriation/or "Taking") published in 1934, Lu Xun advocated overturning the situation in which China was forcibly sold opium. He argued that Chinese people should actively appropriate useful things from the Western cultural system, and turn these things into goods that could benefit China. Extending these notions to the present, many of our participants expressed the view that the presence of Western brands in China was an important opportunity for China's industries to engage in benchmarking, using the best of Western practices as standards. They envisioned a national industry that learned and then ultimately beat Western brands in the global market with the introduction of successful, high-quality, and technologically sophisticated China-made brands, thereby elevating the Chinese economy. The currency for this redemptive narrative is heightened at moments that pose a threat to China's global commercial success. Among others, such events include disputes with the US over trade deficits, and charges of China's violations of intellectual property rights (Gries 2004).

Redemptive fantasies entailed imagined transformations into a more esteemed self in the global arena, though this was often expressed as a collective self.

Because (I) couldn't meet [my girlfriend's] needs of being covered with famous foreign brands all over, we fought, I got mad, I said "bye". . . From then on I hated famous foreign brands, which represented people of vanity. I was determined to have my own company and beat foreign brands. My dream finally came true in my dreams. People all over the world were using my company's products.

(23 year old male survey participant, Tianjin) 
Some of our participants spontaneously expressed a belief that Chinese people are held in low esteem internationally. These participants tied redemption to economic development and China's competitiveness in the global market, irrespective of its impact on cultural heritage.

[In talking about best translation practices] A Western name, Chinese people can accept. I think the biggest shortcoming of Chinese people is that I feel Chinese worship Western things too much. This is an undeniable fact. It's been like this since 1840. Any Westerner . . will be adored like God in China ... if I go abroad, to Europe, how they treat Chinese people, respect can't even be mentioned. . . Although China has a history of several thousand years, you can't live by holding onto history. The history is almost eaten away. Forbidden City? How long is it going to last? Will the Great Wall never fall? Why has the United States developed so fast? . . So the current development is the most important, not the history.

(23 year old female interviewee, Beijing)

The desire to reorder hierarchies such that the oppressed becomes the oppressor is not unique to the Chinese (Gries 2004), but cultural theorists have noted that many Chinese today want to change roles within the relationship, such that China is the "super big-brother" and the United States and other Western nations are likened to small children (Gries 2004). Gries (2004) suggests that this national narrative of redemption has been prompted by academic writings which have crossed over into popular culture, such as Li Fang's (1996) Our Generation's America Complex, which criticizes Chinese consumers' admiration for American culture and fascination with Western brands. Expansionist discourses can be found in populist writings that oppose anti-China discourses, advocating that the United States should build alliances to contain China (Gries 2004). In response, numerous Chinese popular books, including the "say no" books, took the position that the United States had repeatedly forced China into a series of confrontations. These texts "carried a warning to Washington that any containment effort was certain to fail" (Zhao 2004, 10-11).

The opposition to containment fantasized by some participants parallels strategic moves by some Chinese manufacturers to become global. Personal computer manufacturer Lenovo, brewer Tsingtao, appliance maker Haier, and automobile maker Chery are all seeking to become global brands (Cayla and Eckhardt 2008; Wang 2008), with some leveraging from their sponsorship of the 2008 Olympics. The popular catchphrase "created in China," has been interpreted by Wang (2008) as capturing the vision of a China transformed from world factory to a heaven for brand innovators. This vision inspired other redemptive-themed dreams in which Chinese entrepreneurs took over Western corporations, shaping the brand and corporate culture in a different direction.

[Dream] After graduation, I joined a foreign company. Building on nothing, I started from a little clerk and then was promoted to the president of the 
company. I felt high spirited and vigorous and then started a new era of the company. I began to run several transnational corporations and become as rich as Bill Gates. Thus our products monopolized the specially endorsed products for the World Cup, Olympic, and all the major international conferences. Brands like Nike, Adidas, all went bankrupt in the competition.

(20 year old male survey participant, Beijing)

[The more foreign brand products I have...] to some extent the more satisfaction I obtain from the products. [Dream] I will dream of acquiring this foreign brand and making it into a "famous national brand" and then market it in the global market.

(survey participant, no demographic data, Beijing)

Again, and related to the previously noted local cultural differences, the use of this redemptive narrative to shape Western brand fantasies was more common among those from Beijing and Baoding.

\section{The West as economic partner, Western brands as instruments of economic progress}

Other fantasies reflect a national narrative which promotes hopeful idealistic views of Chinese-Western relations. Foreign corporations were deemed eager to share technology and to adapt to and adopt Chinese ways.

I imagined that Western brands and Chinese brands are two people with high quality, optimistic and positive attitudes. They walked together, and became best friends! They learned from each other and helped each other to make up for each other's weaknesses. The Chinese brand was down to earth, and the Western brand was gorgeous. The Chinese brand drew on the Western brand's advanced technology and management experience, and at the same time, it entertained the Western brand and made the Western brand benefit greatly from the Chinese brand. Hand in hand, and shoulder by shoulder, they worked hard together for mankind's happiness.

(29 year old female survey participant, Beijing)

One day, the beautiful girl Head \& Shoulders with a head of floating elegant long hair, the boy Nike in sport clothes and I went to Disney together. This was a Disney in China, I was very happy that the two foreign friends could come to China to play in a foreign amusement park. After that, we went to the Great Wall ... They were very glad, and said they . . . wanted to marry spouses in China, have children, plant their roots in China, and they even wanted to change to Chinese citizenship.

(21 year old male survey participant, Tianjin)

One day I bought a bag of "Haoshi" (Hershey's) chocolate and almost finished eating, with the last piece forgotten at one corner. After a long time, I 


\section{Chinese national narratives and the meanings of Western brands}

found it and thought it might have turned bad. Just when I was throwing it away, suddenly a voice said to me "Oh no! Please don't throw me away!" I was a little surprised, so I searched around but couldn't see anyone. Then a voice spoke again, "It's me! I am in your hand!" I looked and found that it was the little thing talking to me. I was a little scared, but I still talked to it. "Oh, How can you speak? And can you speak Chinese?" It immediately jumped into my palm, "Yes, yes I can." "Ha-ha . . " I laughed. "You must have been in China for so long that you have secretly learnt some Chinese, right?" It smiled back at me, "Right. Please don't throw me away. I have enjoyed living in your home and I don't want to go outside." I said "Oh yeah? OK then, you can be my good friend, but I'm afraid that I would want to eat you!' It said, "No problem!" I was surprised but still kept it. From then on, I found a heap of Hershey's chocolate at my desk every day. I was so pleased. No need to ask, I knew it was my good friend repaying me. Ha-ha!

(20 year old female survey participant, Beijing)

These views of Western brands and corporations as partners can also be seen in discourses within China's commercial brand industry. The China Brand Report 2009 recounts the formation of the partnership between Jian-nan-chun, a Chinese liquor brand, with Absolut Vodka in 2008 after it partnered with Hennessy in 2007 (Yu 2009, 53). This partnership and the subsequent creation of new unique brands is believed to have facilitated its leap from third place to the leader in the strong liquor industry. As Yu (2009) comments:

When you mention Jiannanchun, people immediately think of the long history of Chinese liquor culture. On the other hand, Absolut Vodka would remind people of the bold and modern advertisement and transparent yet versatile packaging. The combination of the two brands is as incredible as the Mars hitting the earth. We all agree that Jian-nan-chun brand image seems to become younger. While traditional culture should be respected, new blood should also be injected. The joining hands of Jiannanchun and Absolut Vodka has taught us a very vivid lesson.

(Yu 2009, 53)

Our participants who drew from an East-West partnering narrative deemed the Chinese people capable of adapting to globalization in a manner that sustains valued aspects of their culture. Here the consumer alters the product to one that better suits Chinese taste.

In a quiet mountain village everything was so pure and clean. One day a traveler came, trying to sell to those simple and innocent villagers a kind of good drink, that is Coca Cola. . . I tried it. It tasted bitter. "It tastes so horrible!" I said. This time, grandma walked over. "Wrong. You should not drink it this way. You should drink it as if you were drinking Chinese herbal medicine. Add 
water and sugar." Then grandma took over the Coca Cola and mixed a big cup for me ... Wow! It tastes great! Thus, I cheered, "Everywhere is home"

(23 year old male survey participant, Beijing)

There does, however, appear to be a porous boundary between adaptive harmony and a subversive takeover tied to cultural redemption. Consider the contrast of the above dream with the one that follows.

I came to Coca-Cola company to be the boss. I sent employees to collect various delicious fruits from all over the world, and made them into fruit flavored soda and offered it three days for free, sprinkled the orange flavored juice from the sky like rain so that people in the whole world would enjoy the taste of Coca Cola soda.

(19 year old female survey participant, Beijing)

Participants often placed Western brands in a relationship of harmony with nature. The boundary transgression between technology and nature that in Asian culture could give rise to disgust is avoided by first transforming the technological foreign good into an element of nature. Further, the non-dualistic conception of society (and man) as being in harmony with nature is preserved (see Tung 1994).

One exhausting final exam was over, I muddle-headedly returned home, and my head itched terribly. Just then, a water honey bee named Head \& Shoulders flew over, it guided me to the bathroom, turned on the shower nozzle, flew around my head. This time, I just felt a miraculous light flash over my head. It took away all my discomfort, my soft and smooth hair cascaded down, and I started to dance. The little honey bee also danced along with me, and we were surrounded by pleasant music.

(21 year old female survey participant, Tianjin)

The sense of international harmony expressed in this dream and others was also found among some of our interview participants, who made comments such as "The world is one entity now. It's not necessary . . . one should not refuse to buy it because it's American." Consistent with views of China's more harmonious relationship with Western brands, some of our participants commented on how Western brands satisfied deep-seated cultural values in China.

I believe all of us want to look nice and young for our own sake, to wear makeup and to dress nicely has just become a free enjoyment for all women. China is a nation with high sensitivity to beauty. I feel make-up has just rendered everyone a chance to be satisfied with our physical appearance and the availability of foreign brand cosmetics answered to our nature.

(40 year old female interview participant, Beijing)

In other dreams, international partnering and cross-national competition reached 


\section{Chinese national narratives and the meanings of Western brands}

the pinnacle of Deng's development policy, whereby moderate affluence for the majority is achieved.

Summarizing, our data elicited through projective techniques suggest that Chinese consumers embed Western brand meanings in various reconstructions of China's history. Fantasies where Western brand consumption resulted in a transformation of the entire nation suggest that consumers find Western brands meaningful in shaping the future China. Such imaginings suggest that Western brand consumption is not routine apolitical behavior (Campbell 1994), but rather consciously motivated actions tied to materializing preferred imaginings of the future China. 


\section{National narratives in imaginative processing of Western brand promotions}

Chapter Five highlighted the multiple national narratives that Chinese consumers use to imbue Western brands with local meanings. We then theorized that, imbued with these meanings, Western brands are used to realize consumers' preferred imaginings of the future nation. From our analysis comes the realization that notions of how citizens should respond to Western brands to assert nationalism are many and competing. Further, the national government at various historical moments is revealed as engaged in rhetoric and policy making that may encourage rather than discourage consumption of foreign brands. Our understanding of how these competing cultural narratives shape individuals' responses to Western brands remains limited. Our emphasis so far has been on the collective cultural imagination that is a source of creative material. Here we shift emphasis from macro-level negotiation of Chinese identity through Western brands to a microlevel focus on how the various narratives affect the psychological processing of Western brand promotions.

\section{Imagined consumption}

It is well documented by consumer research that people may envision how a product they have yet to consume will transform them once it is acquired (Belk et al 2003). A vital tenet of Western consumerist ideology is the belief that "the consumption of new products will transform one's life" (Spring 2003, 6; see also Bauman 2007).

Individuals' imaginings of consumer goods and their dreams of how they will be transformed by them are of considerable relevance in this time of expanding global capitalism (Cayla and Eckhardt 2008). Capitalism, with its central component of the free market, has introduced Western brands to multitudes of individuals in less affluent, non-Western cultures (Arnett 2002; Cayla and Eckhardt 2008; Coulter et al 2003; Kjeldgaard and Askegaard 2006; Liu 2004). A rare study of imagined consumption in this context suggests that consumers who cannot afford the Western goods they desire and aspire to possess, sustain their longings by repeatedly imagining how their identities and lives will be transformed once they do possess them (Belk et al 2003). These mental rehearsals are more aptly termed consumption fantasies (Holbrook and Hirschman 1982): that is, they entail 
mental imagery and hypothetical scenarios of identity and life transformations which mix real and unreal elements (Belk et al 2003). Emerging from a focal interest in consumer desire, these findings highlight imaginings of pleasant consumption experiences and desirable identity transformations. Contesting a universal attraction to Western brands, a singular study conducted in post-socialist nations found that consumers varied in their involvement with branded products. Branded involvement was informed not only by Western advertisements, but also by varied and competing historical meanings of brands from their nations' socialist past (Coulter et al 2003). These works highlight the influence of commercial producers in promoting imaginings of and involvement with Western culture and brands. Prominent among these are the advertising, fashion, entertainment, and consumer products industries, which supply the Western media with a stream of images and brand icons for global dissemination.

Since the turn of the century, Western brand producers operating in China have sought to enliven individuals' consumption fantasies through visual promotions (Wang 2000; Wang 2008). In introducing a typical Western brand advertisement in China at the turn of the century, Wang offers the following description:

At the heart of China's capital city, Beijing, stands a huge electronic roadside billboard. Displayed on the billboard are three "heroes" - a Caucasian man, a Caucasian woman, and a Hennessy bottle ... The dark suited man, glass in hand, is posed in the middle of the background. In the left foreground, barely visible in the scene, the woman is showing only a shoulder draped in a beautiful scarf. On the right is the big Hennessy bottle, with its shape and texture occupying almost a quarter of the billboard space. Between the back and front is a row of Greco-Roman arches. The ad caption written in Chinese characters reads, "Hennessy. The Original X.O."

A moment later the billboard dissolves into a slightly different setting featuring a curved white verandah overlooking the quiet blue sea. Standing on the verandah, the Caucasian man, gazing seaward and still holding a glass, is now impeccably attired in a white tropical suit. The Caucasian woman now appears in a high cut white dress, but only her back from hip to shoulder is shown. She also is looking out to sea. The Hennessy bottle remains prominent, unaltered from its original position on the right side of the billboard.

(Wang 2000, 4)

Like many Western brand advertisements created for Chinese consumers the Hennessey ad plays up difference, exoticism, and the Western origins of the brand (Wang 2000). In our Appendix of billboard and storefront advertising that we photographed in China in 2009 we offer visual examples that suggest these promotional themes are still common. In his analysis of Western brand advertisements, Wang (2000) argues these are deliberately designed with strategic elements to evoke Chinese consumers' fantasies. Consumer goods from foreign cultures promise a magical transformative experience (Belk et al 2003). Such consumption not only offers an experience of the exotic, but also enables consumers to 
experience an extraordinary, idealized self-image - one where they are more cosmopolitan, sophisticated, and important (Belk et al 2003; Coulter et al 2003; Kimura and Belk 2004; Thompson and Tambyah 1999). As Belk (2003) elaborates, accessible objects from ones' own culture are not deemed capable of creating a transformed ideal self, given that everyday encounters render them ordinary.

Like the Hennessy billboard above, Western brands in China often offer an idealized glimpse of the possible self - a self that is magically transformed (Wang 2000). Paradoxically, this magic is achieved by modern technology. Just as the modern technological sophistication of the billboard underlies its metamorphosis, the modern technological sophistication of Western products is often the source of their "foreignness" and their transformational capabilities (Wang 2000). Albeit subtle, the Hennessy ad conveys this via the unchanging bottle - a symbol that, through Western technology, the magical potion has been engineered to be consistent, reliable, and safe (Wang 2000; cf. Thompson 2004) by mysterious processes of blending and aging. Wang's (2000) review of Western billboard advertising and other signboards throughout China revealed that Western producers have commonly promoted themes of exotic Westernness, modernity, newness or novelty, and science and technology. This promotional focus no doubt contributed to our participants' views that Western brands are technologically advanced relative to domestic ones.

Themes of difference or exoticism of course differ from promotions that seek to localize their appeal (Wang 2008) and rare advertisements, such as those in the Introduction, that attempt to leverage from China's past. Yet, these themes are not mutually exclusive, as our participants revealed in their discussions of brand name translation practices. Like brand names, promotions of various types can display local cultural knowledge while nonetheless interjecting cues to their foreignness that render them exotic.

To illustrate, in May 2006 KFC introduced a new television advertisement in China as part of its "encouragement series" (a follow-up of KFC's "brotherhood series"). The new advertisement featured three teenagers, two boys and a girl, studying in a classroom, at a KFC restaurant, and atop the school building. One of the boys, wearing a red jacket, is always leisurely hanging out and eating at KFC, causing his classmates to worry for him. They urge "This is desperate. Are you not planning to take the exams?" The other boy, Xiaodong, offers the contrast of a diligent student. However, at the end of the ad, the girl and the KFC enthusiast are accepted into colleges, whereas Xiaodong surprisingly fails. Many Chinese viewers questioned the message sent by this ad, which seemed to suggest that those who play and embrace Western cultural icons succeed, whereas those who study hard but fail to take pleasure in Western brands will fail. This advertisement is localized by the context of the three-day university entrance exam, recognizing the centrality of education to Chinese families. The airing of the advertisement coincided with the timing of the exam, scheduled in early June every year throughout China, yet it clearly sent a foreign message, one counter to cultural norms. Following media coverage and internet discussions, KFC revised the advertisement so that all three students are accepted into universities (News Guangdong 2006). 
As reactions to this "encouragement" advertisement suggest, Chinese consumers do not merely accept the consumption fantasies and their transformational outcomes promised by Western brand promotions. This illustrates that Chinese consumers were skeptical about the effects of the advertisement, as it disrupted the cultural premise that hard work is the path to educational achievement. Such advertisements and debates fuel and are fueled by the cultural narrative of Western brands as oppressors that appropriate Chinese cultural space. Among the Western brand advertisements shown in the Appendix are additional illustrations of advertisements that localize their appeal while nonetheless conveying a foreignness through values that oppose traditional ones in China.

A couple of other contextual factors surrounding Western brands in China are noteworthy. First, In developing countries Western brands may tantalize individuals with fruits which, albeit apparently within reach, do not often become possessions for consumption (Belk et al 2003). As we found, high price is a distinguishing characteristic of Western goods as perceived by Chinese consumers. This was exhibited in participants' completion of the sentence stem "Foreign brands always ..." with statements such as "have high prices" or "have prices higher than domestic brands." This view was also revealed in dream fantasies, where a common dream entailed winning a lottery which enabled the consumer to buy desired Western brands. Whereas some scholars argue that obstacles to immediate gratification serve to sustain desire that fuels consumption fantasies (Belk et al 2003), this does not preclude that consumers who are uncomfortable with perpetual desire for the unattainable may engage in psychological strategies attempting to diminish such desire. Whereas this may underlie some of the negative or unpleasant dreams of Western brands, as well as those that led to abandonment of such brands, in the example that follows, the consumer explicitly counters desire with the decision to resist dreaming of Western brands.

One evening I suddenly had a weird but fantastic dream. I hoped this fond dream would come true. I spent 20 Yuan and bought 10 lottery tickets. Unexpectedly I won the special award of five million Yuan. To me, this is really an enormous figure and it was truly very important to me. I can just use part of this award to buy all the foreign brand products that I had been longing for day and night all my life-Adidas sport clothing on my body, Nike sport shoes on my feet, Nokia cell phone clipped at my waist, buying a case of Coca Cola drinks from a supermarket and walking into my BMW car. A dream is after all a dream and is not real. I decided to come back to reality and never dream again.

(22 year old female survey participant, Beijing)

For some Chinese consumers, Western brands priced so high as to be unattainable may shut down active imagining or fantasizing about consumption of these brands. The dream further suggests the possibility that this resistance applies also to the category of goods - Coke as well as BMWs. The degree of affordability of these product categories would seem quite different from a Western perspective, 
yet both may exceed a threshold of affordability for some Chinese. Although not addressed by us, a worthy research topic would be to investigate whether practices of closing out consumption fantasies may become a habit or heuristic. To the extent that this occurs, the practice may pre-empt consumption fantasies of Western brands even after consumers' incomes rise, or when Western brand prices are reduced by competition or economies of scale.

A second factor that may be involved in imaginatively processing Western brand promotions in the manner desired by their producers is Chinese consumers' views of technology. Western brands are promoted as modern and technologically advanced relative to their local counterparts (Wang 2000). Through such promotions, Western producers expect to render their branded goods useful to consumers in constructing a more modern self (Wang 2000). Constructing a more modern self is not inherently in conflict with Chinese nationality in light of the government's goal to "catch up with the West" (Croll 2006, 47). Wang's (2000) review of Western brand advertisements recounts how a Sharp VCR promotion meticulously described technological details (e.g., stating in bold print the type of metal of the VCR head) and made the product transparent so that consumers could see the inner complexity. In the early years following economic reform in China, such images became the hallmark of Western advertisements (Wang 2000). Wang (2000) suggests that the techno-speech mystifies the product in a way that leaves consumers impressed with its technological sophistication. The use of modern science rhetoric and images to counter the perceived risks of foreign substances, albeit effective with Westerners (see Thompson 2004), may lead to skepticism among Chinese consumers. There was considerable evidence of this in our participants' dreams and discussions of Western health and beauty products. Participants stated that Western brands in this category were more technologically advanced than those of traditional Chinese medicine in the sense that they had faster or more noticeable results, but also often had unexpected side effects. The following dreams suggest that the value of technologically advanced Western brands in some product categories is viewed differently by Chinese consumers. Thus, imagined consumption of technologically advanced Western brands may depart from the types of imaginings sought by Western brand producers.

My classmate recently had been losing a lot of hair. He almost became bald. One day he dreamed of showering, and suddenly found there were numerous shampoos before him. Therefore he picked one bottle from them, examined it closely. It was gold-packaged Head \& Shoulders. He washed and washed and afterwards, discovered that he was no longer losing his hair and there was a trend of fast growing, so he used more like crazy, pleased to find that his hair had grown back to look like it did before. Extremely happy after waking up from the dream, he has been using Head \& Shoulders since.

(21 year old male survey participant, Beijing)

Dream: Using Head \& Shoulders all your hair will be gone and your dandruff will be left alone. What a horrible dream.

(22 year old survey participant Baoding) 
Dream: After using Safeguard, my skin is not oily but very clean and clear. Who knew that when I woke up the next day, I would have acne all over my body.

(22 year old female survey participant, Baoding)

Again, here the body disfigured by technologically advanced Western brands doubles as a disfigured social self, including the collective sense of self or the Chinese nation (Tung 1994). These dreams again suggest that consumption fantasies regarding Western brands possess layered meanings. A surface meaning may reflect imagined outcomes linked to distinguishing attributes of the brand (for example the side effects of the technology). These imaginings, however, may be shaped at a deeper level by meanings derived from national narratives upon which consumers draw. The negative side effects of the Safeguard soap (above) may refer not only to the consumers' physical body, but also to the collective Chinese body that rejects the Western brand as something foreign.

The point of these illustrations is that the meanings of Western brands disseminated by their producers are not passively received by Chinese consumers. Rather, consumers negotiate and reconstruct these meanings, drawing from other local sources. Local producers as well as nation-state governments also influence individuals' consumption fantasies. As our analysis in Chapter five elaborated, the governments of nation-states transitioning to a market economy creatively adapt rather than completely adopt capitalist ideology and Western consumerist culture (Liu 2004). They form hybrid political ideologies intertwined with prescriptions for consumption practices (Gries 2004; Liu 2004). In vying for individuals' national identity, purveyors of local values compete to shape consumer practices not only in the marketplace, but at a much earlier point: they compete for space in the consumer's imagination (Gries 2004; Wang 2000; Wang 2008).

\section{Individual psychological processes of enlivening consumption fantasies}

Martin's $(2004,142)$ model explaining the enlivenment of consumption fantasy provides a foundation from which to interpret our Chinese consumers' fantasies of Western brands. Martin (2004) suggests that individuals conjure their fantasies by focusing on a visual aid. For Martin, who studied imagining in the context of a magic trading card game, a card depicting a character served as the visual aid, though he asserts that such an aid is not required to evoke imaginative thinking. Individuals' motivation to focus attention on a visual aid with the intention of enlivening the imagination ensues from a predisposition to fantasize, driven by a desire for participation in the imagined setting and the view that fantasy is valuable. Once focusing on the visual aid, imaginers may then engage various strategies to enliven the fantasy.

Martin's (2004) theory recognizes three strategies to enliven consumers' consumption fantasies. Expansion strategies include the mental practice of multiplying what is seen, and adding complementary characters of a different type. 
Embellishment strategies involve extrapolating to fill in what is missing from the visual aid, and adding character interactions. Embellishment strategies also include imbuing the object of visualization with a history. The third strategy is a replacement strategy whereby the imaginer mentally substitutes the visual depiction with a preferred form drawn from memory. These same strategies were present in Chinese consumers' imagining of Western brands.

Martin's (2004) theory also offers insight into how fantasies of the future China (as fueled by national narratives) reinforce or thwart the goals of Western brand promotions. In this context an individual's focus on visual stimuli is a pivotal activity from which fantasizing ensues. Likewise, in extensive studies of Western brand communications in China, researchers note the rapid expansion and predominance of visual appeals (Wang 2008), many of which are crafted to prompt consumers' imaginings of identity transformations that will result from consumption (Wang 2000). Martin's (2004) model suggests that specific national narratives of East-West relations may intervene in the initial stages by heightening desire for different imagined settings that compete with those suggested by Western advertisements, thereby reducing attention to them. Further, after the consumer attends to the visual aid, they may engage a narrative to elaborate and embellish Western brand advertisements in their imagination (Martin 2004), which is a goal desired by Western producers (Escalas 2007). Yet, following on from Martin's $(2004,146)$ identification of a "replacement strategy," consumers may engage memory-based replacements which are antithetical to these producers' intents.

\section{Strategies of enlivening consumption fantasies}

The strategies employed by individuals to enliven their consumption fantasies were also employed by Chinese consumers in their imaginings of Western brands.

Expansion strategies abounded in the dreams told by our participants, as evidenced in the stories of Western brands that become rows of soldiers with knives, or Western brand robot toys that proliferate first to aid and befriend Chinese consumers and then later to enslave them. Expansion strategies were also present in positive dreams, as illustrated by the following.

This evening I had a dream. I dreamed that my favorite Safeguard filled my bathroom. This made me and my friend happy and worried. We were happy because we could use Safeguard to wash and we were worried because there were so many of them and we would be tired of them. Suddenly, there came a small animal before me and she told me that these Safeguards were given by the manufacturer who wanted us to help do some publicity. Meanwhile, this would improve the health of the children from the poor mountain areas. Then they could grow up happily and healthy, free of disease. I smiled with joy. Immediately, my friend and I started working and took care of the task well.

(19 year old female survey participant, Beijing) 
Easy to discern in the above dream is a vision of how a future China (here freed of disease) is materialized through the proliferation of Western brands that reach even the poorer and more rural areas. Here the multiplication of the Western brand Safeguard is used in an imaginative narrative that mimics the saturation of Western brands in urban areas and their producers' desire to expand by moving into relatively more rural areas (Croll 2006; Wang 2008). The narrative also parallels the process whereby urban dwellers are in effect the agents of Western brands, introducing them to their rural-dwelling relatives. Finally, the dream narrative highlights the technological powers of the Western brand Safeguard in its ability to free people of disease, drawing in part from a narrative of the West and Western brands as offering freedom.

Consumption fantasies scripted according to this narrative were contextualized with expansion strategies that took different forms. For instance, instead of multiplying a single Western brand, some participants multiplied Western brands in a variety of product categories.

Last night my friend had a dream. Due to economic reasons, many things are unattainable in real life, but he achieved all of them last night. He owned the big Benz, happily Benzing (driving fast) on the wide road. He was wearing Baoyu clothes, drinking Coca Cola, even the sound from the car stereo was modern style foreign music. He parked the car, used Sony brand camera to shoot the beautiful scenery around him, Kodak and Fuji films were prepared in one minute, instant 3-D photos were made, and they were connected to the Internet, and numerous copies of the photos were printed out from Hewlett Packard printer for everyone to enjoy. After looking at the photos, he went into the bathroom, used Safeguard, Rejoice (Pert) to wash his hair, put on Fun brand [known in China as "famous American brand"] jeans. Everything was so pleasant but it was only a dream.

(25 year old female survey participant, Beijing)

Expansion strategies not only followed scripts tied to the cultural narrative of Western brands as freeing: they were also guided by other national narratives. The narrative of Western brands as oppressors guided one participant to fantasize that she was drowning in a pool filled not with water but with Head \& Shoulders shampoo. Similarly, another participant was inescapably inundated with Western brand promotions even in space.

I was sitting on an airplane. In the room, on the doors of the airplane there were posters of foreign brands everywhere. Looking down to the ground, forests, lands and mountains were all covered with large posters for foreign brands. I felt thirsty, picked up a bottle of water and a print ad appeared in the water, it's also about a foreign brand.

(22 year old male survey participant, Beijing)

Embellishment strategies and character interactions comparable to those identified by Martin (2004) also emerged when we asked Chinese consumers to dream 
(imagine) a Western brand. Several participants introduced angels, immortals, or animal characters to interact with the brand, which they animated as a living entity. Others dreamed of Western brands that morphed into such characters, with whom they held conversations. Such embellishment strategies served the different scripts offered by the competing national narratives.

Motorola turned into a dove and at this time I'm holding it in my hands and it said to me "I'm your message dove, delivering your messages and your voice, the difference is that I don't eat grain, but I eat the bills in your pocket."

(21 year old male survey participant, Beijing)

To summarize, Martin's identified strategies used by Chinese individuals to enliven their consumption fantasies seem also to emerge in our Western brand context.

\section{Narratives and imagined identity transformations from Western brand consumption}

Chinese consumers' choice of a specific national narrative shapes the form and desirability of the imagined transformation of the self and imagined emotional experiences. When Chinese consumers historicized Western brands with a narrative of the West as experiential venue and Western brands as providing a sense of freedom, they imagined transformations in which they became more individual, cosmopolitan, leisurely, mobile, knowledgeable, and esteemed, even world famous, as a result of acquiring Western brands. Accompanying these imaginings were emotions of satisfaction, joy, excitement, hope, and happiness, and sometimes appreciation and gratitude toward the Western brand or its producers. The following dreams culminate in these types of desired transformation.

[The more foreign brand products I have ...] the better quality of life I have. [Dream] I dream that Lancôme turns into a beautiful angel, she is strolling in the purple-colored woods. I say to her, please make me beautiful. She smiles, touches me with her slender hands, kisses me, and says I'm a good girl, and I will be very beautiful.

(22 year old female survey participant, Shanghai)

[The more foreign brand products I have .. .] the higher quality of my life. [Dream] In the evening after brushing my teeth with Colgate, lying in bed the moonlight shines on my face. I smile splendidly and my teeth glow with shine like the stars. And really, little glowing stars and sparkles fly out.

(survey participant, no demographic data, Baoding)

[The more foreign brand products I have...], the higher social status I feel I've achieved. [Dream] I dream that there are foreign brands all around me and all over me. Everybody is surprised at me. I feel very proud.

(21 year old male survey participant, Shanghai) 
[The more foreign brand products I have . . .], the higher status I have. [Dream] I picture myself in a white tennis shirt and skirt, a vigorous body moving on the tennis court. Then wearing famous brand sunglasses I'm on a tropical beach.

(22 year old female survey participant, Shanghai)

[Dream] I spent 20 Yuan, bought a pair of real Nike shoes, and the quality was very good. The shoe store owner told me, you have become the celebrity endorser of Nike company. From now on, you can wear all the Nike products free of charge. I went to the United States and made some commercials for Nike together with Michael Jordan. And I made some movies with America's Hollywood stars, and became famous in the end.

(22 year old male survey participant, Tianjin)

[Dream] Several major famous brands that represent luxury and extravagance were all owned by me at the same time. While having these, it seemed like I became a star, wearing Rolex watch, dressed in Chanel clothes, driving Benz car. It may be only a daydream, but I'm still very happy.

(20 year old female survey participant, Beijing)

[The more foreign brands I have . .] it shows the better my quality of life. [Dream] I was wearing a white sheer dress, with blue silk ribbons at the waist, playing on the swing decorated with flower rings in the quiet and peaceful forest. A breeze was floating gently, and willows swaying slightly. Waves were shimmering in the lake nearby. The grass was so green on the ground, my Lancôme and Ou-bo-lai (Aupres) were accompanying me. What a nice and beautiful dream!

(24 year old female survey participant, Beijing)

These imagined transformations of the self drawing from a national narrative in which Western brands offer freedom and a sense of liberation appear very compatible with general themes of Western brand promotions, as suggested by Wang (2000).

Fantasies historicized with a narrative in which Western brands are instruments of domination led to imaginings in which the self was altered after consumption, and became more individual, wealthy, and colorful. Yet, these transformations were undesired, with connotations of anxiety, fear, isolation, loss, disgrace, humiliation, ruin, and becoming an unauthentic person who through their choices contributed to a demise of traditional Chinese culture and the Chinese nation.

Wearing an Italian brand suit, French perfume and a Swiss brand watch, driving a German brand car, using a Japanese brand computer, and . . living in an American house, this is me. Standing in front of a mirror, I find myself with different colors, as if all these famous brands are glowing, but only myself is missing. Is there anything worse than not being able to find 
oneself? All those things are good things, every one of them, but putting them together just doesn't feel good. Follow nature, why torture myself?

(21 year old male survey participant, Baoding)

Somebody loved foreign brands so much that he would want to buy them even by borrowing money. One day, he was wearing famous brands from head to toe, walking on the street, feeling as proud as a peacock, showing off his famous brands to everyone passing by. However, not a single person cared about him, and they gave him a despising look. Suddenly, one person dashed at him like crazy, pushed him to the ground, and beat him up and yelled "Where did this devil come from?"

(24 year old male survey participant, Tianjin)

One day I'm wearing Chanel high-quality fashion, with CD Poison perfume, Omega diamond luxury watch, riding in the newest model Benz. Just when I am enjoying these things, suddenly many people came up around me and criticized me for "chong-yang-mei-wai" (worshiping Western and adoring foreign) and for not supporting domestic products. I'm scared and sweat all over and throw away everything immediately.

(21 year old female survey participant, Shanghai)

As soon as the man started his Ferrari, his clothes were blown off.

(male survey participant, Shanghai)

Such imagined transformations are no doubt at odds with the promotional goals of Western brand producers.

Western brand fantasies enlivened by the redemptive narrative manifested in dreams that represented a replacement strategy. That is, while asked to write a dream about a Western brand, participants offered imaginings of Chinese national brands that succeeded in the global market, leading to a more esteemed self, bolstered by China's leading economic position in the world economy. Imaginings included not only carrying Chinese domestic brands into foreign markets, like flags marking territorial expansion, but also more honored treatment by Western corporations, who reduced their prices and improved their quality to cater to more discriminating Chinese consumers. Here pride emerges as excelling on capitalist terms in the global market, with no concern for the preservation of an authentic cultural heritage. Here too, imagined identity transformations are at odds with Western promotional objectives, as consumers seek different transformations collective rather than individual. They also seek a different means of transforming the self - elevation of China's brands to global stature.

We might consider whether and how this imagined future China, one where China-made brands thrive globally and elevate the standing of China and its people, disrupts the processing of Western brand promotions. Does this desired setting thwart all processing of Western brand promotions? Or does it merely thwart processing of their fantasy-piquing content? If we apply Martin's (2004) model, two possibilities seem likely. First, Chinese consumers' preferred imagined setting 
is different from that proposed in Western brand promotions; this may lead consumers to ignore Western brands. Second, consumers may attend to the consumption fantasy offered by Western brand producers, but replace it with one that serves their imagined future China. Such replacement fantasies may take the form of a parody or appropriation of the promotionally cued fantasy, or one that otherwise serves to dis-identify the consumer with the Western brand. We sought further insights into these questions from our interview data.

Finally, Western brand fantasies historicized with the narrative in which the West is an economic partner gave rise to imaginings of a moderately affluent self that was not in conflict with China's collectivist orientation. All Chinese individuals were envisioned as more materially affluent. Dreams entailed imagined transformations compatible with those promoted in Western brand advertisements (Wang 2000). They also entailed those that, if engaged as "replacement" fantasies (Martin 2004), would undermine Western brand promotions by shaping meanings different from those intended by the producers. Fantasies of dramatically altering Western brands to suit local tastes would be such a case, such as adding sweeteners or orange flavors to Coca-Cola. Here again, we question whether by asking our Chinese consumers to provide a dream of a Western brand we accessed fantasies that otherwise would not be commonly evoked. Chinese consumers who hold a partnership view of Western brands may not view them as exotic "other" capable of dramatically transforming the self, thereby reducing the identity motivation for enlivening consumption fantasies. We sought additional insights into this question from our interview data.

\section{The influence of national narratives of East-West relations on the processing of Western brand promotions}

Our interview data offered insights into how consumption fantasies enlivened by national narratives may operate in everyday life to influence brand decisions and processing of Western brand promotions. Considering our interview participants as cases, these reveal multiple profiles characterized by distinctive patterns of nationalist discourses, consumption practices, the identity meanings attached to Western brands, propensity to attend to Western brand advertisements, and propensity to fantasize from them. We suggest that participants' national narrative discourses are indicative of mental rehearsal of these narratives. Given this, we offer insights into how imaginings drawn from these narratives precondition consumers' responses to Western brand promotions that seek to pique the imagination, and offer four cases to illustrate.

\section{The West as experiential venue, Western brands as instruments of freedom}

Several interview participants possessed a profile seemingly shaped by discourses of the West as experiential venue and Western brands as instruments of freedom. We illustrate with the case of Ms Roma. 
I often read the "Fashion" and "Ella" magazines. They often promote some new items. When they do, I'll cut the colored page and look to buy them when I go shopping... I don't plan very much. Like setting a maximum amount of money. . . (laughs) I never think about prices . . . Cosmetics, I switch a lot, mostly foreign brands. Now I'm using Lan-kou (Lancôme). Before that I used Bei-jia-en, American brand Ya-shi-lan-dai (Estee Lauder) . . . The glasses I wear, Calvin Klein . . . They are available at Sai-te [Japanese operated department store] and Tai-ping-yang [Atlantic Ocean] Department Store ... I use Swatch a lot . . everybody knows it's made in Switzerland . . . Because [being overweight] I can't buy too many clothes, (laughs) I still have to spend my money. For shoes... it's probably an Italian brand, most of my leather shoes are this brand [Jade Peace] . . I like Lancel the most, it's for bags, a French brand. I think the brand's style fits me very well. . . Lancôme [has the best Western brand name] "Lan" for "Lan-hua" (magnolia or orchid flower), "kou" for "Dou-kou-nian-hua" (early teens of a girl-refering to beautiful age) ... its advertisements are usually around a petal. When we are talking about it now, I feel as if I can see it.

Ms Roma, a 30 year old Beijing resident who works as a director and editor for a local news organization, could well be presumed to be the editor of international news stories or popular business books in the West that report the escalating demand of the Chinese consumer. Consider the similarity of her reported consumption practices with the earlier excerpt from Garner's (2005) The Rise of the Chinese Consumer.

Changes in consumer habits have now rendered some old stereotypes rather dated, especially where it concerns China's rising upper-middle class in the first-tier cities. Sophistication has become more important and taste among the upper-middle class is increasingly converging towards that of the Western consumer, especially as many international magazines are publishing local editions in China (fashion magazines and even Elle Décor) ...

(Garner 2005, 84)

Ms Roma acquires an abundance of Western brands at a level fantasized by some of our study's student participants, as China's future professional class. The brands she acquires are primarily from categories of conspicuous consumption: cosmetics, apparel, shoes, jewelry, and accessories. She reports feeling liberated in having choices and an opportunity to find styles that are compatible with her own. A student of Western cultural practices, she studies Western fashion magazines for instructions on Western brand purchases. She saves and savors their visual imagery. In our discussions she is an unabashed consumerist, who claims that when shopping for Western brands she "never think(s) about price". For Ms Roma, Western brands are a source of identity enhancement. Her practice of switching Western brands within product categories and acquiring these in several varieties, suggests an attraction to the transformational promises of new, exotic Western 
brands. During the interview, when talking about specific Western brands, Ms Roma spontaneously imagines them. She uses both the phonetic sound-meaning of the Chinese $c i$ [word] of the brand name to mentally picture the brand, and visualizes imagery from Western brand ads she has seen.

Exhibiting Deng's promoted erasures of political debates (Liu 2004) throughout the interview, Ms Roma never speaks of political ideology and its relationship to Western brands. Near the end of the session, when questioned on this, she declares that personal comfort with the brand is the only salient criterion. From this profile, we suggest that the national narrative of gaige kaifang, and government discourses of China as a vast market for Western brands, disseminated while China was vying for WTO membership, alleviate identity conflicts of Western brand consumption with nationalism and socialism. Fantasies of individualism and material luxury as forms of play and escape are encouraged by this narrative, rehearsals of which (entailing a "quest for moderate affluence") pave the way for receptiveness to Western brand visual stimuli. As a result, consumers seeking identity enhancement are predisposed to focus attention on Western brand visual stimuli (Martin 2004), and further, to fantasize the positive identity transformations presented in Western brand promotions.

\section{The West as imperialist oppressor, Western brands as instruments of domination}

Our second profile, comprising participants whose discourses reflected the narrative of the West as imperialist oppressor, is illustrated with the case of Ms Nice, a 40 year old Beijing resident and manager for a foreign company.

Actually before we renovated this apartment we bought everything of domestic brands ... Actually we are very patriotic .... We bought this TV this one time because we needed a big one, and our domestic brands don't have this. And its color and size fit this place. Thus we had to buy theirs [a foreign brand]. The same is with cars. The quality of our domestic brand cars is poor. The cars always have problems. Before I had a [domestic car]. When it's hot in summer, you couldn't start it, or it quit while running. This may not sound so good, but anything linked to domestic, their quality will not be good. Now I have a Japanese Nissan. ... Many domestic brands just don't work. My efforts do not fall short of my patriotism, but my satisfaction does. You spend a lot of money but domestic brands always make you uncomfortable. There is nothing you can do about it. Finally we decided to buy imported goods. Why do so many people buy famous brands? The quality is there... There are famous domestic brands too, for example Hai-er air conditioner.

Unlike Ms Roma, early in the interview and without prompting, Ms Nice associated patriotism with loyalty to domestic brands. Although she does not avoid all Western brands, it is noteworthy that, in contrast to Ms Roma, she does not purchase them in luxury or personal care/appearance categories. Ms Nice's Western 
brand acquisitions are only electronic/mechanical goods, which constitute a large financial commitment (her television and automobile). For these, she is compelled to offer justifications. These suggest a theme of bittersweet liberation in which Western brands free her from the exhausting, restraining effects on everyday life wrought by unreliable domestic brands. Ms Nice laments that her patriotism is not rewarded with satisfaction when buying domestic brands.

Ms Nice's conflict was echoed by many survey participants who responded to the multiple sentence-completion items in ways that reflected a desire to buy national brands in the face of their beliefs that these did not offer quality comparable to Western brands.

[If all foreign brands disappeared from the Chinese market, I would ...] feel happy because Chinese can have a good market for our own products; but meanwhile I'm afraid that the stuff I buy will not have guaranteed quality.

(survey participant, no demographic data, Shanghai)

[Foreign brands always ...] offer good service and their product quality is good.

[The greatest disadvantage of foreign brands ...] is that they hurt domestic brands.

(21 year old male survey participant, Shanghai)

[Foreign brands always ...] have good quality and expensive price.

[The more foreign brands I have ...] there will be fewer domestic brands.

(23 year old female survey participant, Shanghai)

[Then more foreign brands I have ...] the more I want to cheer for national industry.

(19 year old female survey participant, Beijing)

[The more foreign brands I have ...] the higher I feel my status is. [Dream] I will dream that Chinese brands become all the rage in the country and foreign brands no longer have the supreme power.

(23 year old male survey participant, Beijing)

At no point during the interview does Ms Nice speak spontaneously of shopping for Western brands, as did Ms Roma. Nor does she imagine foreign brands. She neither visualizes the brand name meaning nor recalls the visual imagery of Western brand advertisements. In line with Martin's (2004) suggestions, Ms Nice does seek active participation in an imagined setting. She imagines China as a society that shares collectivist concerns and a desire to assert this through domestic brand choice (see also Cayla and Eckhardt 2008). Her desire to be in this imagined setting places her outside the identity frame offered by Western brand producers (Wang 2000).

From this profile we suggest mental rehearsals of the national narrative of the West as oppressor may inhibit imaginative processing of Western brand visual promotions in two ways. First, it may pre-empt focus on Western brand visual 


\section{Narratives in the imaginative processing of Western brand promotions}

stimuli, as it places the consumer in an opposing imagined setting in which the imagined settings depicted in many Western ads of a leisurely, cosmopolitan life (Wang 2000) offer little allure. Further, participation in these commercially cued imagined settings would pose identity conflicts, and thus offer benefits of neither escape nor play as facilitating fantasizing (Martin's 2004). Imaginative processing of Western brand promotions may also be inhibited by the narrative of Western brands as instruments of Western domination conjured to shape "replacement" fantasies (Martin 2004). These replacements would counter the imaginings of positive identity transformations which commercial producers of Western brands attempt to incite (Wang 2000), perhaps rendering the advertisements themselves difficult to recall.

We returned to our projective survey data (the dreams) to inquire further into why participants with profiles similar to Ms Nice do not imagine Western brands or spontaneously recall advertisements for them. The following responses reflect our theories of the use of replacement fantasies.

[The more foreign brand products I have], the more I pursue them. [Dream] Have never had this kind of dream. I think if I were to dream, it will be about a brand that is created by me and transferred to China.

(20 year old female survey participant, Beijing)

Replacement dreams in some instances reflect a narrative that begins with the positive transformation promoted by Western brand producers (for example dreams of enhanced or extraordinary athletic performances following the acquisition of Western brand sports equipment). Yet a "replacement fantasy" takes place in that the ultimate outcome of consumption is one that harms the self or identity.

[The more foreign brand products I have] the more I feel that China's national industry should learn from those foreign companies. I actually very much support domestic products, but deep in my heart don't feel comfortable when buying. [Dream] One day, I'm wearing a pair of Nike shoes and playing basketball with friends. Because of the shoes, I played very actively on the court, very engaged, and that makes all my friends stare at my shoes. Later I don't know how, my foot stepped aside and I sprained my ankle. I can't believe it, with Nike shoes on, my foot was injured!

(21 year old female survey participant, Beijing)

Interpreting the body here as the self or collective self (Tung 1994), the participant conveys that the high-performance brand may ultimately create a loss of standing among Chinese, who feel that Western brands threaten domestic brands.

\section{The West as subjugated, conquered Western brands as redemption}

As a third profile, several of our interview participants were sensitive to what they deemed humiliating or disrespectful practices by Western companies. 
Ms Sun, a 26 year old pharmaceutical representative residing in Tianjin, serves as our example.

In fact, I didn't really find anything better than other brands such as Zhonghua (China)... I couple of years ago, I used to use Piao-rou (Rejoice), Panting (Pantene), Sha-xuan (Sassoon), and Li-shi (Lux). But in recent years, I found that other, domestic brands, even those not very famous brands have similar effects, but their prices are much lower. So, I sometimes use those brands... Since childhood, we progressed from hair washing paste to shampoo, the popular brands were Feng-hua (bee flower) . . . Later when Piao-rou and Pan-ting entered the market, they immediately took over the domestic market, because after you use them, the effect is really good ... But in recent years, I feel all brands are similar. . . except for their fame and ads, there isn't much difference in quality... No domestic appliance brand is satisfactory to me...I use Sony and Aiwa ... I read an article which suggests that ... Japanese products made for Europeans are better quality than those made for Asian people. After reading it, I was very angry and really didn't want to buy any Japanese products. Why is it that way? ... Supermarkets such as Jia-le-fu (Carrefour), ... it's from France ... there are occasions when the quality is not good, it's really discriminating against Chinese. . . They know that Chinese consumers are just that, thus they aren't as strict with some products as they are in France. But it still is better than others. If something feels good to use, I would be satisfied, whether or not it's foreign.

Like Ms Nice, Ms Sun acquired both domestic and foreign brands, using assessments of quality to judge the merits. There is, though, a reversal of the preference order reported by Ms Nice. Ms Sun, whose discourse seems to be shaped by narratives of "erasure of humiliation," reported early use of better-performing foreign brands, followed by a switch to domestic brands which over time had been able to emulate similar quality at a lower price. Neither conspicuous consumption of Western branded luxury goods nor goods used primarily for the purpose of individualization pose an identity threat to Ms Sun. She compares domestic brand cosmetics and Western brand cosmetics and defends a specific Western brand (Red Earth) as offering novel colors which create a more individual persona. Ms Sun is, however, sensitively aware of specific Western brands whose manufacturers treat Chinese disrespectfully. This took various forms, one being the discrimination seen in offering products to Chinese consumers that were inferior to similarly labeled Western brands sold in the West. Another form was that of Western brand producers offering older versions of the brand in China while distributing newer versions in Western nations. Ms Sun's consumption ideology did not involve wholesale boycotting of Western brands, but rather selective avoidance of those whose corporate practices were revealed as racially/nationally discriminating.

Ms Sun's concerns mirror some of the comments of our survey participants regarding such discrimination. 


\section{Narratives in the imaginative processing of Western brand promotions}

My friend had a dream that his Sony walkman turned into a Japanese person and told him, "You are stupid. I was originally damaged in Japan, and after being packaged again, exported to China and was bought by you at a high price. You are so nice, ha ha!' My friend woke up with cold sweat all over his body.

(20 year old male survey participant, Beijing)

What is thought in dreams is actually the wish to make up what is missing in reality. The following are some of my wishes for foreign brands . . . 1. In any country, the commodity concept that a brand represents is unchanged. There shouldn't be any quality discrimination based on country or region .... . 2. The high cost in delivering high quality should not necessarily be expressed by locking into high end consumers. Otherwise it would seem snobbish, and Chinese are very disgusted by snobbish petty men. Instead products should be developed to fit different consumer groups. 3. The claimed product quality should be consistent to the actual quality. . .

(24 year old female survey participant, Beijing)

Some survey participants expressed a desire for redemption for this disrespectful treatment in dreams where Western brands compete for their attention, treating them as discerning consumers who demand quality products.

I dream of being in Paris, coming to the square. There is a clear blue sky and suddenly a flock of doves in formation fly above me as a crowd of salespeople of various famous foreign brands come my way. Everyone of them is shouting to me, "Come! Little girl! Try the newest Nike running shoes and see if they are comfortable." "No, Do not use Nike. Reebok products are better" ... After leaving the square driving a Mercedes which was loaded with various famous brand products, I returned home. My face was all smiles!

Returning to the case of Ms Sun, her consumption experiences also offer a striking contrast to those of Ms Roma, who embellished her imaginings of Western brands by drawing from Western brand icons and advertisements. During the interview, Ms Sun does not draw from these to enliven her imagination, but rather comments on Western brand advertisements as well-funded manipulative tactics to generate perceptions of familiarity and fame irrespective of meaningful differences in quality. Indeed, not all survey participants who noted that "foreign brands always ..." "have well funded ads," viewed this as positive. Many, like Ms Sun, saw it as potentially deceptive and manipulative. Further, whereas some Chinese consumers admired the pretty packaging of Western brands, others found it a weakness, and still others found it deceptive. In the sentence-completion items a few participants noted that "the greatest weakness of foreign brands is . .." "too much packaging." Interview participants also made comments such as "I think the reason why foreign brands are so popular is because they have too much advertising, it's like everywhere. Turn on the TV, many are foreign brand commercials" (23 year old female interview participant, Beijing). 
Drawing from Ms Sun's profile, we suggest that mental rehearsal of the national narrative of redemption which seeks "erasure of humiliation" does not impede consumers' attentiveness to the visual stimuli of Western brand promotions. However, it does seem to thwart fantasies of positive identity transformation (Wang 2000) by rendering consumers sensitive to manipulation and discrimination. Earlier research that activated "skepticism" by having consumers play the role of critic found that consumers shift away from imaginative processing and towards benefit-based processing (Escalas 2007). We suggest that the redemptive narrative with its themes of discriminatory treatment serve to activate skepticism, leading these Chinese consumers to engage in benefit-based processing of Western brand promotions rather than imaginative processing (Escalas 2007). This finding echoes and elaborates the findings of the 2007 China Brand Report, which announces “Today's Chinese consumers no longer have the mentality to look up to foreign brands. Rather, they consider what's behind a brand name with more cognitive thought" (p. 326). The Report's documentation of discriminatory practices by Western producers serves to activate Chinese consumers' skepticism while contributing to a national narrative of redemption from past humiliations at the hands of Western nations.

\section{The West as economic partner, Western brands as instruments of economic progress}

Finally, our fourth profile represents those who fully embraced the ideology of the market economy, whereby Western brands are both partners and rivals that spur improvement. Ms Jin, a 28 year old accountant residing in Baoding, is our illustrative case.

Under the presupposition that the quality of both domestic and foreign products are the same, I'll definitely choose our national brand. But if that condition is not met, it will depend. If our domestic products don't have good quality, buying them does not mean patriotism, but it will even hurt the economy's growth in the long run .... When you buy computers, you choose Lianxiang [Lenovo], you would think it's a Chinese brand. But as a matter of fact, its core technology is foreign with a Chinese shell. I think in these instances it does not matter if you choose Chinese or foreign . ... I think medicine has its special characteristics. Chinese medicine, it has to be domestic; Western medicine or antibiotics, it has to be foreign ... In the clothes category, I never buy any foreign brands because they are all made in China anyway, only they are changed into a Western brand name. China is the number one clothes manufacturing country in the world, including many famous Italian brands. ... I like shopping at Yi-jia [IKEA] furniture store. It's Swedish and its items are really very expensive. .. If something is too expensive, I will go to other stores and buy something similar. Brands are not important, the first consideration is price, then quality, and third is brands. 


\section{Narratives in the imaginative processing of Western brand promotions}

Ms Jin argues early in our interview that to choose an inferior-quality domestic brand does not reflect patriotism at all. She argues that, indeed, to prop up inferiorquality goods is detrimental to China's economic growth.

This theme also was common in sentence-completion statements from our survey participants.

[If all foreign brands disappeared from the Chinese market, I would . . .] feel sad for my country and nation because competition is good for the growth of the domestic industry.

(survey participant, Baoding)

[If all foreign brands disappeared from the Chinese market, I would . . .] feel disappointed and scared because from then on Chinese brands will degenerate because of lack of competition.

(survey participant, Beijing)

[The more foreign brand products I have...] the more threat it is to domestic products of the same kind, but this kind of competition is beneficial to the development of industry.

(20 year old female survey participant, Beijing)

In subsequent discussions, Ms Jin notes the irrelevance of brands owing to increased Chinese-Western partnering in assembly and manufacturing. In particular she calls attention to clothing brands, noting that even Western brands are made in China. The lesser importance of the choice between domestic brands and Western brands manufactured in China was expressed in other ways in our survey data. Here, one participant echoes Ms Jin's sentiments that "In the clothes category, I never buy foreign brands because they are all made in China anyway, only they are changed into a Western brand name."

[Dream] Two people went to purchase clothes for interviews. The shopping center was filled with famous brands, what brand should they buy? Domestic? Imported? Which one? They would walk around first. Wow. Pierre Cardin looked so good when trying it on. The prices seemed to be O.K. They came to the cashier who told them the price. They were shocked, as it turned out that they had overlooked a "0." Embarrassed they had to flee out of there. Ah, maybe we should just go to the market to take a look. They came to a small store. The owner who overheard it was clothes for interviewing immediately introduced "Look at this one, it looks exactly the same as the Pierre Cardin in another store, but the price is far different. Try it on?" Putting it on the effect was really good, but it was a counterfeit product. Never mind, that's it, 3000 Yuan, "Pierre Cardin". He gladly went to the interview. What a coincidence! The interviewer was wearing the same suit. My goodness, surprisingly, the first thing that the interviewer said was "Our tastes are very similar!" He was very happy.

(22 year old female survey participant, Tianjin) 
Where foreign versus domestic designations have relevance to Ms Jin is in areas where product development is tied to cultural history, for example Chinese medicine or Western antibiotics. She recognizes that foreign brands, if unaffordable, can be imitated more cheaply, with satisfactory results. As she sums up, "brands are not important." Ms Jin, and others possessing a similar profile, never mentions imagining Western brand advertisements, icons, logos, or phonetic sounds. From this profile we suggest that mental rehearsal of the narrative whereby the West is deemed partner diminishes the sense of "otherness," "exoticism," and transformational power attributed to Western brands (Wang 2000). Western brands as a meaningful consumption category are diminished, as are preconditions to fantasizing about them (Martin 2004). As occurred for those endorsing a redemptive narrative, our interview participants who spoke of Western brands as partners engage in benefit-based processing of brand promotions rather than imaginative processing, where they become transported in personal narratives of how the brand will change their lives. It would seem that, for these participants, awareness of manufacturing partnering led to skepticism regarding the source-quality arguments advanced by others who held Western brands to be of better quality. In turn, this skepticism thwarts imaginative processing while encouraging benefit-based processing. The ambivalence toward national versus Western brand categories exhibited by these participants does not, however, mean that they see brand choice as apolitical, as they remain aware of the nationalistic meanings attached to brand choices by other consumers.

\section{Discussion}

Our findings suggest refinements and extensions to Martin's (2004) theory. First, we found that consumers use historical cultural narratives to enliven their fantasies. This history was a repository for creative imaginings which hold meanings that are both compatible with and in contrast to those disseminated by Western brand producers. We also found that the enlivenment of consumption fantasies need not require visual aids, as the concept "Western brands" is linked in memory to the material objects they represent. In our research, which did not cue commercial sources of meaning, individuals' consumption fantasies were revealed as drawing from various discourses and depictions of Western brands, including those disseminated by non-Western brand producers of local national culture, both commercial entities and the governing body. These varied representations comprise the stock from which individuals may either embellish commercial images of Western brands or replace them with their own imagination (Martin 2004).

Martin's (2004) theory does not link such use of a historically embellishing strategy with resources provided by national or cultural narratives. In Martin's (2004) game context, participants shaped their own narratives piecemeal, from one turn at play to the next. Their historical contextualizations drew from familiar scenes in science fiction books and films in the fantasy genre, an example of which would be Lord of the Rings. Yet, Martin's (2004) work does connect with those of other consumer culture theorists who recognize the value of cultural narratives 


\section{Narratives in the imaginative processing of Western brand promotions}

in shaping consumption fantasies. These studies carried out in Western contexts reveal that cultural narratives embody salient identity meanings, providing not only content for enlivening consumption fantasies, but also the motivation for doing so (Arnould and Price 1993; Arnould, Price, and Tierney 1998; Peñaloza 2001). When a cultural narrative is accessible, however, imaginings may draw from this as a script, much like Martin's participants drew from novel and film scripts.

We also found that national narratives used by our Chinese participants emerged as organizing scripts, which guided the use of other strategies for shaping fantasy (Martin 2004). A given strategy, such as multiplying Western brands (Martin 2004), could render a pleasant fantasy via a mental image of an abundant leisurely life, or an unpleasant fantasy of domination via widespread instantiation of Western culture. As guided by the narrative, consumers relied on specific strategies to express consumption ideologies symbolically. As well as drawing on cultural narratives, consumers are at the same time engaging in an embellishment strategy whereby they imbue the consumption object with a history: that is, they "historicize" it (Martin 2004, 145).

Martin's (2004) theoretical antecedent - the desire to participate in an imagined setting - applies not only to magic games. As noted by political science scholars and consumer culture theorists, through their responses to Western brands individuals can imagine themselves part of an imagined global community (Arnett 2002), an imagined regional community (the Asia-Pacific; Cayla and Eckhardt 2008), or an imagined nation-state (Arnett 2002). An imagined China is conceived differently by different individuals in ways shaped by cultural narratives, which have multiplied since the economic reforms of the 1970s (Cayla and Eckhardt 2008; Gries 2004). These narratives, which draw selectively from China's history, guided some participants' consumption fantasies.

National narratives are creative resources for contextualizing Western brand consumption fantasies with historical settings and meanings, leading to different propensities to fantasize about Western brands. Whereas some narratives lead to imaginative processing which is advantageous to Western brand producers, others lead consumers to conjure replacement fantasies or to carefully scrutinize promotional content by way of benefit-based rather than imaginative processing (Escales 2007).

Beyond the desire for escapism and play (Martin 2004), individuals' compulsion to fulfill identity projects provides motivation to enliven and historicize fantasies of consumption. Our participants enlivened their consumption fantasies by engaging national narratives of East-West relations - that is, how China as a nation-state is related to national powers of the imagined West. These fantasies embodied ideals for enacting Chinese nationality via consumption practices. Our findings suggest that, because national narratives shape individuals' identity projects (Mick and Buhl 1992) and comprise the extended self (Belk 1988), they offer both motivation and content for enlivening consumption fantasies (Arnould, Price, and Tierney 1998; Mick and Buhl 1992). Contrary to the simplistic notion that nationalism or patriotism is asserted via protectionism and domestic brand loyalty (Pecotich and Rosenthal 2001), our analysis reveals a more complex meaning. 
Nationalist narratives include forms which encourage international exchange and Western brand consumption in the "spirit of nationalism" to promote the economy of a nation-state and elevate the living standard of its citizens. With prescriptions ranging from boycotting to selective screening out to indulgence, these narratives reflect the complex ideological scene in China (Liu 2004). In individuals' fantasies of Western brands, China's revolutionary legacy and the various ways it has been framed in nationalist discourses permeate Chinese consumers' imaginings.

In fantasizing, individuals imagine transformative outcomes of consumption experiences (Arnould and Price 1993; Belk et al 2003). We found that the form of the imagined transformation was guided by the choice of narrative (Arnould, Price, and Tierney 1998). In our global context of Western branded consumption, narratives prompted transformation such that once individuals engaged a cultural narrative to embellish a thought, they became caught up in it, often imagining themselves as actors who evolved within the narrative (Escalas 2007; Wang and Calder 2006).

Consumption fantasies can be not only pleasant but also unpleasant, for example victimization narratives that drew from collective memories of cultural loss, including losses that predated the imaginers' lives. Individuals also enlivened consumption fantasies with hypothetical scenarios of cultural demise at the hands of oppressive Western brands, reflecting geopolitical concerns regarding the global economy. The imagined transformations drawn from these narratives were of disparagement and lost identity. Thus, whereas earlier works highlighted consumers' use of cultural narratives to enliven fantasies that reinforce the value of commercial offerings, our work suggests that some narratives challenge the goals of Western brand producers.

Our findings show that nationalist narratives may influence consumers' processing of Western brand visual stimuli in four ways. First, they may reinforce attempts to pique the consumer's imagination, as in the case Ms Roma, whose discourses drew from a narrative of the West as offering freedom. Here, by representing a compatible imagined setting (Martin 2004) and eliminating identity conflicts, this narrative paves the way for pleasurable escapism (Martin 2004) and encourages consumers to imaginatively process brand promotions that play to this theme (Escalas 2007; Wang and Calder 2006).

Second, imaginings drawn from nationalist narratives may counter Western brand fantasies by supplying opposing imagined settings and replacement fantasies that undermine the effectiveness of visual stimuli. This emerged as the likely effect of the narrative portraying the West as imperialist oppressor and calling for loyalty to domestic brands. Earlier research suggests that the downside of getting consumers to process brand advertisements narratively is that they will be transported too far in their autobiographical memories (Escalas 2007). Proposed remedies involve creating tighter linkages of the brand with self-narratives (Escalas 2007). Remedies tied to promoting rehearsal and imagining of self-narratives may be more challenging or less effective in cultures where collective interests are valued. Drawing from Martin's (2004) theory of "replacement" fantasies, we suggest that counter-fantasies are an additional threat to brand ads that promote narrative processing. Among Chinese consumers, elicited autobiographical mem- 
ories may be linked to collective memories of the nation-state, the "iron bowl," and the recent dismantling of the "iron bowl" as a result of economic transformation (Croll 2006).

Third, imaginings enlivened by nationalist narratives may heighten skepticism regarding Western brands. Our participants' comments drawing on a redemptive narrative showed that they felt Chinese consumers were seen as gullible and treated unfairly relative to consumers in the West. Heightened skepticism associated with rehearsing this nationalist narrative promoted benefit-based rather than imaginative processing of brand advertisements (Escalas 2007). Finally, narratives such as the West as partner may neutralize the "otherness" of foreign brands to the extent that they impede the fantasies of identity transformation that brand producers seek to encourage (Wang 2000).

Future research might increase our understanding of this interplay. Readerresponse studies of specific Western brand advertisements may offer some insights (Mick and Buhl 1992). Future research might also consider marketers' efforts to counteract consumers' engagement with particular nationalist narratives that might result in unpleasant imaginings. Further, it would be interesting to see how advertisements that attempt to evoke one narrative can be undermined by elements that inadvertently activate others. Returning to the advertisement described in the Introduction, Kentucky Fried Chicken created an advertisement depicting a host of hungry Chinese soldiers who received and then devoured boxes of KFC chicken. This imposes a historical context in which the United States and China are allies. Even though the theme was intended to represent friendliness and alliance, other elements in the ad seemed to activate a sense of humiliation, such that overall the advertisement would have a damaging effect on the Chinese people's image.

Future research might consider whether such commercially imposed contexts pre-empt others that consumers might more readily imagine. If Western brand fantasies are conducive to the formation of marketplace rituals, a comparison made by McCreery (1995) seems relevant. Highlighting that rituals are often challenged by the lures of advertising, he observes that whereas "ritual accesses a settled world in which cultural categories are fixed, where cultural principles never change," "ads assume a world in which . . . media-based messages propose transformations in relationships between persons and goods" $(1995,326)$. Here, the historical context attempts to represent the KFC brand as a gift to an ally, which might challenge a ritualized fantasy of Western brands as the weaponry of an opponent.

In summary, individuals may engage nationalist narratives to enliven their consumption fantasies of Western brands. In so doing, individuals assert culturally shaped consumption ideologies, and in the process bolster national aspects of their identity. This process may either reinforce or undermine the imaginative processing that guides the design of Western brand advertisements. Although various institutions (both commercial and the nation-state) disseminate narratives that map out alignments of nationalism with competing prescriptions for responding to foreign brands, these positions are not shaped solely by a ruling elite: individual consumers may choose their own narratives when imagining marketplace offerings, and in doing so shape cultural consumption ideologies. 


\section{Citizen-consumers in an age of globalization}

Chinese consumers use Western brands to assert their version of national identity. This emerged from findings that Chinese form meanings for Western brands, drawing from select historical national narratives of East-West relations: the West as experiential venue and Western brands as instruments of freedom; the West as oppressor and Western brands as instruments of domination; the West as subjugated and Western brands, by their own subjugation, as symbolically erasing China's past humiliations; and, the West as partner, such that Western brands are instruments of economic progress (Gries 2004). Our theory elaborates processes by which Western brands are shaped by macro-level sociohistorical forces to motivate consumers' responses to them as acts of nation-making (Gerth 2003, 2008). Further, we theorize the different ways in which national narratives of international relationships can intervene in individual processing of Western brand promotions that seek to pique consumers' imaginations.

Our theory of the use of Western brands in Chinese nation-making aligns with broader academic discourses of "citizen-consumers" which recognize that individuals' actions are increasingly guided by civic concerns (Trentmann 2007, 147). As observed by Trentmann (2007), the notion of citizen-consumers represents a conjoining of concepts during the last decade which in academic tradition and public discourses were placed in opposition. This oppositional relationship emerged through discourses of a modern world that enticed people towards individualistic consumerist pursuits and away from civic interests. More recently, global brands from Western nations, rather than material goods in general, are vilified as reducing people's engagement in the collective public interest (Klein 2003). Owing to their large capital bases and political influence, Western brands are observed to dominate public spaces and the media, leaving no realm free to voice public concerns that are outside the market interest (Klein 2003). Trentmann's (2007) work calls attention to the nature of this oppositional relationship between citizenship and consumption. As he argues, the conception of citizenship and consumption is tied to a particular historical shaping of civic-mindedness, whereby citizens were deemed independent arms-bearing men, rooted to the land and living an organic communal identity (Trentmann 2007). The shift in Western research over the past decade towards the civic potential of consumption is attributable to multiple movements noted by Trentmann (2007). First, the spread of neoliberalism 
spanning the latter part of the 20th century and the start of the $21 \mathrm{st}$, which had the effect of privatizing territory that previously belonged to the public domain (Trentmann 2007). In developed Western nations, particularly the United States and the United Kingdom, the spread of neoliberalism was manifested in the privatization of education, utilities, and the military - whereby these former state-run operations were handed over to commercial entities or otherwise expected to operate as profit centers (Giroux 2005; Singer 2003; Stromquist 2002). This has given rise to social movements, some of which appropriate the neoliberal discourses of "consumer choice" to advocate for more voice and participation in these institutions (Rosen 2003). Certainly, in post-reform China privatization has been a more sweeping experience, changing the once government-supplied housing, education, healthcare, jobs, manufacturing facilities, retirement plans, vacation/holiday sites, and other aspects of everyday life (Croll 2006).

A second impetus to this increased attention to the civic potential of consumption has been advanced through gender studies calling attention to the agency of women in influencing public affairs through consumption (Trentmann 2007). Others call attention to the promotions of public and private institutions seeking to engage women as civic-minded consumers capable of cultivating in their children the patriotic consumption of national goods (Gerth 2003, 2008). Historical studies also recognize consumer boycotts as a form of civic action for colonized people (Trentmann 2007).

Together these streams of historically oriented research recognize consumption as a sphere of political action. Such studies have often been anchored in nationalism and imperialism, whereby consumers' support for domestic brands is used to assert patriotism (Gerth 2003, 2008; Trentmann 2007). More recently, consumer culture researchers have recognized that transnational corporations do not hold a monopoly on the institutional shaping of brand meanings and have enhanced our understanding of state influence on the meanings of consumer goods (Zhao and Belk 2008). National governments are active in creating identity frames for their citizens, which in some countries include ideals for responding to branded consumer goods (Belk, Ger, Askegaard 2003). We extended theorizing by recognizing that national brand choices are not the only ones used to assert patriotism or nationalism. Rather, for some, consuming Western brands was consistent with a national project of asserting China's status in the global economy, elevating the status of its consumers, and supporting its entry into the World Trade Organization.

Our work contributes to studies of citizen-consumers, filling knowledge gaps noted by Trentmann (2007), who calls attention to the need for an understanding of how shifts in the notions of citizenship and consumption are appropriated by institutions and individuals in their daily lives.

. . . there remains a gulf between the study of behavior, values and symbols, and the study of institutions broadly defined. Law, regulatory regimes, national and transnational processes of governance - these deserve greater attention in the study of consumer cultures. Finally, there is a gap between 
micro and macro levels of understanding consumers as citizens. The long and rich literature on citizenship has been oriented towards the public side of norms and practices [that elides the everyday workings of politics that might be revealed by study of consumer practice] . . . Following practice reveals consumption as a series of evolving processes. Consumption is about doing things, purpose and accomplishment as well as symbols and communication: it is about fulfilling certain tasks ... It is the practice that shapes public life, rather than the goods themselves or their symbolic value. . . Consumption practices depend on external conditions, including policy and infrastructures, but consumers, through their practices, also help to shape these systems ... Consumers through their everyday practices, consciously or unconsciously leave their mark on these larger social systems.

(Trentmann 2007, 155)

Our research shows that the social processes of citizen-consumer practice emerge out of national traditions and the reconstructions of national cultural heritage and cannot be uncoupled. This book reveals how Chinese people attempt to leave their mark on a larger social system by responding to Western branded products in various ways to realize their imaginings of the future China. They are attempting to brand the "new China" in the same way that governing administrations in China are actively involved in "country brandings" (Wang 2008, 2). We note that many of the branded products of the West discussed by our Chinese participants also refer to corporate brands, for example Coca-Cola, Jeans West, KFC, Nike, and Mercedes. That is, products comprising the corporation's portfolio have been branded through icons, labels, and promotional campaigns that attempt to infuse them with the identity of the corporate brand. Corporate brand identity is built from communications that articulate who the company is and what it stands for that distinguish it from other organizations (Schultz and Hatch 2006). The values and beliefs of the corporation shape the brand identity and serve as the basis for securing consumers' affinities toward, identification with, and emotional attachments to the brand. Our findings suggest that the more specific, distinctive, or niche-oriented identity and lifestyle positions that Western corporations seek to cultivate through their branded products may to some extent become conflated in the eyes of Chinese consumers, for whom the brand's association with "the West" is its most distinguishing feature. Yet, as our analysis highlights, the meanings of "West" in relation to nationalism are multiple and competing, and require an indepth knowledge of specific consumer groups.

Looking to the future of brand research in China, we note that other studies of citizen-consumers take global brands and the transnational corporations that produce them as focal, and examine citizen activism asserted through the consumption of brands whose producers practice fair trade, reject sweatshop products, and otherwise engage in corporate practices that reflect sensitivity to or participation in global human rights causes (Klein 2003; Trentmann 2007). Development-oriented non-governmental organizations (NGOs) have begun to engage significantly with the market and consumer culture. NGOs now target consumers with goods 


\section{Citizen-consumers in an age of globalization}

that compete with global brands in the realms of clothing, jewelry, gifts, music festivals, and travel venues, yet by distinguishing themselves from these global offerings they present themselves as "humankind" brands (http: //www.youtube. $\mathrm{com} / \mathrm{watch}$ ? $\mathrm{v}=\mathrm{eQK} 6 \mathrm{ODxDfDY}$ ). This positioning is a double-mission one: in positing a human race that encompasses the global community, it presents a challenge to national identity with a collective identity that supersedes it. Thus, it poses a challenge to the commercial brands of for-profit organizations (whether domestic or foreign) that seek to tap into nationalistic sentiments. The "humankind" rhetoric of NGOs also references their particular mandates to eradicate poverty, protect the environment, and guarantee human rights. Thus, their branded goods claiming to accomplish these missions while satisfying consumers' needs and desires position them as ethical relative to those of corporations that rarely link to such values, except in cases where they partner with NGOs in social marketing programs. We suggest that the future of brands in China as a domain for asserting citizenship will likely continue to be dichotomized in terms of competition between Western and China-made (Gerth 2003, 2008). Global NGOs, however, may shift the terms of brand competition from price, quality, and technological sophistication to the relative benefits they offer society. 


\section{Appendix: Outdoor advertisements of Western brands in China}

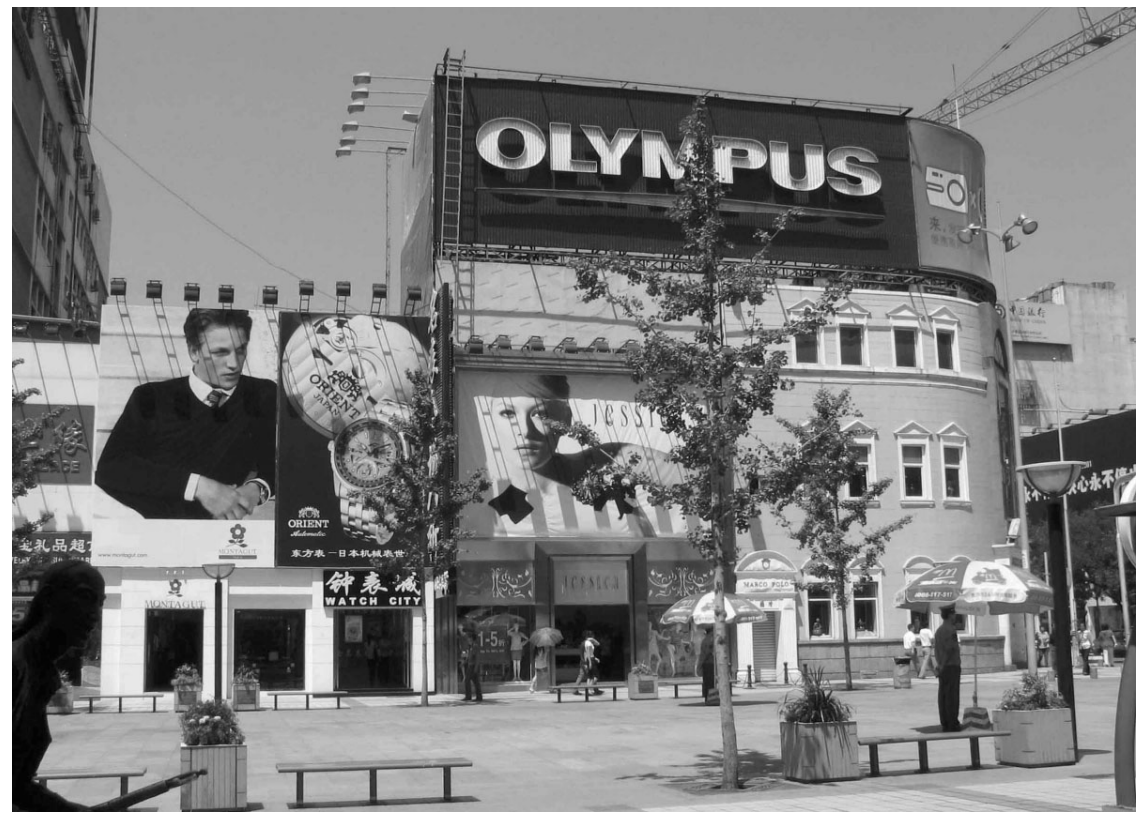

Image 1. Outdoor advertisements of Western brands are a prominent part of China's consumption-scape. As depicted here, many Western brand advertisements play up their exoticness through the use of Western Caucasian models. 


\section{Outdoor advertisements of Western brands in China}
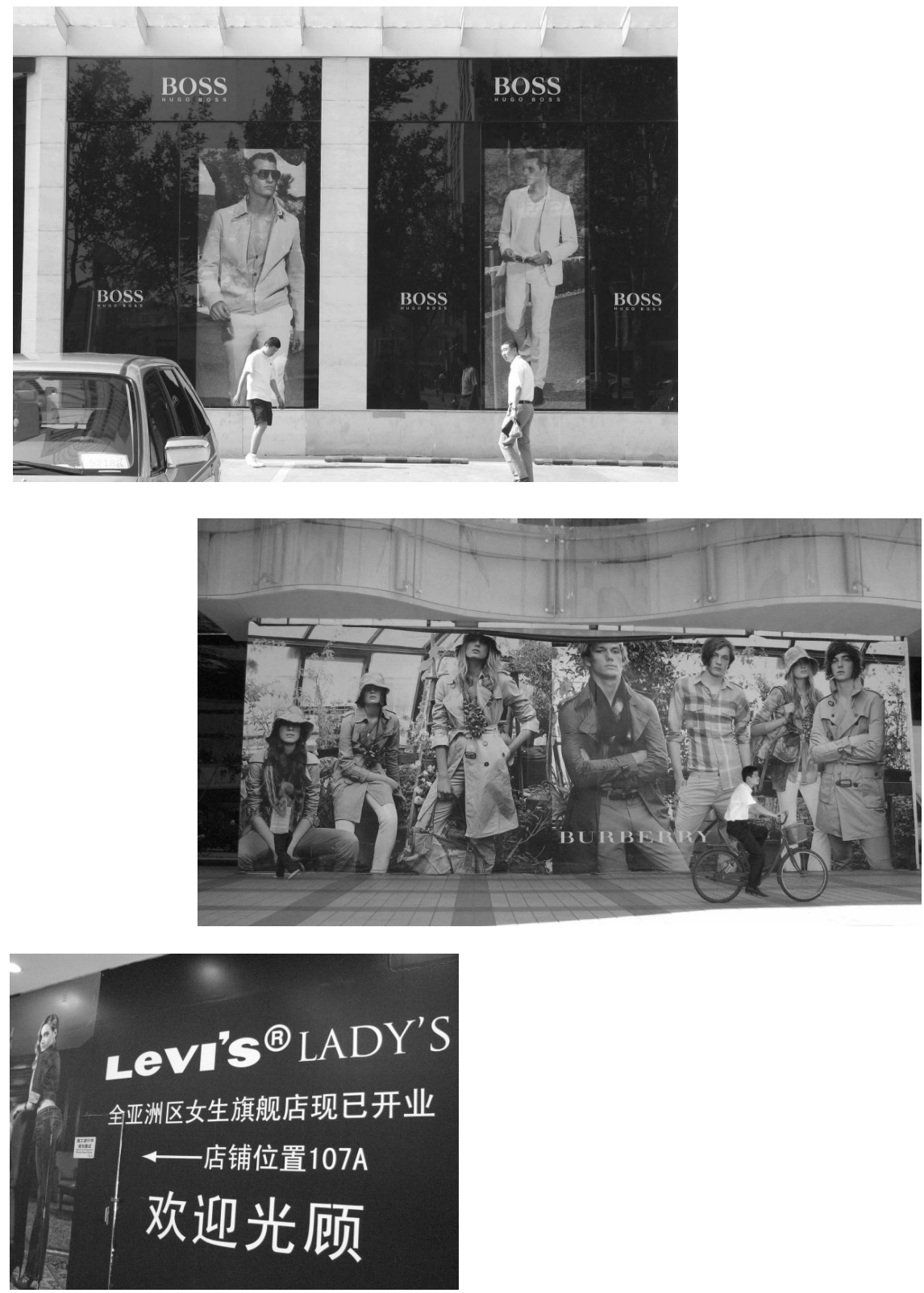

Image 2. Clothing brand Hugo Boss highlights Western otherness through use of Caucasian models in a Beijing store front.

Image 3. Burberry similarly plays up its Western culture origins through youthful Caucasian models in outdoor advertising in Wangfujing, a major shopping street of Beijng.

Image 4. Levi's conveys foreign-ness through both models and use of English terms such as "lady." 


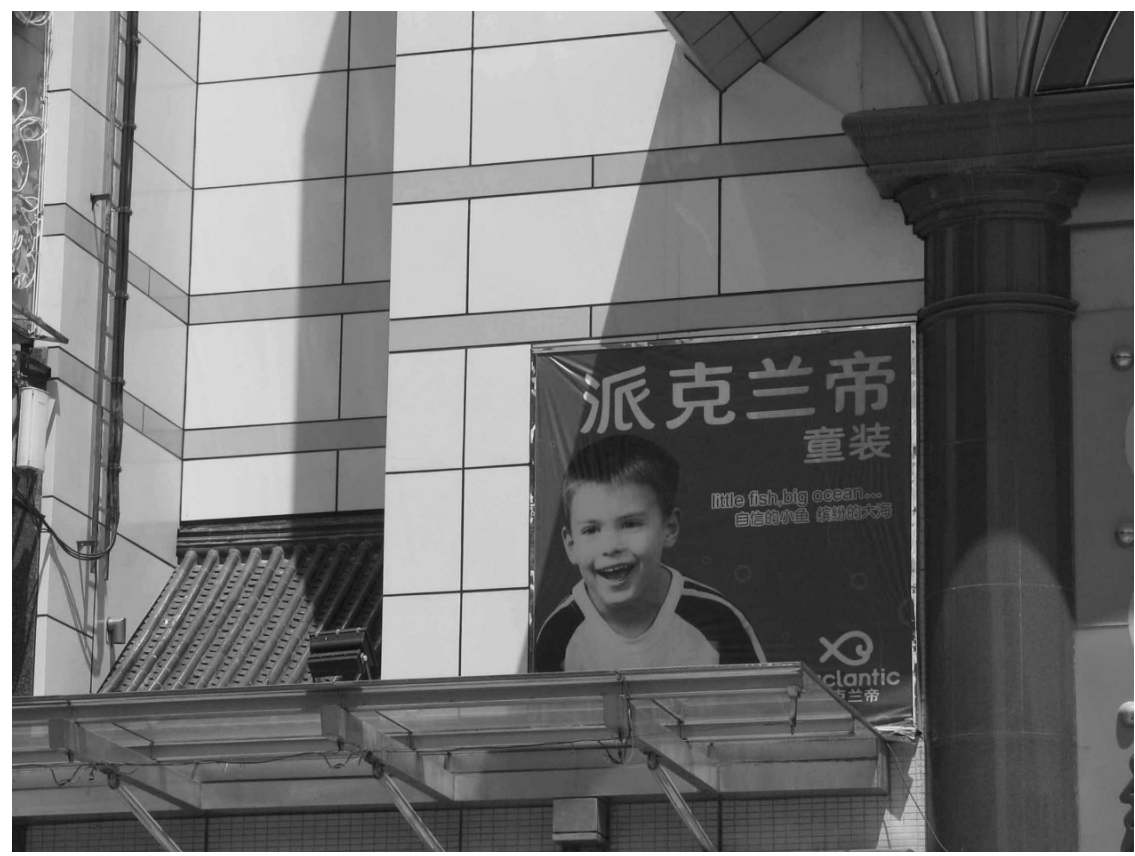

Image 5. Even Caucasian children are used as models in this advertisement for Paclantis, which sells children's clothing and plays up Western-ness, despite its AsiaPacific origins. Paclantis, founded in 2002, has survived the years of market competition. This brand, created by a business man from Taiwan, is "pacificatlantic" $\rightarrow$ Paclantis, though the translated name PaiKeLanDi is used on all marketing activities. The translated name gives people a subtle implication that this is a western brand. Not surprisingly, the image of a white boy is used on its $\mathrm{ad} /$ poster. 


\section{Outdoor advertisements of Western brands in China}
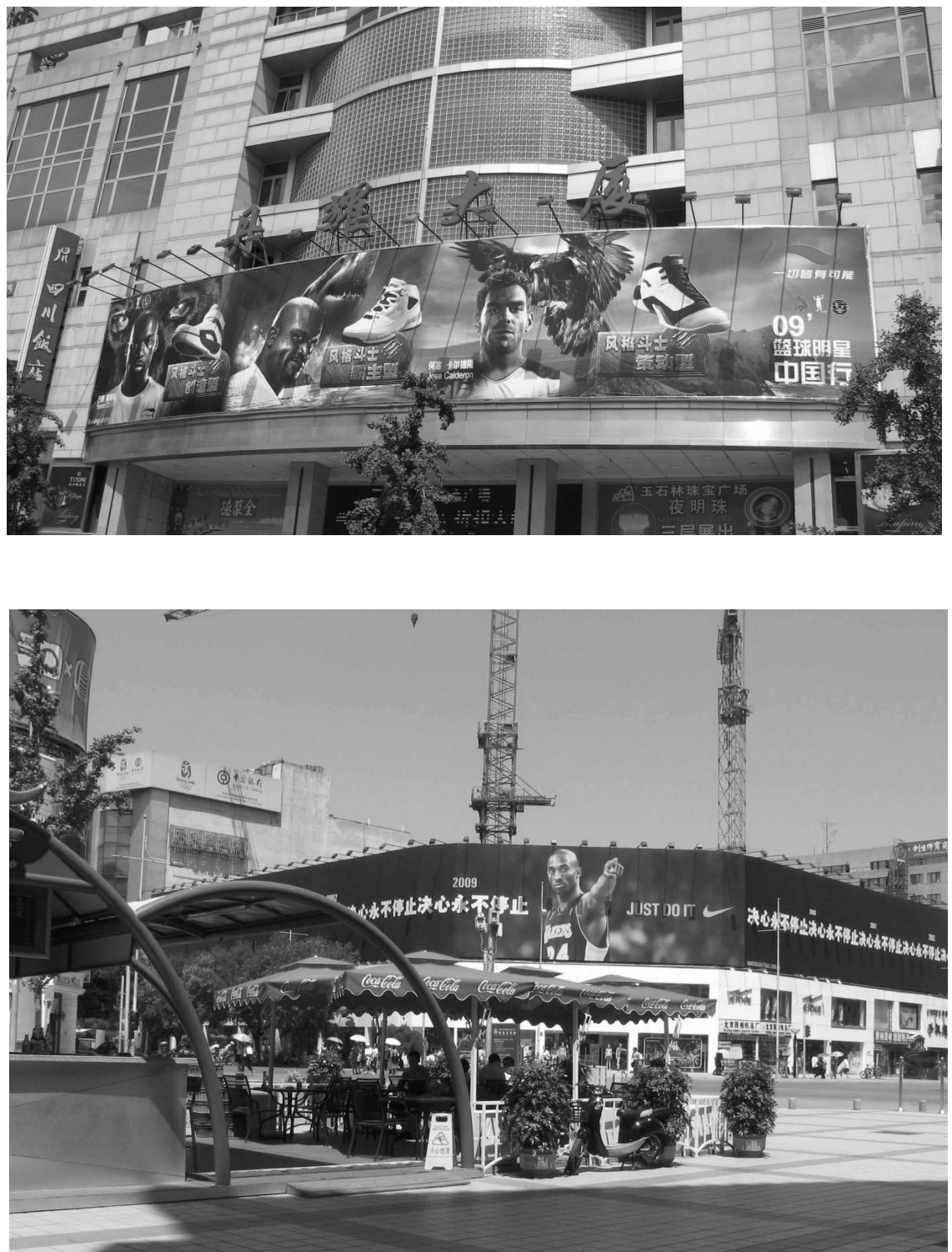

Image 6 and 7. Western sports brands, such as Nike, also convey Western otherness through use of internationally famous sports celebrities. 


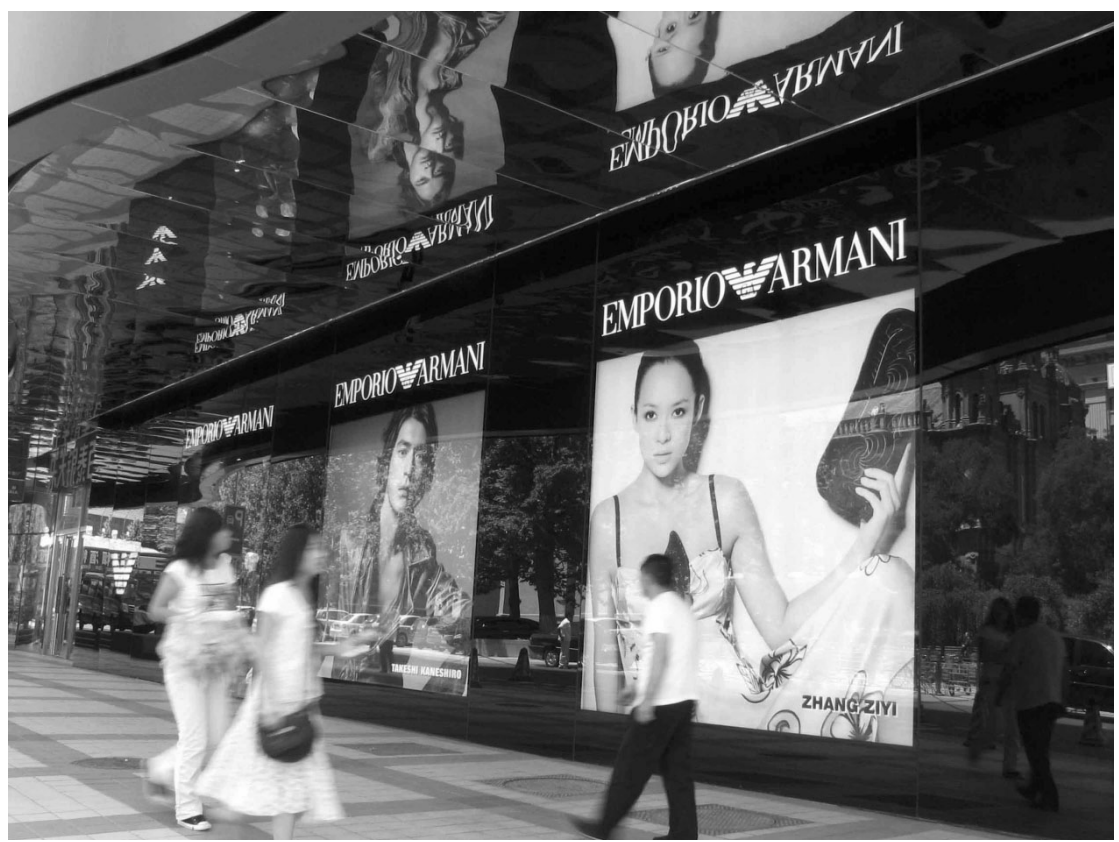

Image 8. Armani engages globally known Asian actors/actresses to suggest its brand's global fame while at the same time localizing its appeal. Here the film stars of the 2005 release "House of Flying Daggers" Zhang Ziyi and Takeshi Kaneshiro are featured. 


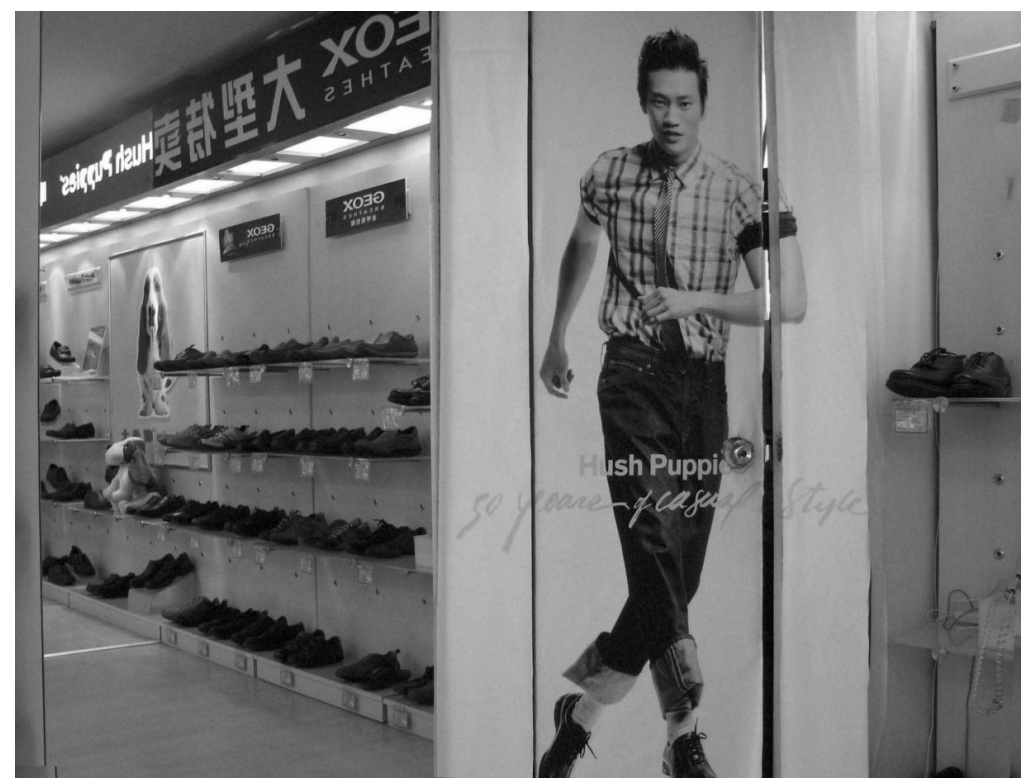

Image 9. Western shoe brand, Hush Puppy, uses an Asian model to localize its appeal while using the English language slogan " 50 years of casual style" to designate foreignness. The slogan references the brand's history of casual style that predates China's economic reforms.

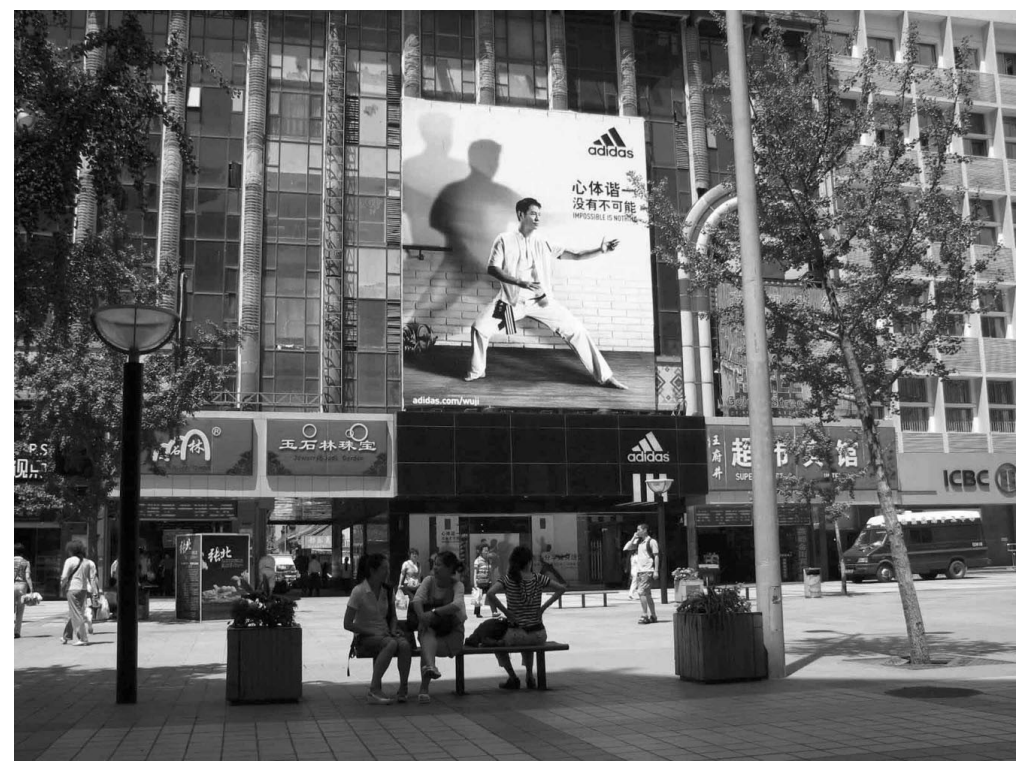

Image 10. Contrasting Nike's use of Western athletes in advertisements, here Adidas localizes its appeal through use of both an Asian model and a martial arts context. 



Image 11 and 12. Kissing in public is considered as belonging uniquely to Western culture and lifestyle. A London-based Western brand features kissing on its billboard affixed to a multi-story store building that sells specifically expensive "internationally famous brands." 

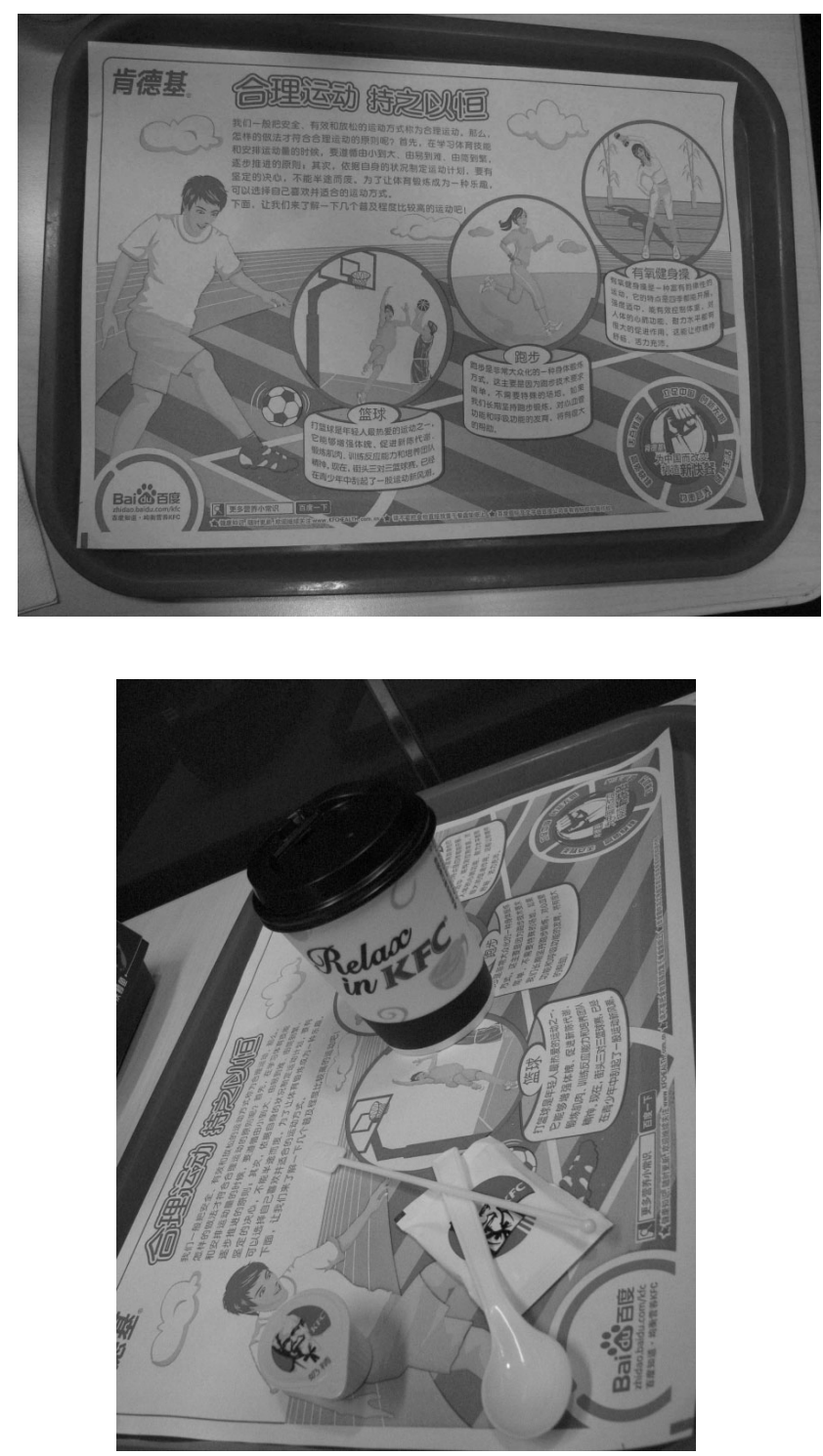

Image 13 and 14. Some efforts of Western brands to localize their offerings are more explicit. Unlike the tray liners in the United States, the tray liner in the Beijing KFC contains information/tips on how to exercise wisely. Parts of the KFC tray insert read: "Exercise reasonably and frequently" and "We have changed for China and created new fast food. To have a foothold in China, we strive for endless innovation, and delicious and safe food that is good and fast while balancing nutrition for a healthy life." Other information offers instructions on how to exercise. The coffee cup reads in English "Relax in KFC," conveying its localization, in contrast to the "fast-food" notion of the West. 


\section{References}

Abbas, Ackbar (2000), "Cosmopolitan De-scription: Shanghai and Hong Kong," Public Culture, 12 (3), 769-86.

Abu-Lughod, Lila (2005), Dramas of Nationhood: The Politics of Television in Egypt, Chicago, IL: University of Chicago Press.

Arnett, Jeffrey J. (2002), "The Psychology of Globalization," American Psychologist, 57 (October), 774-83.

Arnould, Eric J. and Linda L. Price (1993), "River Magic: Extraordinary Experience and the Extended Service Encounter," Journal of Consumer Research, 20 (June), 24-45.

Arnould, Eric, Linda Price and Patrick Tierney (1998), "Communicative Staging of the Wilderness Servicescape,” Services Industries Journal, 18 (July), 90-115.

Arnould, Eric J and Craig J. Thompson (2005), "Consumer Culture Theory (CCT): Twenty Years of Research," Journal of Consumer Research, 31 (4), March, 868-82.

Askegaard, Søren (2006), "Brands as a Global Ideoscape," in Brand Culture, ed. Jonathan Schroeder and Miriam Salzer-Mörling, New York: Routledge, 91-102.

Balmer, John M. (2006), "Corporate Brand Cultures," in Schroeder, Jonathan E. and Miriam Salzer-Mörling eds., Brand Culture, New York: Routledge, 34-49.

Baum, Richard (1994), Burying Mao: Chinese Politics in the Age of Deng Xiaoping, Princeton, NJ: Princeton University Press.

Bauman, Zygmunt (2007), Consuming Life, Malden, MA: Polity.

Belk, Russell (1988), "Possessions and the Extended Self," Journal of Consumer Research, 15 (September), 139-67.

(2003), Tourist Photos: Signs of Self, Salt Lake City, UT: Odyssey Films.

Belk, Russell, Güliz Ger, and Søren Askegaard (2003), "The Fire of Desire: A Multisited Inquiry into Consumer Passion," Journal of Consumer Research, 30 (December), 32651.

Belk, Russell and Nan Zhou (2001), A Reader Response Analysis of Global and Local Appeals in Chinese Consumer Advertising, Salt Lake City, UT: Odyssey Films.

Bonsu, Samuel K. and Russell W. Belk (2003), "Do Not go Cheaply into That Good Night: Death-Ritual Consumption in Asante, Ghana," Journal of Consumer Research, 30 (June), 41-55.

Brownell, Susan (2001), "Making Dream Bodies in Beijing: Athletes, Fashion Models, and Urban Mystique in China," in China Urban: Ethnographies of Contemporary Culture, ed. Nancy Chen et al., Durham, NC: Duke University Press, 123-42.

Business Week (2001), "The Best Global Brands," August 6. Online. Available http://www. businessweek.com/magazine/content/01_32/b3744001.htm (accessed December 21, 2009). 


\section{References}

Campbell, Colin (1994), "Capitalism, Consumption and the Problem of Motives: Some Issues in the Understanding of Conduct as Illustrated by an Examination of the Treatment of Motive and Meaning in the Works of Weber and Veblen," in Consumption and Identity, ed. Jonathan Friedman, New York: Routledge, 23-46.

Cayla, Julien and Giana M. Eckhardt (2008), "Asian Brands and the Shaping of a Transnational Imagined Community," Journal of Consumer Research, 35 (August) 216-30.

Cha, Ariana Eunjung (2008), "Chinese Consumers Eager to Excel at the American Pastime," The Washington Post, November 15 ${ }^{\text {th }}$, A11, http://www.washingtonpost.com/wp-dyn/ content/article/2008/11/14/AR2008111403648.ht . . .

Chang, Iris (1997), The Rape of Nanking: The Forgotten Holocaust of World War II, New York: Basic Books.

China Daily (2003), “Ad Posters, Billboards Seen Around Late Chinese leader's Statue in SW City," December 30. Online. Available: <http://www.chinadaily.com.cn/en/ doc/2003-12/30/content_294675.htm> (accessed December 20, 2008).

China Daily (2007a), "New Coffee Shop Replacing Starbucks in Forbidden City," September 24. Online. Available < http://www.chinadaily.com.cn/china/2007-09/24/ content 6129640.htm $>$ (accessed December 21, 2009).

China Daily (2007b), "Starbucks Must Leave Forbidden City," March 14. Online. Available $<$ http://www.chinadaily.com.cn/china/2007-03/14/content_826979.htm> (accessed December 21, 2009).

China Daily (2007c), "Will Starbucks Move From the Forbidden City," January 17. Online. Available <http://www.chinadaily.com.cn/citylife/2007-01/17/content_785987.htm> (accessed December 21, 2009).

China Economic Times (2007). Available <http: //www.sina.com.cn 2007年07月26日 23: 25 中国经济时报> (accessed December 21, 2009).

Ci, Jiwei (1994), Dialectic of the Chinese Revolution: From Utopianism to Hedonism, Stanford, CA: Stanford University Press.

Comaroff, John L. and Paul Stern (1995), "New Perspectives on Nationalism and War," in Perspectives on Nationalism and War, ed. John L. Comaroff and Paul C. Stern, Amsterdam: Gordon \& Breach.

Coulter, Robin, Linda Price, and Lawrence Feick (2003), "Rethinking Origins of Involvement and Brand Commitment: Insights from Postsocialist Central Europe," Journal of Consumer Research, 30 (September), 151-69.

Croll, Elisabeth (2006), China's New Consumers: Social Development and Domestic Demand, New York: Routledge.

Cui, Geng (1997), "The Name Game: Foreign and PRC Brands Race to Build Their Reputation and Market Shares in China," China Business Review, 24 (6), 40-3.

Deng Xiaoping (1993), Den Xiaoping wenxuan (Selected works of Deng Xiaoping), Vol. 3, Beijing: Renmin chubanshe.

Escalas, Jennifer E. (2007), "Self-referencing and Persuasion: Narrative Transportation Versus Analytical Elaboration," Journal of Consumer Research, 33 (March), 421-9.

Fog, Klaus, Christian Budtz, and Baris Yakaboylu (2005), Storytelling: Branding in Practice, Berlin: Springer.

Fong, Mei and Norihiko Shirouzu (2009), "Chinese Consumers Buck Trend by Spending More," http://online.wsj.com/article/SB124017282486432633.html.

Friedman, Jonathan (1992a), "Myth, History, and Political Identity," Cultural Anthropology, 7 (May), 194-210.

(1992b), "The Past in the Future: History and the Politics of Identity," American Anthropologist, New Series, 94 (December), 837-59. 
(1994), Consumption and Identity, New York: Routledge.

_ (1996), "The Politics of De-authentification: Escaping from Identity, A Response to

'Beyond Authenticity,' by Mark Rogers,' Identities, 3 (1-2), 127-36.

(1997), “GlobalCrises, the Struggle for Cultural Identity and Intellectual Porkbarrelling:

Cosmopolitans Versus Locals, Ethnics and Nationals in an Era of De-hegemonisation," in

Debating Cultural Hybridity: Multi-Cultural Identities and the Politics of Anti-Racism, ed. Pnina Werbner and Tariq Modood, London: Zed Books, 70-89.

Garner, Jonathan (2005), The Rise of the Chinese Consumer: Theory and Evidence, West Sussex, England: John Wiley \& Sons.

Gerth, Karl (2003), China Made: Consumer Culture and the Creation of the Nation, Cambridge, MA: Harvard University Press.

- (2008), "Consumption and Politics in the Twentieth-Century China," in Citizenship and Consumption, ed. Kate Soper and Frank Trentmann, New York: Palgrave Macmillan, $34-50$.

Giroux, Henry A. (2005), "Kids for Sale: Corporate Cutlure and the Challenge of Public Schooling," in H. Svi Shapiro, David E. Purpel eds. Critical Social Issues in American Education: Democracy and Meaning in a Globalizing World (3 ${ }^{\text {rd }}$ ed.), 143-162.

Gries, Peter Hays (2004), China's New Nationalism: Pride, Politics, and Diplomacy, Berkeley, CA: University of California Press.

Hamilton, Gary G. and Chi-Kong Lai (1989), "Consumerism Without Capitalism: Consumption and Brand Names in Late Imperial China," in The Social Economy of Consumption, ed. Henry J. Rutz and Benjamin Orlove Lanham, MD: University Press of America, 253-79.

Han Zhongkun (1999), “Zhongguo, bushi yibajiujiu [This Is Not 1899 China]” Renmin Ribao [People's Daily], 12 May 1999.

Hilgard, Ernest R. (1980), "Consciousness in Contemporary Psychology," Annual Review of Psychology, 31, 1-26.

Hoffman, Lisa (2001), "Guiding College Graduates to Work: Social Constructions of Labor Markets in Dalian," in China Urban: Ethnographies of Contemporary Culture, ed. Nancy Chen, et al., Durham, NC: Duke University Press, 43-66.

Holbrook, Morris B. and Elizabeth C. Hirschman (1982), "Experiential Aspects of Consumption: Consumer Fantasies, Feelings, and Fun," Journal of Consumer Research, 9 (September), 132-40.

Hong Kong General Chamber of Commerce (2004), "PRD Patriot's Paradox," Online. Available <http: www.chamber.org.hk/info/the_bulletin/feb2004/brands.asp > (accessed December 21, 2009).

Hroch, M. (1996), "From National Movement to the Fully-formed Nation: The Nationbuilding Process in Europe," in Becoming National: A Reader, ed. G. Eley and R. G. Suny, New York: Oxford University Press, 60-78.

Ind, N. (2001), Living the Brand, London: Kogan Page.

Kimura, Junko and Russell Belk (2004), Santa Claus is Coming to Town: Assimilation of Christmas in Japan, Film Festival Screening, Association for Consumer Research, North American Conference.

Kjeldgaard, Dannie and Søren Askegaard (2006), "The Glocalization of Youth Culture: The Global Youth Segment as Structures of Common Difference," Journal of Consumer Research, 22 (September), 231-47.

Klein, Naomi (2003), No Logo: Brands, Globalization \& Resistance, Northhampton, MA: Media Education Foundation.

Knowledge@W.P. Carey (2009), “Trade, China and the World Economic Order, Part 3: 


\section{References}

Business Leaders' Advice on Succeeding in China," May 6. Online. Available $<$ http:// knowledge.wpcarey.asu.edu/article.cfm?articleid $=1773>$ (accessed December 21, 2009).

Kozinets, Robert V. and Jay M. Handelman (2004), "Adversaries of Consumption: Consumer Movements, Activism, and Ideology," Journal of Consumer Research, 31 (December) 691-704.

Kuhn, Robert (2000), In Search of China, PBS documentary co-produced with K2 Media and WETA, Alexandria, VA: PBS.

Li Fang (1996), Women zhe ydairen de meiguo qingjie (Our Generation's America Complex), in Zhongguo ruhe shuo bu (How China should say no). Special issue of Zuojia tiandi (Writer's world Journal).

Li Guangdou (2004), The Competitiveness of Brand, Beijing: People's University of China Press.

Liu Kang (2004), Globalization and Cultural Trends in China, Honolulu: University of Hawaii Press.

McCreery, John (1995), "Malinowsky, Magic and Advertising: On Choosing Metaphors," in Contemporary Marketing and Consumer Behavior, ed. John Sherry, Sage, 309-29.

Manning, Paul and Ann Uplisashvili (2007), “'Our Beer': Ethnographic Brands in Postsocialist Georgia," American Anthropologist, 109 (December), 626-41.

Martin, Brett S. (2004), "Using the Imagination: Consumer Evoking and Thematizing of the Fantastic Imaginary," Journal of Consumer Research, 31 (June), 136-47.

Mason, Roger S. (1981), Conspicuous Consumption: A Study of Exceptional Consumer Behavior, Farnborough, Hants: Gower Publishing.

Mick, David G. and Claus Buhl (1992), "A Meaning-based Model of Advertising Experiences," Journal of Consumer Research, 19 (December), 317-38.

Mick, David G. and Susan Fournier (1998), "Paradoxes of Technology: Consumer Cognizance, Emotions and Copying Strategies," Journal of Consumer Research, 25 (2), 123-43.

Miller, Daniel (1994), "Style and Ontology," in Consumption and Identity, ed. Jonathan Friedman, New York: Routledge, 71-96.

Miller, Daniel (1998), "Coca-Cola: A Black Sweet Drink from Trinidad," in Material Cultures: Why Some Things Matter, ed. Daniel Miller, Chicago: University of Chicago Press, $169-87$.

News Guangdong (2006), "KFC Forced to Re-shoot TV Advertisement," April 21. Online. Available http://www.newsgd.com/news/China1/200604210011.htm (accessed December 21, 2009).

O'Cass, Aron, and Kenny Lim (2002), "Understanding the Younger Singaporean Consumers' Views of Western and Eastern Brands," Asia Pacific Journal of Marketing and Logistics, 14 (4), 54-70.

Pecotich, Anthony and Melissa J. Rosenthal (2001), "Country of Origin, Quality, Brand, and Consumer Ethnocentrism," Journal of Global Marketing, 15 (2), 31-60.

Pei, Minxin (2008), China's Trapped Transition: The Limits of Developmental Autocracy, Harvard University Press.

Peñaloza, Lisa (2001), "Consuming the American West: Animating Cultural Meaning and Memory at a Stock Show and Rodeo," Journal of Consumer Research, 28 (December), 369-98.

People's Daily (2000), "Starbucks Café in Forbidden City Under Fire." November 24. Online. Available <http://english.people.com.cn/english/200011/24/eng20001124 56044.html $>$ (accessed December 21, 2009). 
Price, Linda and Eric Arnould (1998), "Conducting the Choir: Representing Multi-method Consumer Research," in Representing Consumers' Voices, ed. Barbara Stern, London: Routledge, 339-64.

Ratner, Jonathan (2009), "Chinese Consumer Growth Could Hurt U. S.," National Post, June 15, http://network.nationalpost.com/np/blogs/tradingdesk/archive/2009/06/15/chinese-consumers ... .

Reissman, Catherine Kohler (1993), Narrative Analysis, Newbury Park, CA: Sage Publications, London.

Rook, Dennis (1985), “The Ritual Dimension of Consumer Behavior,” Journal of Consumer Research, 12 (December), 251-64.

Rosen, Lisa (2003), "The Politics of Identity and the Marketization of U. S. Schools: How Local Meanings Mediate Global Struggles," in Kathryn Anderson-Levitt, ed. Local Meanings, Global Schooling: Anthropology and World Culture Theory, New York: Palgrave McMillian, 159-82.

Rowlands, Michael (1994), "The Material Culture of Success: Ideals and Life Cycles in Cameroon," in Consumption and Identity, ed. Jonathan Friedman, London: Routledge, 147-66.

Schroeder, Jonathan E. and Miriam Salzer-Mörling (2006), Brand Culture, New York: Routledge.

Schultz, Majken and L. de Chernatony (2002), "Special Issue on Corporate Branding," Corporate Reputation Review 5.

Schultz, Majken and Mary Jo Hatch (2006), "A Cultural Perspective on Corporate Branding: The Case of LEGO Group," in Brand Culture, ed. Schroeder, Jonathan E. and Miriam Salzer-Mörling eds., New York: Routledge, 15-33.

Singer, Peter (2003), Corporate Warriors: The Rise of the Privatized Military Industry, Ithaca, NY: Cornell University Press.

SOHU.com (2005). Available http://business.sohu.com/s2005/maidlad.shtml (accessed December 21, 2009).

Song, Qiang et al., (1996a), Zhongguo keyi shuobu (China Can Say No). Beijing: Zhonghua gongshang lianhe chubanshe.

Song, Qiang et al., (1996b), Zhongguo haishi neng shuobu (China Can Still Say No). Beijing: Zhongguo wenlian chubanshe.

Spring, Joel (2003), Educating the Consumer-citizen: A History of the Marriage of Schools, Avertising, and Media, Mahwah, NJ: Lawrence Erlbaum Associates.

Stromquist, Nelly P. (2002), Education ina Globalized World: The Connectivity of Economic Power, Technology, and Knowledge. Oxford: Rowman \& Littlefield.

Thakor, M. V. and C. S. Kohli (1996), "Brand Origin: Conceptualization and Review," Journal of Consumer Marketing, 13 (3), 27-42.

Thompson, Craig (2004), "Marketplace Mythologies and Discourses of Power," Journal of Consumer Research, 31 (June), 162-80.

Thompson, Craig and Siok Kuan Tambyah (1999), "Trying to Be Cosmopolitan," Journal of Consumer Research, 26 (December), 214-41.

Trentmann, Frank (2007), "Citizenship and Consumption," Journal of Consumer Culture, 7, 147-58.

Tsui, Anne (2007), "From Homogenization to Pluralism: International Management Research in the Academy and Beyond," Academy of Management Journal, 50 (December), 1353-64.

Tsui, Anne S., Claudia Bird Schoonhoven, Marshall W. Meyer, Chung-Ming Lau, and George T. Milkovich (2004), "Organization and Management in the Midst of Societal 


\section{References}

Transformation: The People's Republic of China," Organization Science, 15 (MarchApril), 133-44.

Tung, May P. M. (1994), "Symbolic Meanings of the Body in Chinese Culture and 'Somatization'," Culture, Medicine, and Psychiatry, 18 (4), 483-92.

Veblen, Thorstein (1925), The Theory of the Leisure Class, London: George Allen and Unwin.

Voight, Kevin (2009), "Will Chinese Consumers Rescue World Economy," CNN.com/ world business, April 28 ${ }^{\text {th }}$, http: //edition.cnn.com/2009/BUSINESS/04/28/china.consumer/index.html.

Wang, Jian (2000), Foreign Advertising in China: Becoming Global, Becoming Local, Ames, IO: Iowa State University Press.

Wang, Jian and Zhiying Wang (2007), "The Political Symbolism of Business: Exploring Consumer Nationalism and Its Implications for Corporate Reputation Management in China," Journal of Communication Management, 11 (2), 134-49.

Wang, Jing (2008), Brand New China, Cambridge: Harvard University Press.

Wang, Jing (1996), High Culture Fever: Politics, Aesthetics and Ideology in Deng 's China, Berkeley: University of California Press.

Wang, Jing and Bobby J. Calder (2006), "Media Transporation and Advertising," Journal of Consumer Research, 33 (September), 151-162.

Watson, James L. ed. (2006a), Golden Arches East, Stanford California: Stanford University Press.

Watson, James L. (2006b), "McDonald's in HongKong: Consumerism, Dietary Change, and the Rise of a Children's Culture," in ed. James 1. Watson, Golden Arches East, Stanford, California: Stanford University Press, 77-109.

Weber, Max (1930), The Protestant Ethic and the Spirit of Capitalism, trans. Talcott Parsons, London; Unwin Books.

Weng Xiangdon (2002), Branding Strategy in China, Hangzhou: Zhejiang People's Publishing House.

Wilk, Richard (1994), "Consumer Goods as Dialogue about Development: Colonial Time and Television Time in Belize," in Consumption and Identity, ed. Jonathan Friedman, London: Routledge, 97-118.

Yan, Yunxiang (2006), "McDonald's in Beijing: The Localization of Americana," in James Watson, ed. Golden Arches East, Stanford California: Stanford University Press, 39-76.

Yu, Mingyang (2007), 2007 China Brand Report, Brand Research Center of Shanghai, Jiaoton University and Shanghai Brand Promotion Center.

Yu, Mingyang (2009), 2009 China Brand Report, Brand Research Center of Shanghai, Jiaoton University and Shanghai Brand Promotion Center.

Zhang, Shi and Bernd Schmitt (2001), "Creating Local Brands in Multi-lingual International Markets," Journal of Marketing Research, 38 (August), 313-25.

Zhao, Suisheng (2004), Nation-state by Construction: Dynamics of Modern Chinese Nationalism, Stanford, CA: Stanford University Press.

Zhao, Xin and Russell Belk (2002), "Sinolization: An International Advertising Strategy for China," Journal of Asia Pacific Marketing, 1 (1), 3-18.

Zhao, Xin and Russell Belk (2004), Sinolization of a Western Holiday: The Sweethearts' Christmas, Film Festival Screening, Association for Consumer Research, North American Conference.

Zhao, Xin and Russell W. Belk (2008a), "Advertising Culture in 1930s Shanghai: globalization and Localization in Yuefenpai," Journal of Advertising, 37 (Summer) 45-56.

Zhao, Xin and Russell W. Belk (2008b), "Politicizing Consumer Culture: Advertising's 
Appropriation of Political Ideology in China's Social Transition," Journal of Consumer Research, 35 (August), 231-44.

Zhou, Lianxi and Michael Hui (2003), "Symbolic Value of Foreign Products in the People's Republic of China," Journal of International Marketing, 11 (2), 36-48.

Zhou, Nan and Russell W. Belk (2004), "Chinese Consumer Readings of Global and Local Advertising Appeals," Journal of Advertising, 33 (Fall), 63-7. 



\section{Index}

Absolut Vodka 94

Abu-Lughod, Lila 34

Adidas 69, 82, 83, 87, 93, 100, 130

advertising: adaptation of strategies 34 ;

Chengdu central square 1 ; consumption

fantasies 98-9; "famous foreign

brands" 60; images 125-31; incitement

of identity transformations 112 ;

KFC 2-4, 99-100, 120; meanings taken

from 28; nationalist narratives 119 ,

120; perceived as manipulative 114 ;

semi-colonial period 40,41 ;

technologically advanced products 101

affordability $100-1$

after-sales $61,62-3$

agency 9,26

Aiwa 113

American Standard 40

Angels 79

apocalyptic themes $85-6$

Aquascutum 131

Armani 129

Asia-Pacific 7

Askegaard, Søren 35-6

Aupres 106

Avon 44, 46

B\&Q 45

"backwardness" 77, 88, 89

Baleno 69

Baoding 53, 87, 93

Baoyu 104

Bauman, Zygmunt 51

Bausch Lomb 90

Beaty 86

beer industry 47

Beijing 2, 44, 53, 87, 93, 98

Belk, Russell W. 25, 28-9, 31, 34, 35, 99

benefit-based processing 115, 117, 118, 120
Benetton 44

billboard advertising 98-9

BMW 51; dreams about 10, 11, 71, $81-2,86,90,100$; translation of brand name 58

Bo Xilai 33, 47

Boxer Rebellion 72

boycotting $18,25,32-5,85,122$

brands $\mathrm{xv}-\mathrm{xvi}$, xvii; consumer research 35-6; historical perspective $18-19,37-50$; motives for consumption 18, 21-36; nongovernmental organizations 20, 123-4; "sinocization" 3; survey research 5169; translations of brand names 8, 56-9, 67; see also domestic brands; Western brands

Bright Dairy 11, 86

Brockevsky, Charlene 46

Buhl, Claus 16

Buick 74

Burberry 126

Cadillac 75

Calvin Klein 75, 109

Campbell, Colin 29, 32, 36

capitalism 16, 39, 41; conspicuous consumption 23; Deng's reforms 71-2; emergence of brands 37 ; globalization 6,7 ; imagined consumption 97; imperialist oppressor narrative 83; redemption narrative 13 ; transition to market economy 33 ; triumphant global 78; Weber on 29-30; see also economic reforms; market economy

Carrefour 45, 89, 113

Cat, Principle of the 72, 86-7

celebrity endorsements 59-60, 128, 129 
censorship 13

Chanel 11, 75, 82, 86, 106, 107

Chengdu 1-2, 14

Chery 92

Chiang Kai-shek 87

China Brand Report 23, 48-9, 77, 89, 94, 115

Chinese Communist Party (CCP) 21, 45, $72,73,80-1,84$

Chinese Red Flag 12, 90

Chivas 12-Year 89, 90

Christian Dior 44, 55, 66, 75

citizen-consumers $20,121,122-3$

Clinique 56

Coca-Cola 8, 51, 55, 123; dreams about 11, 14, 68, 79, 86, 94-5, 100, 104; emulative motive for consumption 23 ; standardization 66

Colgate 40,79, 105

colonialism 30; see also semi-colonial period

Communist Revolution 41

Confucianism 80, 84

conspicuous consumption $16,18,23$, 27-8, 113; collective outcomes 76; economic reforms 31 ; imperialist oppressor narrative 78 ; liberator narrative 109; see also emulative model of consumption

consumer autonomy 15,17

"consumer nationalism" $18,25,32-5$

consumer research 35-6, 97

consumption: citizen-consumers 20, 121 , 122-3; civic potential of 121-2; cultural narratives 16,17; encouragement of 15 , 21, 44-5, 74; fantasies 20,69, 97-105, 108, 117-20; as freedom 75; identity transformed through 76 ; imperialist oppressor narrative 78 ; individual psychological processing 102-5; motives for 18, 21-36; National Products Movement 41; partnering narrative 14-15; as self-expression 25; semi-colonial period 39; waves of 437 ; see also conspicuous consumption copyright issues 62,67

cosmetic products $43,65-6,95,101,109$

counterfeit goods $8,38-9,49,62$

Croll, Elisabeth 15, 18, 21-3, 30-1, 34, $42-7,50,60,69,73,75$

cultural anthropology $3,19,27-8,31-2$ cultural bias 28

cultural domination $81-4$

cultural heritage $2,4,123$; partnering narrative 14 ; redemption narrative 92 , 107

cultural hybridization 24

cultural narratives xvii, 9-15, 17, 19-20, 70-96, 118-20; consumption fantasies 117-18; imagined identity transformations 105-8; imperialist oppressor narrative $9,11-12,77-88$, 100, 104, 106-7, 110-12, 119-20; individual imaginings 103; liberator narrative $9,10-11,70-7,104,105-6$, 108-10, 119; nationalist 16; partnering narrative 9, 13-14, 93-6, 108, 115-17, 120; redemption narrative $9,12-13$, $33,88-93,107-8,112-15,120$; survey research 53

"cultural protection" 5

Cultural Revolution 1, 15, 31, 34, 42, 44, $71,81,84$

Dabao 23, 77

DeBeer's 75

Deng Xiaoping 15, 19, 37, 42, 60, 86; aspirations for affluence 73,96 ; folk art 80 ; legitimation crisis 84 ; pragmatism 78,80 ; silencing of ideological debate 71-2, 110; Southern Tour talks 44, 73

discrimination $113-14,115$

Disney 93

Disney Land 75

domestic brands: dismissal of competitiveness of 22 ; economic reform period 46-9, 50; emulative model of consumption 23; imperial China 37-9; imperialist oppressor narrative 12 , $79,110-11,112,119$; increase in 69 ; loyalty towards 16, 31, 118; National Products Movement 40-1; partnering narrative 93-6, 115-17; patriotic support for 122; quality 61 ; redemption narrative $12-13,88-93,107-8,113-15$; technological shortcomings 64-5;

"Ten-Thousand Mile Brand Journey" 33, 47-8; "time-honored" 19, 42

Donald, Jim 4-5

Dongfeng 58

double standard of Western brands 13, 49, 89-90, 113-14

Double-star 12, 90

dreams 54, 59, 62-3, 67, 68-9; consumption fantasies 100 , 101-2, 103-5; imperialist oppressor narrative $11-12,77-87,106-7,112$; 
liberator narrative $10-11,70-1,73-5$, $76,105-6$; partnering narrative $13-14$, 93-6, 116; redemption narrative 12 , $88-93,114$

economic growth 21

economic partner, the West as 9, 13-14, 93-6, 108, 115-17, 120

economic recession 46

economic reforms $15,19,31,33-4,37$,

42-9, 50, 60, 71-2; see also capitalism; gaige kaifang; market economy

electronic goods $64-5$

elites 15, 23, 30, 77

Elizabeth Arden 44

embellishment strategies 103, 104-5, 117, 118

emulative model of consumption 18 , $22-4,26-32,36$

envy 23-4

Ermou (film) 83

Estee Lauder 44, 66, 109

Europe 7, 39-40, 55

exoticism 98-9, 117, 125

expansion strategies $102,103-4$

expensiveness $68-9$

experiential venue, the West as 9, 10-11,

70-7, 104, 105-6, 108-10, 119

exports 46,47

face $28-9,86$

"famous brands" 38-9, 49, 51, 59-60

fashion $30,31,44,76,98,109,115$

Feige 56

Feng-hua 113

Fifth Avenue 79

Flying Eagle 40

folk art re-enactments $80-1$

Forbidden City 4-5, 13, 26, 84

foreign (Western) brands xvi, xvi-xvii, 2-3, 6-8, 121-3, 124; advertising images $125-31$; consumption fantasies 117-18, 119; cultural narratives 9-15, 17, 19-20; double standard 13, 49, 89-90, 113-14; economic reform period 43-7; emulative motive for consumption $18,22-4,26-32,36$; expensiveness 68-9; failures of 22; historical perspective 18-19; imagined consumption 97-102; imagined identity transformations $105-8$; individual psychological processes of enlivening consumption fantasies 20 ,
$102-5,118,119,120$; as instruments of domination $11-12,77-88,100$, 104, 106-7, 110-12; as instruments of freedom 10-11, 70-7, 104, 105-6, 108-10; international fame 59-60; lack of knowledge about Chinese responses to 5-6; National Products Movement 40; "otherness" 55-9; partnering narrative 93-6, 108, 115-17, 120; quality 60-3; redemption narrative $88-93,107-8,112-15$, 120 ; resistance to $18,24-6,32-5$, 36,50 ; ritualized responses to 16 ; semi-colonial period 40-1; survey research 19,51-69; as technologically advanced $63-7,101$; translations of brand names $8,56-9,67$

Foreign Affairs Movement 91

Forever 46

Fournier, Susan 53

freedom: seductive promises of 82-3;

Western brands as instruments of 10-11, 70-7, 104, 105-6, 108-10

Friedman, Jonathan 15, 16, 17, 34, 41, 50

Fuji 104

Fumble, Principle of the 72

Fun brand 104

gaige kaifang 37, 42-3, 71-2, 110; tourism $4,74,84$; values of $86-7$; see also economic reforms

Gao Tao 22

Gap 44

Garner, Jonathan 21, 22, 24, 109

General Electric (GE) 40

Gerth, Karl 8, 9, 18, 39, 40, 50, 59, 80

Giordano 44

globalization xv, 6, 24; brand choices xvi; center/periphery models 30 ; fragmentation 50

glocalization 24

Goodyear 56, 79

Great Britain 40, 88, 122

Great Leap Forward 84

Gries, Peter Hays 7, 19, 89, 92

Gucci 8, 23, 44, 73

Haier 92

Hamilton, Gary 18, 37-9

Hardrock Café 44

harmony 14,95

Head \& Shoulders 79, 93, 95, 101, 104

Hennessy 94, 98, 99

Hershey 56, 93-4 
Hewlett Packard (HP) 79, 104

historical perspective 18-19, 37-50; economic reform period $42-9,50$; imperial China 37-9, 49-50; semi-colonial period $39-41,50$

history, cultural 34,36

homogenization 24, 28

Hong Kong 9, 31, 40

Hongqi 58

Hongxing 56

Hu Jintao 2, 17

Hudie 56

Hugo Boss 126

Huiyuan 77

"humankind" rhetoric 124

humiliation, national $9,13,33,71,88-9$, $113,115,120$

Hush Puppy 130

identity: competing notions of 50 ; conflicts of 110,112 ; consumption fantasies 97-8, 110, 118, 119; corporate 8,123 ; cultural 15 ; historical conditions 16, 17; imagined identity transformations $105-8$; motives for brand consumption 36 ; nationalist 17 ; partnering narrative 14 ; transformed through consumption 76 ; Western brands as source of identity enhancement 109, 110; see also national identity; self

ideology 9-10, 32-3, 120; capitalist 102; Deng's reforms 72; Western consumerist 97

IKEA 115

imaginative processing 97-102, 103, $105-8,111-12,118,119,120$

imagined nation 34,118

imperial China 18, 19, 37-9, 49-50

imperialist oppressor narrative 9, 11-12, 77-88, 100, 104, 106-7, 110-12, 119-20

individualism 28, 81, 110, 121

"instinct school" 27

insurance companies 1

international fame 51,59-60

Jade Peace 109

Japan 7, 40, 55, 88-9

Japanese brands xvii, 12, 113

Jeans West 8, 123

Jiang Hongbin 5

Jian-nan-chun 94

Johnson \& Johnson 77
KFC 8, 44, 51, 123; advertising 2-4, 13, 99-100, 120; Chengdu central square 1; dreams about 10, 69, 71; emulative motive for consumption 23; translation of brand name 57; tray liners 132

Kodak 1, 40, 104

Kraft 56

labeling, social 28

Lai, Chi-Kong 18, 37-9

Lancel 109

Lancôme 66, 79, 105, 106, 109

Lao Zhang 72, 81-2

Legend 46

legitimacy $7,15,17,80$

Lenovo 13, 92, 115

Levi's 126

Li Fang 92

liberator narrative $9,10-11,70-7,104$, 105-6, 108-10, 119

lifestyle 8, 22-4, 123

Liu Kang 72, 80

L'Oreal 87

Louis Vuitton (LV) 44, 75

Lu Xun 91

Lux 57, 67, 113

luxury goods 27

make-up 43, 65-6, 95, 101, 109

Mao Zedong 12, 15, 19, 23, 37, 81;

China-as-victor discourses 88-9;

expansionism 13; National Products

Movement 41; nationalism 80;

revolutionary discourses 86 ; statues

of 1

market economy $31,33-4,45,50,73$, 102, 115; see also capitalism; economic reforms

Marlboro 56

Martin, Brett S. 102-3, 104-5, 107, 111, 117-18, 119

Marxism 72, 80

Mary Kay 44

McCreery, John 120

McDonald's 31, 44, 55, 67, 74; antiads 89; Chengdu central square 1; dreams about 68 ; emulative motive for consumption 23; localization 24; standardization 29,66

meaning $17,36,102$

media $23-4,83-4$

medicines $14,38,65,115$

Mercedes Benz 8, 51, 55, 123; dreams about 10, 70-1, 75, 82, 104, 106, 
107, 114; emulative motive for consumption 23

Metro 45

Mick, David G. 16, 53

Microsoft 10-11, 74, 75, 85, 87

military dominance $85-8$

motives for brand consumption 18 , 21-36; consumers as active meaning makers 35-6; emulative model 18 , 22-4, 26-32, 36; resistance to

Western brands $18,24-6,32-5,36$; understanding 27-8

Motorola 56, 105

National Day 2, 7, 12, 17, 26, 85 national identity $15,16,50,121$, 124; competing narratives 70 ; consumption fantasies 102 ; folk art reenactments 80-1; resistance to Western brands 25; survey research 53 ; see also identity; nationalism

National People's Congress 5

National Products Movement 40-1, 71, 77,80

national unity $16-17,84$

nationalism 3, 6, 7, 16, 19, 122; Chinese tradition 84; "consumer" $18,25,32-5$; cultural narratives 17,70 ; imperial China 39; imperialist oppressor narrative 78; Marxism integrated with 80; "Patriot's Paradox" 18, 25, 35 ; resistance to Western brands 24-5, 32-5, 36, 50; semi-colonial period 39, 41; "spirit of" 11, 118-19; Western consumption fantasies 110, 119-20; see also national identity; patriotism nation-building 6 nation-making $6,12,16,19,26,50,121$ nation-state $15,16-17,32-3,34,46-7$ nature 14,95

neoliberalism 121-2

Neumann, Frederic 26-7

Nike 8,55,67, 123; celebrity endorsements 128; dreams about 10 , $11,71,76,79,86,93,100,106,112,114$

Nokia 55, 69, 79, 100

Nongfu Spring 23

non-governmental organizations (NGOs) 20, 123-4

Ogilvy \& Mather $18,25,35$

Oil of Olay/Ulan 23, 57-8, 74-5

Olympic Games (2008) 5, 48, 92

Omega 107
Opium Wars 39-40, 91

"otherness" 6, 25, 51, 55-9, 117, 120, 126

packaging 60,114

Paclantis 127

Pampers 79

Panasonic 64, 69

Pantene 57, 113

partnering narrative $9,13-14,93-6,108$, $115-17,120$

patriotism 11, 118, 122; education in 84; National Products Movement 40-1, 80; partnering narrative 115-16; resistance to Western brands 24-6; see also nationalism

"Patriot's Paradox" 18, 25, 35

Pei, Minxin 33-4

Pepsi 55, 76

Pert 10,71, 104

Philips 64

Pierre Cardin 44, 55, 116

pirating 38-9, 49

Pizza Hut 23, 58

Poison 75, 107

political conflict 24

Prada 75

price $51,68-9,100-1,116$

Printemps 45

privatization $45,82,122$

Proctor \& Gamble (P\&G) 89

protectionism $11,12,16,80,81,118$

puddle metaphor $15-16$

Pu-dun 12, 90

Qing Dynasty 39, 87

Qingdao 46

Quaker Oats 40

quality 7-8, 51, 60-3; double standard of Western brands 49, 89-90, 113-14; imperial China 38-9; partnering narrative $115-16,117$

Red Earth 11, 113

redemption narrative $9,12-13,33,88-93$, $107-8,112-15,120$

Reebok 67, 114

regional brand names 47,50

Rejoice 113

replacement fantasies $103,107,108,112$, 119

reputation 61

restaurants 29, 34

ritual 16,120

Rolex 75, 106 
Rong-wei 48-9

Rook, Dennis 54

Rui Chenggang 4-5

Russia 40

Safeguard 58, 79, 102, 103-4

Samsung 10,71

san min zhuyi (Three Principles of the People) 3

Sanyo 64

Sassoon 87, 113

Schmitt, Bernd 57

self: collective sense of $91,102,112$;

construction of modern 101; loss of 82,83 ; partnering narrative 108 ;

possible 99 ; redemption narrative 107 ; see also identity

self-narratives 119

self-sufficiency $16,71,77$

semi-colonial period $8,18,19,30-1$, $39-41,50,91$

Shanghai 53

Sharp 101

Shenzhen 31, 35, 44

Shiseido 66

Shi-si 11, 86

shopping 82

silk 73

"sinocization" 3

Sino-Japanese War 88

skepticism 115, 117, 120

SK-II $65,89,90$

social status $23,28-9,105-6$

socialism $15,33,71,72,110$

Sony $11,86,104,113,114$

"sophistication" 22, 23, 109

Spring Festival 1, 14

Sprite 66

standardization 29,66

Starbucks 4-5, 13, 26, 84, 87

state-owned enterprises 42,45

stories 70

Sun Yat-sen 3, 13, 76

survey research 10, 19, 51-69; data collection methods 53-5; data

collection sites 53 ; overview of research method 52-3

Swatch 109

Taiwan 3

tariffs $39,40,47$

taste 22,28

tea 39

technology $\mathrm{xv}, 51,63-7,99,101$
Telunsu 48

temporality $30-1$

"Ten-Thousand Mile Brand Journey" 33, 47-8, 50

Three Principles of the People 3

Tianjin 53

Tongrentang 38

Toshiba 2, 12, 17, 26, 61, 64, 85

tourism $4,74,84$

Toyota Reiz 89, 90

trade $39,40,47$

translations of foreign brand names 8 , $56-9,67$

transnational corporations $20,32,122$, 123

Trentmann, Frank 121-3

Tsingtao 92

Tsui, Anne 18, 42, 45, 47, 60

Tung, May P. M. 86

unemployment $45-6$

United States 7, 22, 55, 85, 89, 92, 122

Valentino 79

Veblen, Thorstein 18, 23, 24, 27, 29, 32

Versace 59

victimization narrative $84,85,88-9,119$

visuality $8,59,102-3,111-12$

Voight, Kevin 26-7

Wal-Mart 23, 45

Wang, Jian 25, 98, 99, 101, 106

Wang, Jing 25-6, 60, 92

Wang, Zhiying 25

war metaphors 80

Watson, James L. 9, 66

Weber, Max 29-30, 32

the West: as economic partner 9, 13-14, 93-6, 108, 115-17, 120; as experiential venue $9,10-11,70-7,104,105-6$,

108-10, 119; as imperialist oppressor 9, 11-12, 77-88, 100, 104, 106-7, 110-12, 119-20; multiple meanings of 123 ; redemption narrative $9,12-13,33$, 88-93, 107-8, 112-15, 120

West Data 62-3

Western brands xvi, xvi-xvii, 2-3, 6-8, 121-3, 124; advertising images 125-31; consumption fantasies 117-18, 119; cultural narratives $9-15,17$, 19-20; double standard 13, 49, 89-90, 113-14; economic reform period 43-7; emulative motive for consumption 18 , 22-4, 26-32, 36; expensiveness 68-9; 
failures of 22; historical perspective 18-19; imagined consumption 97-102; imagined identity transformations 105-8; individual psychological processes of enlivening consumption fantasies 20, 102-5, 118, 119, 120; as instruments of domination 11-12, 77-88, 100, 104, 106-7, 110-12; as instruments of freedom 10-11, 70-7, 104, 105-6, 108-10; international fame 59-60; lack of knowledge about Chinese responses to 5-6; National Products Movement 40; "otherness" 55-9; partnering narrative 93-6, 108, 115-17, 120; quality $60-3$; redemption narrative 88-93, 107-8, 112-15, 120; resistance to $18,24-6,32-5,36,50$; ritualized responses to 16 ; semi-colonial period 40-1; survey research 19 , 51-69; as technologically advanced
63-7, 101; translations of brand names 8, 56-9, 67

Wilk, Richard 9, 15-16, 28, 30, 77

women 76,122

World Trade Organization (WTO) 25-6, 46-7, 62, 77, 122

World War II 2-3, 89

Wrangler 23

Yan, Yunxiang 24, 26, 29, 31

Yaohan 45

youth: Hong Kong 9; "Patriot's

Paradox" 25; survey research 52

Yu Minyang 42, 47, 94

Zeng Guofan 91

Zhang, Shi 57

Zhao, Xin 34

Zhong-hua 113

Zhou, Nan 25, 28-9, 31, 35

Zhu Rongji 45 